\title{
Thought And Reality In Hegel's System
}

\section{Gustavus Watts Cunningham}

A Former Fellow and Scholar in the Sage School of Philosophy

\section{A Thesis}

Presented to the University Faculty of Cornell University in Partial Fulfilment of the Requirements for the Degree of Doctor of Philosophy 
Cornell Studies in Philosophy No. 8

Longmans, Green, and Company

New York, London, Bombay, Calcutta

1910

This edition published 2001.

Batoche Books Limited

52 Eby Street South

Kitchener, Ontario

N2G 3L1

Canada

email: batoche@gto.net

ISBN: 1-55273-063-8 


\section{Contents}

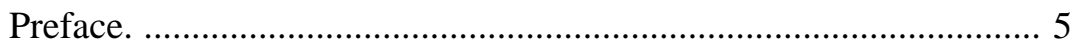

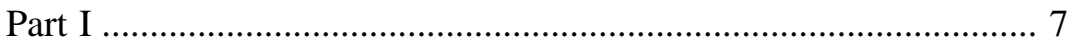

Chapter I: Thought as Objective and Universal. ............................... 7

Chapter II: The Process of Thought: Mediation and Negation. ....... 26

Chapter III: Ontology and Epistemology......................................... 43

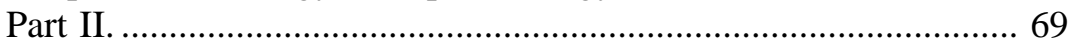

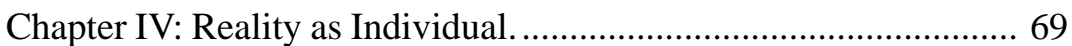

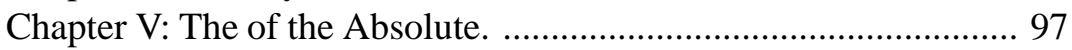

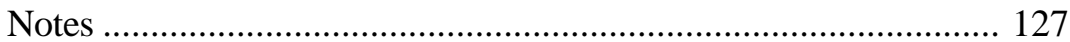





\section{Preface.}

Perhaps it would not be an exaggeration to say that there is no system of thought more intimately bound up with one fundamental principle than is the system of Hegel. Even a cursory reading of his works is sufficient to convince one that the doctrine of the Notion, whatever it may be, is basic to the system; and a more detailed study only forces the conviction home. In the Phenomenology, in the Encyclopaedia, in the History of Philosophy, in the Philosophy of Religion, everywhere it is this doctrine of the Notion upon which emphasis is laid. Indeed, if one were to say that the entire system is just the explication of this doctrine, its elaboration by definition and application, one would be well within the bounds of justification. A correct interpretation of the system, consequently, depends upon a thorough comprehension of the doctrine of the Notion; if this doctrine is neglected, the system must remain a sealed book. The aim of the present monograph is to set forth this doctrine of the Notion, to emphasize its importance for a theory of knowledge, and, in the light of it, to give some insight into Hegel's conception of ultimate reality.

The first chapter of this study was read in part before the meeting of the American Philosophical Association at Cornell University in December, 1907. Subsequently it was published in an expanded form in The Philosophical Review (Vol. XVII, pp. 619-642), under the title "The Significance of the Hegelian Conception of Absolute Knowledge." My thanks are due to the editor of the Review for his permission to reprint it here substantially as it appeared there.

My very great indebtedness to various books and authors is sufficiently testified to by the footnotes. The references to the larger Logic are to the edition of 1841, published by Duncker and Humblot. The translations of Hegel's works, to which I have referred for assistance 
and from which I have freely quoted, are: W. Wallace, The Logic of Hegel (second edition, 1892); W. Wallace, Philosophy of Mind (1894); S. W. Dyde, Philosophy of Right (1896); E. B. Speirs and J. B. Sanderson, Philosophy of Religion (three volumes, 1895); E. S. Haldane and F. H. Simson, History of Philosophy (three volumes, 1894); J. Sibree, Philosophy of History (reprint of 1902). I have not followed the translations verbatim in every case; but what few changes have been made are, I trust, not less faithful to the original.

To the members of the Sage School of Philosophy I am deeply indebted for many suggestions both consciously and unconsciously given. Professor G. H. Sabine, of Leland Stanford Jr. University, has read a portion of the study in manuscript and has aided me in the not very pleasant task of proof-reading. My heaviest debt of gratitude is to Professor J. E. Creighton, of Cornell University, at whose suggestion the study was first undertaken and under whose guidance and encouragement it has been brought to completion. The study would be much more imperfect than it now appears, were there not incorporated in it Professor Creighton's many valuable suggestions and criticisms. For the content of the monograph, however, I myself must alone be held responsible.

G. W. C.

Middlebury College, September, 1910. 


\section{Thought and Reality in Hegel's System}

\section{Part I \\ Chapter I. \\ Thought as Objective and Universal.}

Perhaps no part of Hegel's system has been more persistently overlooked or misunderstood than has his doctrine of the nature of thought. Certainly no part of his system deserves to be more carefully studied. For this is the doctrine that is absolutely fundamental to his system; and it must be understood before any fair appreciation of his system can be arrived at or any just criticism of his contentions be advanced. To give an exposition of the Hegelian doctrine of thought, and to do this as much as is practicable in the author's own words, is the aim of this chapter.

Almost universally it is taken for granted that the Logic contains all that Hegel thought it worth while to say about the nature of thought. His epistemology is criticized and defended against criticism exclusively on the basis of the dialectical development of the categories, the assumption of both critic and champion being that here we find Hegel's last word concerning the nature of knowledge. That such an assumption is erroneous and leads to positive error in interpreting the Hegelian epistemology will, I trust, appear in what is to follow. The Logic does, indeed, purport to give an account of the essentially organic nature of thought, by showing how one category necessarily loses itself in its negative, which proves to be, not an abstract negative, but a negative that dialectically leads on to a more concrete synthesis of the two opposed categories. The Logic leads progressively from the abstract categories of Being, through the more concrete categories of Essence, to the still more concrete categories of the Notion; and finally to the most concrete cat- 
egory of all, that category in which all the lower categories find their 'truth,' namely, the Absolute Idea. This the Logic does; but this is all that it does. It tells us nothing direct about the empirical significance of the categories themselves. Except by frequent hints - which indeed are quite emphatic and significant - the Logic gives us no insight into that fundamental problem of epistemology, namely, the significance of the subject-object relation. On the contrary, as Hegel himself declares, the very purpose of the Logic is to deal with the categories in the pure ether of thought and in abstraction from their empirical setting. ${ }^{1}$ So in the Logic we search in vain for an exposition of this most important aspect of our knowing experience; the implications of the objective reference of thought are not explicitly touched upon there. For such an exposition we must look elsewhere.

The exposition for which we seek is to be found in the Phenomenology of Spirit. Perhaps this will appear beyond dispute from a consideration of some of Hegel's own statements on the point. In the preface to the Phenomenology he says: "The task which I have set myself is to elaborate the fact that philosophy approaches the form of science approaches the point where it lays aside the name of love for knowledge, and becomes real knowledge." ${ }^{2}$ Again, later in the same preface we read: "The process of science in general, or of knowledge, is set forth in the Phenomenology of Spirit. Knowledge as it is at first, or the immediate spirit, is spiritless or sensuous consciousness. In order to become real knowledge, to reach the element of science which is its pure notion itself, this sensuous consciousness has to work itself through a long way." 3 This way is, of course, that traced by the Phenomenology. A little later in the same work we are told that the problem of the Phenomenology is simply "an investigation and proof of the reality of knowledge."4 This same point Hegel is emphasizing when he urges that the Phenomenology is the science of experience; for experience, he tells us, is only the "dialectical process (Bewegung) which perfects consciousness in itself, both in its knowledge and in its object." ${ }^{5}$ In other words, since experience is essentially a subject-object relation, its truth is to be found in the determination of the real import and significance of that relation. Thus it seems that the problem of Phenomenology is pretty clearly defined: it is simply the progressive definition and exposition of the significance of this duality within experience. It is not merely to trace an organic development from one to another stage of consciousness, as Professor Baillie would seem to suggest. ${ }^{6}$ Rather is it to dis- 
close the important change that takes place between subject and object as the knowing experience is traced through the various attitudes of consciousness. As Lasson aptly remarks in the introduction to his recent edition of the Phenomenology, the point of interest in the work is the transition "from one relation of consciousness to the entire world of being, to another such relation." ${ }^{\prime 7}$ Hegel's purpose in this novel Introduction to Philosophy is not like Kant's in the first of the Critiques, namely, to investigate the possibility and limitations of knowledge. He accepts knowledge and the knowing experience very much as it is accepted by common-sense, and then proceeds to develop its implications. Passing dialectically from sensuous consciousness through self-consciousness, reason, spirit, and religion, he finally arrives at what seems to him to be the true attitude of consciousness, the truth of the knowing experience. This final result of the Phenomenology, which Hegel calls Absolute Knowledge (das absolute Wissen), is thus his definition of the real nature of knowledge; it is his final statement of the significance of the subject-object relation within concrete experience.

It is very important to notice at the outset, and to keep constantly in mind, the fact that Hegel bases this conception of absolute knowledge directly and unequivocally upon our common knowing experience. This point is so fundamental, and is so generally neglected by the critics, that it needs emphasis even at the risk of digression. If there is wanted more evidence than has already been adduced, it is not far to seek. In the Preface to the Phenomenology itself, we find an explicit statement to the effect that there is no break between consciousness as it appears in sensuous perception and in absolute knowing; and this very fact, Hegel argues, makes possible the transition from the lower to the higher stage. "The beginning of philosophy," he says, "makes the presupposition or demand that consciousness be in this element" (i.e., as the context indicates, in the 'element' of 'absolute science,' which is simply the point of view of absolute knowledge). "But this element receives its completion and clearness only through the process of its development.... On its side, science demands of self-consciousness that it raise itself into this ether.... On the other hand, the individual has a right to ask that science at least let down to him the ladder to this standpoint, that is, show him the standpoint within himself." ${ }^{8}$ Furthermore, in the Introduction to the larger Logic we read: "Absolute knowledge is the truth of all modes or attitudes of consciousness." 9 Finally, there is a passage in the smaller Logic which runs thus: "In my Phenomenology of Spirit... the method adopted 
was to begin with the first and simplest phase of mind, immediate consciousness, and to show how that stage gradually of necessity worked onward to the philosophical point of view, the necessity of that view being proved by the process." ${ }^{10}$ Now it would seem that the import of such passages as these is unmistakable. The Phenomenology begins with the most naive attitude of consciousness, where the matter of intuition is looked upon as a mere datum; its progress, as Professor McGilvary suggests, ${ }^{11}$ consists just in showing that this sensuous consciousness is an essential element in absolute knowing. In other words, the standpoint of absolute knowing is involved in every, even the simplest, phase of consciousness; it is implied in every act of knowledge, in every subject-object relation, - which is tantamount to saying that it is conterminous with experience itself.

Near the end of his discussion of the Phenomenology, Haym, looking back over the course of its development, remarks: "This whole phenomenological genesis of absolute knowledge was nothing other than the presence of the Absolute, which unfolded itself before our very eyes in the methodical manner peculiar to its spiritual nature. It was the selfdevelopment of the Absolute as it has mirrored itself in consciousness and in history." ${ }^{2}$ One is led to believe that the critic means by this, as he says later, that the ego "is at the beginning of the Phenomenology exactly where it ought to be at the end, — not in itself, but in the Absolute." ${ }^{13}$ The suggestion of such a point of view as this, however, seems to me to be at best misleading. Whatever may be said concerning the relation of the result of the Phenomenology to the standpoint of an Absolute Intelligence,${ }^{14}$ there is certainly no reason for maintaining that Hegel would ask us to assume such a standpoint at the beginning of the Phenomenology. He asks us merely to place ourselves at the point of view of sensuous consciousness, and to try to discover its logical implications. It is, indeed, true that in the attitude of sensuous consciousness Hegel sees the standpoint of absolute knowing, which thus finds its basis in the actual knowing experiences of finite individuals; and it is also true that these experiences are never left out of consideration by him. But this means nothing more than that absolute knowledge is logically involved in every knowing experience, and that investigation can prove that it is so involved. Hegel himself has very clearly put the matter in another context: "It may be said that the Absolute is involved in every beginning, just as every advance is simply an exposition of it.... But because it is at first only implicit, it is really not the Absolute.... The 
advance, therefore, is not a sort of overflow, as it would be were the beginning truly the Absolute; rather the development consists in the fact that the universal determines itself.... Only in its completion is it the Absolute." ${ }^{15}$ Even granting, then, for the sake of the argument, that Hegel finally identifies absolute knowledge with the point of view of an omniscient Intelligence (which assumption is by no means self-evident, - indeed, it is difficult to prove that Hegel's Absolute is such an Intelligence), we are certainly not justified in saying that he emerges from the Phenomenology with nothing more than the assumption with which he began his investigation. The standpoint of absolute knowledge is not assumed at the beginning; it is arrived at only at the end. And to accuse Hegel of having begun with the point of view of the Absolute is an indication that his actual procedure has been misconstrued. Absolute knowledge does not, as Haym asserts, find its justification in the fact that "the Weltgeist has completed itself in history," but, as we shall see later, in the fact that it is the necessary presupposition of all concrete individual experience.

Lotze, too, has brought practically the same accusation against Hegel. "It was not after Hegel's mind," he tells us, "to begin by determining the subjective forms of thought, under which alone we can apprehend the concrete nature of this ground of the Universe, - - a nature perhaps to us inaccessible. From the outset he looked on the motion of our thought in its effort to gain a clear idea of this still obscure goal of our aspiration as the proper inward development of the Absolute itself, which only needed to be pursued consistently in order gradually to bring into consciousness all that the universe contains." ${ }^{16}$ Now I submit that such an accusation entirely overlooks the procedure of the Phenomenology in establishing the category of absolute knowledge. The very purpose of this effort was 'to determine the subjective forms of thought' as they appear in the knowing experience of the individual. It is true that Hegel did not enter into psychological discussion of individual minds; his aim was epistemological and not psychological. ${ }^{17}$ It is also true that he ended his investigation by exhibiting the essential objectivity of these so-called 'subjective forms' of thought. But the fact still remains that he took his stand on actual human experience and began his inquiry with common everyday consciousness. In the case of the Logic (provided one forgets the fact that the result of the Phenomenology is its presupposition) it may be argued with some show of plausibility that from the outset the author regards thought as the "proper inward development of the Abso- 
lute itself." But there can be no doubt whatever concerning the baselessness of the charge when made with reference to the Phenomenology of Spirit. The category of absolute knowledge is not a first principle shot out of a pistol at us, as it were, but a conclusion laboriously reached; and it is attained only by a careful and painstaking examination of all stages of consciousness from the sensuous to the scientific and religious. Wherever there is a subject-object relation, there the characteristics of absolute knowledge are disclosed.

Absolute knowledge being, then, Hegel's interpretation of the essential characteristics of thought as it appears in every actual knowing experience, the question arises concerning the details of the conception. What are the fundamental characteristics of thought as defined in this Hegelian category? It is to an attempt to answer this question, partially at least, that we now address ourselves.

In the first place, Hegel claims that his conception of absolute knowledge gives thought release from the subjectivity in which it was bound by both the Kantian and Fichtean systems. Kant, he admits, does indeed give to thought a quasi-objectivity, namely, universal validity. "Kant gave the title objective to the intellectual factor, to the universal and necessary; and he was quite justified in so doing." 18 That is to say, for Kant objectivity means the universally valid in contradistinction to the particularity and relativity of sense-perception; and this is a step in the right direction towards true objectivity. "But after all," Hegel continues, "objectivity of thought, in Kant's sense, is again to a certain extent subjective. Thoughts, according to Kant, although universal and necessary categories, are only our thoughts - separated by an impassable gulf from the thing, as it exists apart from our knowledge." 19 In other words, Kant's categories cannot, by their very nature, express the real: they are mere ideas, which can indeed tell us about the temporal and spatial relations of objects, but which just for this reason can give us no insight into the nature of ultimate reality. Hegel elsewhere speaks of them as prisms through which the light of truth is so refracted and broken that it can never be had in its purity. Such idealism, Hegel justly concludes, is purely subjective. ${ }^{20}$ Heroic as were Fichte's efforts to break through to reality, they were, Hegel asserts, unavailing. "Fichte," he says, "never advanced beyond Kant's conclusion, that the finite only is knowable, while the infinite transcends the range of thought. What Kant calls the thing-by-itself, Fichte calls the impulse from without, - that abstraction of something else than 'I,' not otherwise describable or definable 
than as the negative or non-Ego in general." 21 To express it otherwise, Fichte, in his search for objectivity, finds nothing more satisfactory than an unattainable ideal, an eternal Sollen. But this vanishing ideal does not meet the difficulty; thought, which merely ought to be objective, is still subjective, even though an infinite time be allowed for transition to objectivity. Consequently, Fichte's position, like Kant's, is in the last analysis nothing more than subjective idealism. Now the standpoint of absolute knowledge, Hegel maintains, transcends the dualism in which the systems of Kant and Fichte seem hopelessly involved. It gives to thought, not a quasi-objectivity or an objectivity that ought to be, but an objectivity that is at once genuine and actual.

Hegel has left us in no doubt as to what he thinks such an objectivity implies. In the context of the above criticism of Kant, he says: "The true objectivity of thinking means that the thoughts, far from being merely ours, must at the same time be the real essence of the things, and of whatever is an object to us." Later in the same context he tells us that objectivity means "the thought-apprehended essence of the existing thing, in contradistinction from what is merely our thought, and what consequently is still separated from the thing itself, as it exists in independent essence." From these very explicit statements it is evident that objectivity of thought means for Hegel at least two things: (a) that thought which is truly objective is not particular and individual, but in a sense transcends the individual; and (b) that truly objective thought does actually express the essence of things. A consideration of these two points will now occupy our attention for a time.

The first of these points, that thought is really more than an individual affair, Hegel states very explicitly in the smaller Logic. In the twenty-third section he asserts that thought is "no private or particular state or act of the subject, but rather that attitude of consciousness where the abstract self, freed from all the special limitations to which its ordinary states or qualities are liable, restricts itself to that universal action in which it is identical with all individuals." Furthermore, he constantly insists that the dialectic of thought is really der Gang der Sache selbst. "It is not the outward action of subjective thought, but the personal soul of the content, which unfolds its branches and fruit organically." 22 The question, however, at once arises, Are not such statements meaningless? Is the "abstract self, freed from all the special limitations to which its ordinary states or qualities are liable," anything more than an hypostatized entity? Do we know anything about the 'universal action' of 
thought apart from an individual experience? Is the finite knower merely a passive observer of the 'march of the object,' or of the organically unfolding 'soul of the content'? To meet the objection implied in these questions, a preliminary consideration is necessary.

Every act of thought may be looked at from two points of view. It may be regarded as a process in time, that is, as a mere psychological event, or as a meaning. As a process in time, it is a state of consciousness among other such states to which it is related and by reference to which it may be explained. As a meaning, it is the expression of the relation of subject to object, the expression of which relation gives it its significance as an act of knowledge. Neither of these aspects of thought can, of course, be neglected; a timeless act of thought is as much a nonentity as a meaningless act of thought. But, on the other hand, the two aspects must not be confused; thought as a process in time is something quite different from thought as a meaning. Both points of view are legitimate and, indeed, necessary in dealing with concrete mental experience. If, now, these ways of viewing thought be the standpoints of psychology and epistemology, respectively, we are perfectly right in saying that, from the psychological point of view, thought is subjective and particular, while from the standpoint of epistemology it is transsubjective. As a psychological process, thought is subjective and particular for the simple reason that, when so viewed, it is nothing more than an element in a complex presentation which at a particular moment makes up the mental life of the individual subject. Even belief in a trans-subjective world, the psychologist treats, as Professor Seth Pringle-Pattison says, "simply as a subjective fact; he analyzes its constituents and tells us the complex elements of which it is built up; he tells us with great precision what we do believe, but so far as he is a pure psychologist he does not attempt to tell us whether our belief is true, whether we have real warrant for it." ${ }^{23}$ Epistemology, on the contrary, necessarily transcends this subjective standpoint of psychology. It deals, not with the knowing experience of any particular mind, not with knowledge as it is possessed by any particular subject, but with knowledge as it is in itself. Epistemology finds its special field just in determining the validity or falsity of the claims of our trans-subjective belief. Its business is to give us a criterion of truth, to investigate the subject-object relation within experience and to develop its implications. In doing this it must neglect the particular experiences, or, to use Professor Bosanquet's phrase, it must abstract from the abstractions of psychology, and fix its attention upon 
the essential nature of knowledge qua knowledge. It does not, of course, deny the significance of the psychological aspect of thought, nor does it try to escape from the implications of experience when read from that angle of vision. It simply deals with thought from its own specific standpoint, its aim being to handle its data unencumbered as much as possible by psychological considerations. ${ }^{24}$

Now, as I understand Hegel, we can accuse him neither of confusing these two points of view, nor of overlooking one in his zeal for the other. As has been pointed out, his interest in the discussion of knowledge is primarily epistemological in the sense above defined; and he keeps consistently to this point of departure. He sees clearly that, from this point of view, knowledge must be investigated as it is in and for itself and freed from the prejudices and preconceptions which attach to it in individual minds; if an adequate standard of truth is to be attained, relativity in knowledge must be overcome. But it should be very carefully noted that Hegel does not, at any rate need not, forget that thought is always a process in a knowing mind. The objectivity which he claims for thought in the category of absolute knowledge is claimed for the thought of every individual who knows; the truth of absolute experience, truth as it is in itself and for itself, is simply the truth of the experiences that are here and now. This point I tried to emphasize at the beginning of the discussion. Thus the 'abstract self,' freed from the limitations of its ordinary states and busy in its universal mode of action, turns out to be the finite self making an unusually strenuous effort to be consistent. Genuinely objective thought is not the private possession of A or B; it is rather the thought activity in which, so far as they are rational creatures, A and B participate. Even if we are fully convinced that Hegel has gone too far in the identification of the finite knower with the Absolute, still we must admit the legitimacy and necessity of this demand of the category of absolute knowledge. For if the subjectivity in which experience is involved by the Kantian and Fichtean philosophies is really to be transcended, experience must be given some form of genuine objectivity; and if that form of objectivity is to be found in thought, then thought must be looked upon as it is in its essential nature and not as it appears in this or that individual mind. And this, it would seem, is all that Hegel means when he says that truly objective thought transcends the individual experience.

The second factor involved in the conception of true objectivity, namely, the capacity of thought to express the essential nature of its 
object, Hegel shows to be the necessary presupposition of all knowing experience. Thought must disclose the constitution of reality, he maintains, otherwise experience is doomed to a hopeless dualism. "The truth as such," he tells us, "is essentially in knowledge." 25 "Only in so far as reflection has relation to the Absolute is it reason and its activity that of true knowledge (Wissen)." ${ }^{26}$ Every individual who knows does, by virtue of that very fact, transcend the dualism which seems to exist between subject and object; on any other assumption it is not easy to see how experience can be brought into actual contact with ultimate reality. To elaborate this argument is exactly what Hegel undertakes in the Phenomenology. He shows there by dialectical procedure how the lowest and most naive attitude of consciousness to its object subsumes the opposition which prima facie seems such a barrier to the comprehension of reality; such subsumption must be assumed, or we shall never be able to say that experience and reality are one. One might summarily say, without doing violence to Hegel's own words, that the purpose of the Phenomenology is to show, in opposition to the Kantian philosophy, why the Ding-an-sich must be known and how it can be known. It must be known, because this is the presupposition of experience from its earliest and simplest stages; it can be known, because thought is no merely subjective and private process going on in our heads, but in its very essence is a significant relation to objects. Thus Hegel solves the problem of the opposition between subject and object by pointing out that the problem is really made by our own abstract procedure in dealing with experience. In point of fact, he tells us, there is no such opposition; on the contrary, the very fact that we can have significant knowledge forces us to the conclusion that thought is truly objective, and that the object is in reality as it is in knowledge.

Hegel's position on this point can, perhaps, be more clearly understood when contrasted with Lotze's view. In his Logic Lotze summarizes his position thus: "We have convinced ourselves that this changing world of our ideas is the sole material given us to work upon; that truth and the knowledge of truth consist only in the laws of interconnection which are found to obtain universally within a given set of ideas." 27 Now when we recall that these ideas are for Lotze more or less subjective, mere 'tools' by means of which we somehow come in contact with reality, but through which the essence of objects can never be known, the contrast between his position and Hegel's is plain. According to the one, we are shut off from reality by means of the very tools we vainly 
endeavor to work with; reality is a realm 'whose margin fades forever and forever' as we move. According to the other, we are never out of touch with reality, since to know is ipso facto to know the essential nature of the objects of knowledge. To the former, truth is nothing more than consistency within a given set of ideas; to the latter, truth is nothing less than reality itself. In a word, on the theory of Lotze thought is after all still subjective, still confined to the abstract realm of bare universals, impotent to overtake the phantom reality it pursues: Hegel teaches, on the contrary, that thought is essentially objective, that form and content interpenetrate, that the process of knowledge is the process of things. And this conception of the objectivity of thought, Hegel would urge, is a necessary presupposition of experience, unless indeed we are willing to abide by the consequences of an epistemological dualism.

But if thought expresses the essence of its object, then thought ipso facto comprehends its object and so exhausts reality. This implication of his doctrine of the objectivity of thought Hegel not only recognizes but insists upon. "Conception is the penetration of the object, which is then no longer opposed to me. From it I have taken its own peculiar nature, which it had as an independent object in opposition to me. As Adam said to Eve, 'Thou art flesh of my flesh and bone of my bone,' so says the Spirit, 'This object is spirit of my spirit, and all alienation has disappeared."' 28 This same idea Hegel has in mind when he speaks of thought as begreifendes Denken. "Begreifendes Denken," says Professor McGilvary, "is grasping, clutching thought, thought that grips its object as its own inalienable possession. Perhaps we might translate das begreifende Denken by the phrase 'object-appropriating thought'; for the logical relation of such thought to its object is analogous to the legal relation of the master to the slave; the slave had no independent status; he stood only in his master, who engulfed him." ${ }^{29}$ Again, the one distinguishing feature between what Hegel terms 'finite' and 'infinite' thought is that the latter destroys the opposition between form and content, which opposition the former never transcends; as Hegel puts it, 'finite' thought is "subjective, arbitrary, and accidental," while 'infinite' thought is what alone "can get really in touch with the supreme and true." ${ }^{30}$ And, of course, it is 'infinite' thought with which Hegel has to do in his category of absolute knowledge. Furthermore, in the Introduction to the larger Logic Hegel argues that to separate the form and content of knowledge is to presuppose an external objective world which is independent of thought; and this, he objects, is unjustifiable. ${ }^{31}$ And later in the same 
Introduction, we read: "In logic we have nothing to do with thought about something which lies independently outside of thought as the basis of it." ${ }^{32}$ Finally, in the smaller Logic, he asserts: "In the negative unity of the Idea, the infinite overlaps and includes the finite, thought overlaps being, subjectivity overlaps objectivity." 33 Other passages bearing on this point might be quoted, did it seem necessary; but the above passages state very clearly Hegel's position. In fact, the position is inevitably involved in his whole conception of the objectivity of knowledge. Truly objective knowledge cannot have opposed to it an unaccountable residuum of fact, which it is unable to comprehend or interpret; on the contrary, it must be conterminous with reality.

The following quotation from Mr. McTaggart presents an admirable antithesis to Hegel's position here. "Thought is a process of mediation and relation, and implies something immediate to be related, which cannot be found in thought. Even if a stage of thought could be conceived as existing, in which it was self-subsistent, and in which it had no reference to any data... at any rate this is not the ordinary thought of common life. And as the dialectic process professes to start from a basis common to every one,... it is certain that it will be necessary for thought, in the dialectic process, to have some relation to data given immediately, and independent of that thought itself." ${ }^{34}$ It makes no difference that this statement is given by the critic as an interpretation of Hegel; it is in truth exactly contrary to Hegel's view of the matter. Thought, as Hegel conceives of it, certainly has no data opposed to, and independent of it; nor is it merely a process of mediation and relation among phenomena external to it. It bears no relation whatever to immediately given data, 'nuclei' of being, which lie outside of and beyond it, for there are no such. On the contrary, it transcends this dualism, and always finds itself 'at home' in its object from which every trace of alienation has disappeared. ${ }^{35}$ Perhaps I can best bring out the contrast between Hegel's real position and that attributed to him by his critic by letting him once more speak for himself: "If under the process of knowledge we figure to ourselves an external operation in which it is brought into a merely mechanical relation to an object, that is to say, remains outside it, and is only externally applied to it, knowledge is presented in such a relation as a particular thing for itself, so that it may well be that its forms have nothing in common with the qualities of the object; and thus, when it concerns itself with an object, it remains only in its own forms, and does not reach the essential qualities of the object, that is to 
say, does not become real knowledge of it. In such a relation knowledge is determined as finite, and as of the finite; in its object there remains something essentially inner, whose notion is thus unattainable by and foreign to knowledge, which finds here its limit and its end, and is on that account limited and finite." So far we have a statement of the critic's view with its attendant difficulties. By way of criticism and exposition of his own position, Hegel continues: "But to take such a relation as the only one, or as final or absolute, is a purely made-up and unjustifiable assumption of the Understanding. Real knowledge, inasmuch as it does not remain outside the object, but in point of fact occupies itself with it, must be immanent in the object, the proper movement of its nature, only expressed in the form of thought and taken up into consciousness." 36 This passage is self-explanatory, and comment on it seems superfluous. In it Hegel has simply pointed out the inevitable dualism involved in the position which Mr. McTaggart has attributed to him; and in opposition to such a position he has stated his own more objective standpoint

An objection which arises just here seems prima facie unanswerable. If it be true that thought actually does exhaust reality, then it must be that thought, or knowing experience, and reality coincide. But can such a view possibly be seriously entertained? Is it not nonsense to say that thought is co-extensive with the real, when so much of our everyday experience, our hopes, our fears, our loves, our hates, fall outside the thinking process? Can one be so mad as to attempt to reduce existential reality to terms of ideas? Lotze has put the objection very forcibly thus: "Nothing is simpler than to convince ourselves that every apprehending intelligence can only see things as they look to it when it perceives them, not as they look when no one perceives them; he who demands a knowledge which should be more than a perfectly connected and consistent system of ideas about the thing, a knowledge which should actually exhaust the thing itself, is no longer asking for knowledge at all, but for something entirely unintelligible." ${ }^{37}$ Mr. Bradley, in a classic passage, has voiced the same feeling: "Unless thought stands for something that falls beyond mere intelligence, if 'thinking' is not used with some strange implication that never was part of the meaning of the word, a lingering scruple still forbids us to believe that reality can ever be purely rational.... The notion that existence could be the same as understanding strikes as cold and ghost-like as the dreariest materialism. That the glory of this world in the end is appearance leaves the world more glorious, if we feel it is a show of some fuller splendour; but the sensu- 
ous curtain is a deception and a cheat, if it hides some colourless movement of atoms, some spectral woof of impalpable abstractions, or unearthly ballet of bloodless categories." 38 Now Hegel's answer to this objection is, I think, found in the second characteristic of thought as he has defined it for us in absolute knowledge; and this we shall proceed at once to examine.

Thought, Hegel argues, is not mere abstract cognition, but, on the contrary, is truly universal. In answer to Mr. Bradley he would say that thought does stand for something which falls beyond mere intelligence. That is to say, actual concrete thought, in Professor Bosanquet's phraseology, is a process, not of selective omission, but of constructive analysis; its universals are syntheses of differences. ${ }^{39}$ In Hegel's own words: "The Notion is generally associated in our minds with abstract generality, and on that account it is often described as a general conception. We speak, accordingly, of the notions of color, plant, animal, etc. They are supposed to be arrived at by neglecting the particular features which distinguish the different colors, plants, and animals from each other, and by retaining those common to them all. This is the aspect of the Notion which is familiar to the understanding; and feeling is in the right when it stigmatizes such hollow and empty notions as mere phantoms and shadows. But the universal of the Notion is not a mere sum of features common to several things, confronted by a particular which enjoys an existence of its own. It is, on the contrary, self-particularizing or self-specifying, and with undimmed clearness finds itself at home in its antithesis. For the sake both of cognition and of our practical conduct, it is of the utmost importance that the real universal should not be confused with what is merely held in common. All those charges which the devotees of feeling make against thought, and especially against philosophic thought, and the reiterated statement that it is dangerous to carry thought to what they call too great lengths, originate in the confusion of these two things." ${ }^{40}$ In other words, universality may mean two very different things. On the one hand, it may indicate nothing but abstract generality which is arrived at by neglecting the marks peculiar to particular objects. On the other hand, it may mean the synthetic analysis of the particulars, and so include within itself the essential characteristics of them. If one only remembers this distinction, and remembers that the true universal of thought is the subsumption, not the annihilation, of the particular, then, Hegel would say, there should be no objection raised against the assertion that ultimately the real is comprehended by thought. 
For, in this meaning of thought, experience and thinking experience are synonymous terms.

There are various passages in which Hegel emphasizes this aspect of thought by insisting that thought is not one mental faculty among others coordinate with it, but that it is the principle of universality in mind and includes within itself the other so-called mental faculties as essential elements. In his lectures on the History of Philosophy occurs a criticism of Kant which is very suggestive in this connection: "With Kant the thinking understanding and sensuousness are both something particular, and they are merely united in an external, superficial way, just as a piece of wood and a leg might be bound together with a cord." 41 Against any such atomistic conception of the mind Hegel would insist: "Even our sense of the mind's living unity naturally protests against any attempt to break it up into different faculties, forces, or, what comes to the same thing, activities, conceived as independent of each other." ${ }^{42}$ But he would go further than this. Not only does he maintain that thought is not one element in an aggregate of disparate parts; he also urges that thought is rather the very life of the one organic whole which we call mind, "its very unadulterated self." ${ }^{43}$ For example, in the smaller Logic he asserts that thought is present in every perception and in every mental activity. ${ }^{44}$ "We simply cannot escape from thought," he elsewhere says, "it is present in sensation, in cognition, and knowledge, in the instincts, and in volition, in so far as these are attributes of a human mind." 45 In the Philosophy of Right we read: "Spirit in general is thought, and by thought man is distinguished from the animal. But we must not imagine that man is on one side thinking and on another side willing, as though he had will in one pocket and thought in another. Such an idea is vain. The distinction between thought and will is only that between a theoretical and a practical relation. They are not two separate faculties. The will is a special way of thinking; it is thought translating itself into reality; it is the impulse of thought to give itself reality." 46 The conclusion of the whole matter is, that "in the human being there in only one reason, in feeling, volition, and thought." ${ }^{47}$

Overlooking this conception of universality in Hegel's doctrine of thought, Mr. McTaggart criticizes him for holding "that the highest activity of Spirit, in which all others are transcended and swallowed up, is that of pure thought." 48 Such a contention, we are informed, ignores a fact which Lotze has emphasized in many parts of his system. And that fact is "that Spirit has two other aspects besides thought - namely, 
volition and feeling - which are as important as thought, and which cannot be deduced from it, nor explained by it." ${ }^{49}$ Now this criticism assumes that Hegel actually tried to reduce the contents of mind to terms of abstract cognition. But, as we have just seen, such an assumption is entirely groundless. Hegel never thought of reducing will and feeling to knowledge, meaning by knowledge what his critic means by it, namely, one of several coordinate elements within the life of mind. What Hegel means by thought, when he asserts that it is conterminous with experience, is simply that principle by virtue of which experience is an organic and unitary whole. It is that life of mind itself, which includes within itself feeling, will, and cognition, and which finds its very being in the expression of this living unity of the mind's activity. ${ }^{50}$ For Hegel, there is "only one reason, in feeling, volition, and thought."

After all, the difference between Hegel and his critics on this point is not so great as might at first appear. Mr. McTaggart is perfectly willing to admit that it is not impossible that these elements of mind "might be found to be aspects of a unity which embraces and transcends them all"; but he is unwilling to call this unity thought. ${ }^{51} \mathrm{Mr}$. Bradley, likewise, demands an ultimate synthesis; but it must fall beyond the category of rationality. ${ }^{52}$ Though Lotze states it as his conviction "that the nature of things does not consist in thoughts, and that thinking is not able to grasp it," yet he goes so far as to say that "perhaps the whole mind experiences in other forms of its action and passion the essential meaning of all being and action." ${ }_{33}$ Thus it would seem that the real quarrel between Hegel and the critics is concerning the real nature of the synthesis. What the critics vaguely term an ultimate unity, Hegel prefers to call thought, reason, or Spirit. The former try to find a synthesis of elements which they have defined as practically exclusive and independent, though, of course, not ontologically separable from each other; and they seek this synthetic principle in feeling or intuition, - something ultra-rational. Hegel, on the other hand, insists that mind is an organic unity, and that it is such only by virtue of its own most characteristic activity; it is a one reason. Every concrete act of knowledge, he argues, is an activity of the whole mind; and this unitary, synthetic activity can be made intelligible and given true objectivity, not, as the critics seem to maintain, in terms of intuition or feeling, but only in terms of rationality. And reflection on the point will, I think, convince us that Hegel is in the right. ${ }^{54}$

We are now in a position to expose another aspect of the current 
misconception of Hegel's doctrine of universality. The misconception concerns Hegel's supposed identification of thought and being, and is, perhaps, one of the most prolific sources of adverse criticism of the Hegelian philosophy. I refer to the prevalent view, implied in the above quotations from Mr. Bradley and Lotze, which Professor Seth PringlePattison expresses thus: "The result of Hegel's procedure would really be to sweep 'existential reality' off the board altogether, under the persuasion, apparently, that a full statement of all the thought-relations that constitute our knowledge of the thing is equivalent to the existent thing itself. On the contrary, it may be confidently asserted that there is no more identity of Knowing and Being with an infinity of such relations than there was with one." 55

Now this idea that Hegel tried to reduce things to pure thought about things, or that he for a moment maintained that thought could possibly be the existent thing, seems to me a monstrous misinterpretation of his real meaning. It is inconsistent with the presupposition of his whole philosophy, namely, that reality is essentially a subject-object relation. It is also inconsistent with the explicit statements quoted above concerning the universality of the Notion, which always involves particularity. And, as we shall see in the next chapter, he emphatically repudiates such a view in his account of mediation and the function of the negative in thought. But, apart from these facts, it seems that we might credit Hegel with sufficient acumen to see the inherent absurdity of such a position. Surely he saw the contradiction involved in an attempt to attain by thought an ideal which would result in the annihilation of thought itself. Indeed, was it not Hegel who first impressed upon us the fact that knowledge always requires an object, and that, if that object be taken away, knowledge itself ceases to be? As Professor Jones has said: "It is inconsistent with the possibility of knowledge that it should be the reality it represents: knowledge is incompatible alike with sinking the real in the ideal, and the ideal in the real." ${ }^{56}$ And I think we are safe in saying that Hegel was well aware of this truth; his essential disagreement with Spinoza is that in the Spinozistic philosophy object is reduced to and identified with subject.

Hegel seems to have taken special pains that he should not be misunderstood on this point. The passages already quoted might be paralleled with others just as positive. I shall content myself, however, with adding only two which show, as plainly as words can show, that the author was not an advocate of the theory of abstract identity. The first 
of these is to be found in the eighty-second section of the smaller Logic: "If we say that the absolute is the unity of subjective and objective, we are undoubtedly in the right, but so far one-sided, as we enunciate the unity only and lay the accent upon it, forgetting that in reality the subjective and objective are not merely identical but also distinct." In the Philosophy of Mind is found the other passage, which so well forestalls the above criticism and so forcefully emphasizes the necessity of distinguishing between merely formal identity and concrete unity that I may be pardoned for quoting it at length: "The close of philosophy is not the place, even in a general exoteric discussion, to waste a word on what a 'Notion' means. But as the view taken of this relation is closely connected with the view taken of philosophy generally and with all imputations against it, we may still add the remark that though philosophy certainly has to do with unity in general, it is not however with abstract unity, mere identity, and the empty absolute, but with concrete unity (the Notion), and that in its whole course it has to do with nothing else; that each step in its advance is a peculiar term or phase of this concrete unity, and that the deepest and last expression of unity is the unity of absolute mind itself. Would-be judges and critics of philosophy might be recommended to familiarize themselves with these phases of unity and to take the trouble to get acquainted with them.... But they show so little acquaintance with them... that, when they of unity — and relation ipso facto implies unity - they rather stick fast at quite abstract indeterminate unity, and lose sight of the chief point of interest - the special mode in which the unity is qualified. Hence all they can say about philosophy is that dry identity is its principle and result, and that it is the system of Identity. Sticking fast to the undigested thought of identity, they have laid hands on, not the concrete unity, the notion and content of philosophy, but rather its reverse. ${ }^{.57}$ If in these passages Hegel does not deny any attempt to arrive at the blank identification of thought and being, of subject and object, and if in them he does not criticize such a goal as an essentially mistaken ideal of philosophical inquiry, then so far as I am concerned the import of the passages is lost. Surely by concrete unity he means something quite different from abstract identity, and concrete unity is that with which philosophy, as he conceives it, has to do.

It seems only fair to insist that such considerations as the preceding be taken into account before Hegel is accused of attempting that which is at once impossible and absurd. He never had any idea of reducing the 
'choir of heaven' and the multifarious passions of the human soul to a 'ballet of bloodless categories.' Such an attempt would have seemed to Hegel as nonsensical as it seems to his critics. When he speaks of the unity of thought and being, he always means identity in difference, and never the undifferentiated identity of Schelling's system. And when he asserts that subject comprehends object, he does not mean to reduce experience to abstract subject, as did Spinoza. He does indeed insist upon unity, but it is always upon concrete unity, the unity of the 'Notion'; and this unity does not annihilate or even harm its differences. In a word, Hegel transcends dualism, and yet, at the same time, does justice to the duality within and essential to experience. He neither denies nor attempts to explain away the factual side of experience; he simply denies that an inexplicable datum has any part or lot within experience. Not immediacy, but abstract immediacy, immediacy apart from interpretation, is unreal.

This chapter may be brought to an end by an attempt to state in one paragraph its essential points. Hegel's doctrine of thought, philosophic thought, is given in the category of absolute knowledge, which is arrived at through the procedure of the Phenomenology of Spirit. The conception is thus based directly upon our actual knowing experience, and claims to give us an account of thought as it essentially is. Thought, as here defined, is genuinely objective, transcending the relativity of individual experiences and being the determination of things as they are in themselves. But this is not to say that reality is identical with abstract cognition. For thought finds its capacity to express the real in the fact that its universals are always the syntheses of differences, and not the blank universals of purely formal logic. Actual living thought includes within itself the data of so-called intuitive perception, of feeling, of volition, of cognition, and it is adequately conceived of only as this unifying principle of experience; it is the living unity of mind, the one reason which appears in every mental activity. Therefore, when Hegel teaches that thought is conterminous with the real, he is simply stating the doctrine that experience and reality are one. 


\section{Chapter II \\ The Process of Thought: Mediation and Negation.}

In criticism of Hegel's position that the science of Philosophy can adequately express the nature of the ultimately real, Mr. McTaggart says: "Philosophy itself is knowledge, it is neither action nor feeling. And there seems nothing in Hegel's account of it to induce us to change the meaning of the word in this respect." 58 I quote this criticism because it contains an assumption which I wish to challenge, and thus sets the problem for the present chapter. The assumption is that philosophical thought, as Hegel defines it, is bare cognition to which the other aspects of the mental life bear only an external relation, that it is simply one among other elements coordinate with it, and that, consequently, it can at most be only a mediating activity among these other elements of experience which forever lie beyond and external to it. It is the justice of this assumption which the following pages will call in question. We have already seen, in the preceding chapter, that such a position is foreign to Hegel's system, and that philosophy for him is action and feeling as well as cognition. But it may be well to emphasize the fact from another point of view. So we now address ourselves to the task of establishing the thesis that Hegel's account of philosophy does force us to give to the word a meaning essentially different from that which the above criticism attaches to it. We shall support this thesis with an exposition of the process of philosophical knowledge as it is presented in Hegel's doctrine of mediation and negation.

In the preface to the Phenomenology of Sprit, ${ }^{59} \mathrm{Hegel}$ has been at pains to point out that, if we are to appreciate what he means by philosophy and the standpoint which it assumes, we must make an effort to understand what he means by absolute knowledge and by mediation. In the preceding chapter we investigated the nature and significance of absolute knowledge. And that investigation showed us that absolute knowledge is simply Hegel's definition of the essential nature of thought as he uses the term, and that thought as thus defined is more than abstract cognition since it is both genuinely objective and truly universal. In the present chapter it is our aim to investigate the nature of mediation, to learn if we can what Hegel has to say about the activity of thought and about its function as a mediating process. The discussion here will, presumably, elaborate further and strengthen the conclusions 
which we have already reached, by showing how philosophical knowledge, in the Hegelian system, is more than a mere mediating activity among phenomena external to it.

It may be helpful at the beginning to state in a general way the order of the discussion before us. No detailed account of the dialectical process, nor any defense of the dialectical method with reference to the development of the categories in the Logic will be attempted here. Our present purpose is a less ambitious one. We shall simply state, as best we may, what Hegel means by thought as a process of mediation, and what is his real contention when he says that negation is the vital and potent element in this process. In accordance with this purpose, therefore, we shall begin our study with a consideration of immediacy and mediation; and this will lead us on to a discussion of negation, which we shall be forced to defend against certain misconceptions that have given rise to some unjustifiable criticisms of Hegel. Our general conclusion will be that thought, as the Hegelian system defines it from this point of view, is a process of mediation which, because of the negative element involved in it, makes it possible for us to say that reality is comprehended in thought; for its universals assume the form, not of abstract indeterminate immediacy, but of concrete determinate immediacy, that is, individuality.

Before passing directly to a consideration of Hegel's conception of mediation and immediacy, steps should be taken to avoid a possible error of interpretation. And this precaution will also serve us as a point of departure in our discussion. Absolutely pure immediacy, immediacy exclusive of mediation, is meaningless for Hegel. This, of course, follows at once from what was said in the preceding chapter concerning the objectivity of thought: these is no indeterminate given. A few quotations, however' will settle the matter. "We must reject the opposition between an independent immediacy in the contents or facts of consciousness and an equally independent mediation, supposed incompatible with the former. The incompatibility is a mere assumption, an arbitrary assertion." ${ }^{60}$ Again, we read: "There is nothing, nothing in heaven, in nature, in spirit, or anywhere else which does not contain both immediacy and mediation." 61 The whole of the second part of the Logic, we are told, is "a discussion of the intrinsic and self-affirming unity of immediacy and mediation." 62 Only the abstract understanding separates the two, and then it finds itself utterly helpless to reconcile them. ${ }^{63}$ It is the business of philosophy, however, to disclose the fallacy involved in 
such arbitrary procedure, and to bring to consciousness the fact of the essential inseparability of that which is immediate and that which is mediated. ${ }^{64}$ "Even if we take up an empirical, an external attitude, it will be found that there is nothing at all that is immediate, that there is nothing to which only the quality of immediacy belongs to the exclusion of that of mediation, but that what is immediate is likewise mediated, and that immediacy itself is essentially mediated." ${ }^{65}$ From these explicit statements it is unmistakably clear that, whatever Hegel may mean by immediacy and mediation, they are indissolubly associated with each other.

The conclusion to which we are thus led is that immediacy is the result of at least partial mediation, or, as Hegel prefers to say, that "immediacy itself is essentially mediated." The degree of truth to which the various stages of immediacy can lay claim depends upon the amount, or rather the exhaustiveness, of the mediation involved. That is to say, imperfect mediation results in an immediacy which is only partially true; immediacy becomes entirely true only when it is exhaustively mediated. This fact might be illustrated by any category of the Logic. Being, for example, is really viewed in its truth only when it is seen in the light of the Absolute Idea; and the same is true of all other lower forms of immediacy. The Absolute Idea itself is the ultimately true immediate solely because it is the perfectly mediated. The nature of true immediacy will thus appear as we determine the essential nature of the process of mediation of which it is the result.

A point which will be of great importance to us when we come to inquire concerning Hegel's doctrine of the ultimately real emerges here. We have just said that the completely mediated is for Hegel the ultimately true. Now when we remember that he identifies the ultimately true and the ultimately real, we are led at once to the important conclusion that the real is the result of this process of mediation. As Hegel views the matter, the various stages of immediacy are more or less concrete according as the mediation involved in each is more nor less exhaustive; the completely mediated immediacy is nothing more nor less than the concreteness of reality itself. The Absolute Idea is an immediacy which is completely mediated; it is therefore the ultimately real category, the very expression of reality itself. Reality thus is a matter of mediation. This point will serve as the basis of our discussion of Hegel's doctrine of the nature of reality. But for the present we are interested to work out the nature of this process of mediation itself. 
If we turn to the preface of the Phenomenology of Spirit, we find there Hegel's formal definition of the process of mediation. Mediation, he there tells us, is "nothing other than self-uniformity (Sichselbstgleichheit) developing itself; or it is reflection into itself, the moment of the Ego which exists for itself (des fürsichseienden Ich), pure negativity, or, degraded from its pure abstraction, simple becoming." ${ }^{\circ 6}$ A page or two preceding this passage he asserts that, according to his view, the whole matter reduces to this: "Truth is to be conceived of and expressed, not as Substance, but as Subject. At the same time it is to be noted that substantiality includes in itself both that which is the immediacy of knowledge itself, namely, the universal, and that which is the immediacy for knowledge, namely, Being...."67

The first of these passages gives us Hegel's conception of the nature and characteristics of the process of mediation; the second emphasizes the nature of the result of the process. Taken together, the meaning of the two seems to be this. If we define truth as substance, our definition is so far right; both thought and being, both the particular and the universal, are included in the definition. But the inadequacy of this definition lies in the fact that It fails to explain satisfactorily the relation of these two aspects of experiences. Thought and being are left existing side by side, as it were, in a blank identity devoid of differences, which identity, like Schelling's, "is absolutely presupposed without any attempt being made to show that this is the truth." 68 The attempt to show that this is the truth inevitably leads us, Hegel thinks, to the standpoint of subject, to the conception of identity in difference which is the central fact of consciousness. Now the process of exhibiting this necessity is the process of mediation, which, when the goal is once reached, appears in its true light as the expression of the interrelation of the parts of an organic whole which itself exists for itself. When viewed from the standpoint of the lower stages of immediacy, mediation seems merely the expression of an external relation among phenomena more or less independent of each other; but when it is looked at in its real nature, when it is viewed sub specie aeternitatis, it is seen to be the expression of the necessary and vital interconnection of phenomena which themselves have significance only as parts of a comprehensive unity. Summarizing, then, we may say that the process of mediation is a development towards greater determinateness and the progressive substitution of necessary and vital, for seemingly accidental and arbitrary, connections among phenomena; and such a development is from the abstract to the con- 
crete, its final goal being the concreteness of reality itself. As Hegel himself elsewhere expresses it: "The progress of development is equivalent to further determination, and this means further immersion in and a fuller grasp of the Idea itself." ${ }^{69}$

A glance at Hegel's criticisms of Jacobi's doctrine of immediacy will give us an insight into his own doctrine of mediation It will accordingly be well for us to notice this criticism before passing on. But first let us remind ourselves of what in general are the nature and significance of Jacobi's doctrine.

The chief significance of Jacobi's doctrine, for our purposes at any rate, is its insistence that after all there is an ultimate reality with which we must somehow come in contact. "Reason," he. tells us, "plainly presupposes the true, as the outer sense space and inner sense time, and exists only as the faculty of this presupposition. So that where this presupposition is wanting there is no reason The true must therefore be possessed by man just as certainly as he possesses reason." ${ }^{70}$ Reason "affords us a knowledge of supersensible objects, that is, affords us assurance of their reality and truth." 71 This insistence upon the ultimate intelligibility of reality is an important point in Jacobi's philosophy, and Hegel does not fail to call attention to it. But, notwithstanding Hegel's recognition of this point, he yet criticizes Jacobi, as he does Kant, for denying in fact that reality can be known. ${ }^{72}$ And we are compelled to admit the justice of the criticism. For Jacobi's only medium through which reality can be known, though at times he calls it reason as above, is in point of fact different from reason; it is something which lies beyond reason, a kind of intuition, a form of immediate knowledge from which all mediation is excluded. From this form of knowing the categories of thought are, to some extent at least, banished as useless. Of course, this is no place to enter into the disputed question whether, in his conception of immediacy, Jacobi attempted to get rid entirely of the categories of thought; to solve this problem is not necessary for our present purpose. However the problem may be solved, there can be no doubt that Jacobi contemned mediation in his grasp of that immediacy which is the ultimately real, and that he arrived at his goal only by means of a salto mortale, baldly asserting that "sometime or other every philosophy must have recourse to a miracle." 73

Now, from Hegel's point of view, this Jacobian position, if true, would be the death-knell of all philosophy and would reduce us to absolute relativity. It corroborates the 'comfortable view' that study, pains- 
taking effort and diligent application are not in the least essential to the search after truth: truth is given, is thrust upon us in immediate, intuitive perception. But this is a dangerous attitude, Hegel urges. It may be that God gives to His beloved in sleep; but, so far as we can see, that which is given in sleep is usually discovered to be simply the wares of sleep. In less figurative language, if truth is a matter of feeling, however high above reason the feeling may be supposed to stand, then it is relative and the search for it is useless: individual perception, immediate intuition, or what not, is too prone to cater to individual prejudices and prepossessions. "What has its root only in my feelings, is only for me; it is mine, but not its own; it has no independent existence in and for itself." ${ }^{74}$ Hence, if ultimate reality is and can be only an object of feeling, whether that feeling be called intuition, faith, immediate certainty, or ultra-rational perception, then there is absolutely no reason why the real should not be denied objectivity; on the contrary, there seems to be every reason to urge that it is reduced to purely subjective terms. Hegel makes merry over this predicament of the Jacobian philosophy, and sarcastically exclaims: "Truth is in a bad way, when all metaphysics is done away with, and the only philosophy acknowledged is not a philosophy at all!" 75

But fortunately for truth it is not in this sad predicament. In supporting this position Jacobi overlooks the fact that short-cuts in philosophy are as useless and hurtful as they are in any other field where assiduous and patient toil is an absolute requisite. Philosophy, the discovery of truth, does not depend upon a miracle, as Jacobi asserts, but upon hard work. Jacobi was led to his false position by his misconception of the nature of thought as a mediating activity. This Hegel sees clearly and criticizes sharply and decisively. As Jacobi conceives the matter, the mediation of thought is merely a progression from finite to finite, from conditioned to conditioning which is in turn conditioned. ${ }^{76}$ It is a process of mediation among phenomena quasi-mechanically related to each other; thus it can be nothing but a regresses ad infinitum. The end of this infinite regress cannot be anything more than a blank abstraction, the empty absolute, a barren identity of thought and being. ${ }^{.7}$ The ultimately real must lie beyond such knowledge, since to know it would be to limit it and a limited absolute is a contradiction in terms. ${ }^{78}$ Thus there is an impassable gulf set between the finite and conditioned and the infinite and unconditioned, between the realm of that which seems and that which really is. And the process of mediation is arbitrarily 
confined to the former sphere. True immediacy, therefore, that immediacy which can be predicated of reality, must exclude all mediation. ${ }^{79}$ So the real task of philosophy is to leap the gulf which cannot be bridged; and it accomplishes this miracle in order to find outside of the ken of human knowledge that which makes human knowledge possible, namely, the ultimately true. But, Hegel argues, this ridiculous contention is based upon a false view of the mediating activity of thought. True mediation is not external mediation. Instead of leading only from the conditioned to the conditioning in an infinite regress, it transforms the conditioned into the self-conditioning and so discloses the infinite and unconditioned just within the realm of the finite and conditioned. Likewise, true immediacy does not consist in transcending mediation; on the contrary, it is the subsumption of mediation, the unity in a higher synthesis of mediated factors. ${ }^{80}$ We may put the whole matter in Hegel's own words: "Immediate knowledge, like mediated knowledge, is entirely one-sided. What is true is their unity, an immediate knowledge which is likewise mediated, something mediated which is likewise simple in itself, which is immediate reference to itself... Here is union, in which the difference of those characteristics is done away with, while at the same time, being preserved ideally, they have the higher destiny of serving as the pulse of vitality, the impulse, movement, unrest of the spiritual as of the natural life." $" 1$

A brief statement of the contrast between Jacobi and Hegel on this point will serve to put in relief Hegel's view of the matter. Jacobi would fully agree with Hegel that "the only content which can be held to be the truth is one not mediated with something else, not limited by other things." 82 And from this both would agree in drawing the conclusion that the ultimately true must be immediate But here they would part company; of the nature of this immediate they would have exactly antithetical conceptions. By immediate Jacobi would mean that which is given independently of all mediation whatsoever; while Hegel would mean by it a completely mediated content, a content "mediated by itself, where mediation and immediate reference-to-self coincide." ${ }^{83}$ Whereas Jacobi conceives of ultimate reality as the postulate of immediate intuition, Hegel defines it as the result of mediating thought: to the one, true immediacy is void of any trace of mediation; while to the other, it is nothing but perfect mediation. This difference between the two thinkers concerning immediacy, is, of course, due to the fact that their views of the mediating activity of thought are different. Jacobi conceives of the 
process as one of simple negation, which passes from content to content without being any the richer for its wanderings; it forever pursues a goal which eternally lies beyond its grasp. Hegel, on the contrary, views the process, not as one of mere negation, but as one of determinate negation; one which "holds fast the positive in the negative," includes its content within itself, and passes by means of the negative into a higher synthesis in which is preserved the truth of the mediated factors. ${ }^{84}$

And this brings us to a consideration of negation, that aspect of thought which gives it its possibility as a mediating activity. I think it may be justly said that an understanding of this Hegelian conception is absolutely essential to a correct appreciation of the system. As the author himself says more than once, it is the very soul and vitality of the dialectic; it is that by virtue of which the dialectic leads us to the concrete fullness of the Absolute Idea itself. Let us first try to grasp its significance, and we shall then be in a position to see how it has been misunderstood. It has been said that in order to understand Hegel properly one must read him backwards. This is nowhere more imperative than in an attempt to see what he means by the negative in thought. $\mathrm{He}$ tells us in the Logic, "To mediate is to take something as a beginning and to go onward to a second thing: so that the existence of this second thing depends on our having reached it from something else contradistinguished from it." 85 But this is by no means all there is to the process as Hegel defines it. He maintains further that this "development of one thing out of another means that what appears as sequel and derivative is rather the absolute prius of what it appears to be mediated by." ${ }^{86}$ In this statement we find set forth, it would seem, the fundamental aspect of the dialectical method: at any rate, here we find given us the right point of view for regarding the process. That which comes first finds its explanation in what follows; what seems to be product is really ground; truth is a last result and not a first principle. Mediation is thus a passage from one object to another which takes place by simply making explicit the inner connection and the essential oneness of the objects. This point we have already dwelt upon above.

Assuming now this point of view, we are in a position to see what Hegel means by the significance and power of the negative in thought. Simple relation to another is, for Hegel, negation: in so far as an object refers beyond itself it involves negation. From this it follows that everything involves negation, that is, every finite object; for by its very nature every finite object refers beyond itself. Hence the potency of negation in 
the dialectic. The particular points beyond itself for its explanation and completion, it finds its 'truth' in the other. Taken as it is given, it is isolated, indeterminate, abstract; but by the power of the negative inherent in it, that is, because of its abstract indeterminateness, it leads on to and passes into its context, and so becomes less indeterminate. Its other, however, in terms of which the object finds its explanation, is in its turn abstract and leads on to its other for its determination; and so the process goes on. Reference beyond self, negation, is thus the power that keeps in motion the machinery of the dialectic. This reference beyond itself, however, is not externally imposed upon the object; it is not the expression of a relation between itself and another essentially different from it. Rather is this reference beyond self the very expression of the deepest nature of the object; the other is not an indifferent other, but the other in which the object finds its true self. The reference beyond self, the negation inherent in the object, is just the indication of the fact that the true self of the object lies elsewhere than in its own factual existence. Thus the negative leads us ever to concrete universality; for the form proves to be the "indigenous becoming of the concrete content," and so the process is one of self-determination in which the particular finds its universal and the universal its particular. ${ }^{87}$

But, in order to see that negation does actually lead us to such a result, it is essential that the exact function of the negative in thought be kept clearly in view. Hegel criticizes Jacobi very severely for neglecting the negative in his doctrine of immediate knowledge; and the chief fault he has to find with Condillac's development of the categories is that in the development the negative aspect of thought is entirely overlooked. So it will be well for us to state explicitly and discuss the two points upon which Hegel lays stress in his doctrine of negation. The first of these points is that negation is negative. The second is that negation is positive. We begin with the first of these two points.

It is necessary for us to remember, says Hegel, that thought really is a process of negation. This is just the point which he has in mind in the above mentioned criticism of Condillac. He grants that Condillac posits the right point of departure, namely, immediate experience: the cardinal error of Condillac's procedure, he urges, is that the negative involved in the development of the categories is completely forgotten. Perhaps it will be well to quote the passage here: "In Condillac's method there is an unmistakable intention to show how the several modes of mental activity could be made intelligible without losing sight of mental unity, 
and to exhibit their necessary interconnection. But the categories employed in doing so are of a wretched sort. Their ruling principle is that the sensible is taken (and with justice) as the prius or the initial basis, but that the later phases that follow this starting-point present themselves as emerging in a solely affirmative manner, and the negative aspect of mental activity, by which this material is transmuted into mind and destroyed as a sensible, is misconceived and overlooked. As the theory of Condillac states it, the sensible is not merely the empirical first, but is left as if it were the true and essential foundation." 88

Now what does this criticism mean? Of course we are not concerned to inquire here whether it is a just criticism of Condillac's theory. Apart from this theory, and expressed in general terms, the criticism means, it would seem, simply that, in the nature of the case, to think the world is virtually to deny that its first immediate aspect is the ultimately true. Thought is not exclusively affirmative; it is negative as well, and its negative function is to transform the immediately given. Expressed in Hegel's own words: "To think the phenomenal world rather means to recast its form and transmute it into a universal. And thus the action of thought has also a negative effect upon its basis: and the matter of sensation, when it receives the stamp of universality, at once loses its first and phenomenal shape." 89 That is, all thinking experience is a process of interpretation in which there is and can be no bare immediacy; for thinking ipso facto involves the transcending of the particular and the transformation of it into the form of the universal. Such, then, is the negative function of thought: and all thought is negative. To think the world is to deny its reality in the form of abstract particularity; its purely immediate aspect is by thought negated.

But, be it noted, the particular is not merely denied; in a very important sense it is also affirmed. And this brings us to the second point, that thought is positive as well as negative. As an abstract particular, qua abstract to think it is to negate it; as a universalized particular, qua universalized, to think it is to affirm it. Reason, in short, is positive as well as negative; and, what is more important still, is positive by virtue of the very fact of its negativity. "To hold fast the positive in the negative is the most important aspect of rational knowledge." 90 Hegel cannot be accused of having neglected to state very definitely what he means by this positive significance of negation. In the introduction to the larger Logic he tells us that what is needed to secure the dialectical movement of thought "is to realize that the negative is just as much positive, or that 
contradiction does not dissolve into zero, into blank nothingness, but only into the negation of its particular content." And he goes on to say: "We must realize that such negation is not total negation, but only negation of a determinate content; consequently it is determinate negation. In other words, the result contains essentially that from which it results.... So the result, that is, the negation, being a definite negation has a content: it is a new concept or notion, but a higher, richer notion than the preceding one which has been enriched by its own negation or opposite. The new notion contains both the old one and its negation, and is thus at the same time the unity of the older with its opposite." ${ }^{91}$ This we find at the beginning of the Logic; at the very end we find the author emphasizing exactly the same point. The negative, he there tells us, is indeed "the negative, but of a positive which it includes. It is the other, not of something to which it is indifferent, else it would be no other.... It is the other in itself, the other of another, and therefore it includes its other within itself." ${ }^{2}$ These passages are so very explicit little need be added by way of interpretation. Their unquestionable meaning is that negation is not to be thought of as abstract contradiction, but as affirmative negation - concrete synthesis. Negation is not merely the tendency of the finite category to negate itself, to pass into its abstract opposite or other; it is not a bare denial of thesis by its antithesis. Rather is it the tendency of the finite category to complete itself, to pass into its other where lies its own true nature; it is a denial of the thesis, which is at the same time a synthesis of the thesis and its formal opposite. Thus it is that the negative has a very positive import.

This is a very vital point upon which Hegel is here insisting. Real negation must be significant negation: the infinite judgment, we must agree with Hegel, is a 'nonsensical curiosity' of formal logic. ${ }^{93}$ As Mr. Bradley has well put it: "A something that is only not something else, is a relation that terminates in an impalpable void, a reflection thrown upon empty space. It is a mere non-entity which can not be real."94 All significant negation ipso facto has a positive import; it presupposes a system within which the negative is to fall, a unity of differences, and within the system negation affirms, more or less explicitly, some really significant conclusion about the unity. Bare negation simply denies identity of contents that have nothing in common, and is consequently a mere tautology; significant negation, on the other hand, denies identity of contents which are in some respects one, and so asserts real difference. Of course, if disjunction within the unity is exhaustive, negation 
may to all intents and purposes be affirmation, if only two alternatives are possible, for example, the denial of the one is the affirmation of the other. ${ }^{95}$ It is indeed true that negation may carry with it very little positive significance: the judgment, 'This is not black,' tells us practically nothing so far as the actual color of the object under consideration is concerned. But if the judgment is really a significant one, if it has any meaning at all, it partially at least introduces a determination into the universe of discourse by telling us, for example, that the subject of the judgment is a colored object, and in so far it gives us positive knowledge of the object of interest. ${ }^{96}$ And this negation approximates to direct affirmation as the differences within the system in which it falls are more sharply defined - it is to be noted that this very definition may be the result of negation; negative instances are always more than negative. Ultimately, from the denial of blackness there might arise positive knowledge concerning the actual color of the object of judgment.

Now in view of the above considerations we can more clearly see what Hegel means by the constant assertion that the negative is the very soul and vitality of thought. Thought is at once analytic and synthetic; it does not first negate and then synthesize, but it synthesizes in its negation. It denies abstract unrelatedness, and affirms and defines complex interrelatedness among phenomena. It rejects the unrelated particular and the blank universal as alike indefinable and meaningless; it asserts the necessity of identity in difference, of unity within multiplicity. Thought as a process of mediation is thus of a two-fold nature: it is the denial of a world of unrelated elements, and the affirmation of the world as concrete totality. Such is the double function of negation: it denies the abstract and affirms the concrete. Because thought is negative, it drives us from the standpoint of immediate sense experience and forces us to seek the eternal and true elsewhere; because thought is positive in its negation, it perforce "produces the universal and seizes the particular in it." 97 Thus, by its very nature, thought is a process of mediation which gives as a result, not mere abstract generalization, but real determination - the concrete individual.

I know of no better summary of Hegel's view concerning the negative in thought than the one which he himself has given in the preface to the first edition of the larger Logic: "Reason is negative and dialectical, in that it dissolves the determinations of the understanding into nothing; it is positive in that it produces the universal and preserves (begreift) the particular in it. As the understanding used to be taken as something 
separated from reason in general, so dialectical reason used to be taken as something separated from positive reason. But in its true nature reason is mind (Geist), which is higher than both cognitive (verständige) reason and rational understanding. Mind is the negative, that which constitutes the quality of dialectical reason as well as of the understanding. It negates simplicity and so, like the understanding, posits determinate difference; but it also destroys this difference and so is dialectical. Its result, however, is not mere emptiness, but is just as much positive; thus it returns to and establishes the first simplicity, which now is a universal concrete in itself." 98

Our conclusion, then, concerning Hegel's doctrine of the process of thought as dialectical is that thought is a process of negative mediation. As a mediating activity, thought is not limited to the finite and conditioned as those who appeal to the necessity of immediate knowledge would have us believe. On the contrary, its very mediation is the definition of reality; by relating it defines, and by negating it affirms. In other words, the process of thought is the progressive explication of the implicit, the disclosure of the essential nature of the objects of knowledge Negation is not construed in terms of formal contradiction; it is that function of the dialectic by virtue of which it leads ultimately to the essence of reality. However faultily Hegel may be thought to have worked out this conception in the Logic, its illuminating suggestiveness for any theory of knowledge cannot be denied and should not be overlooked. ${ }^{99}$

Perhaps enough has been said about this Hegelian doctrine of negation. But, like most of Hegel's teachings, it has not escaped misconstruction at the hands of the critics. So it may not be amiss, at the conclusion of our exposition, to add a few words in reply to some of the most characteristic criticisms; not, indeed, for controversial purposes, but in the hope that the attempt to set Hegel right in the eyes of his critics will at least serve to call attention to the fact that another interpretation of him is possible.

The criticisms of Haym and James seem unquestionably to rest upon an entirely false notion of what Hegel means by negation. Haym seems to think that Hegel absurdly contended that the essence of things consists in their being contradictory; and he contrasts this supposed position of Hegel's with the Herbartian principle that the way to truth lies through the elimination of contradiction. ${ }^{100}$ Such an interpretation evidently takes it for granted that Hegel can mean by contradiction, negation, nothing more than what formal logic means by it, namely, sheer 
incompatibility and absolute opposition; to all appearances, the critic is innocent of the fact that negation or contradiction, as Hegel is at great pains to define it, is just the doing away with bare negation, abstract opposition, and that the term embodies Hegel's unwearied insistence that formal contradiction has no significance when applied to reality. Naturally the criticism is no more significant than the assumption upon which it leans for support. The same oversight is at the basis of Professor James's criticism of this Hegelian conception, in a characteristic discussion "On Some Hegelisms," in his volume of popular lectures on philosophy entitled The Will to Believe. At a very dramatic point in this essay Hegel is presented to us, standing amidst a jarring, jolting world of incoherent facts, frantically lifting 'vain hands of imprecation' at the wild and tumultuous scene before him. "But hark! What wondrous strain is this that steals upon his ear? Muddle! is it anything but a peculiar sort of transparency? Is not jolt passage? Is friction other than a kind of lubrication? Is not a chasm a filling? - a queer kind of filling, but a filling still. Why seek for a glue to hold things together when their very falling apart is the only glue you need? Let all that negation which seemed to disintegrate the universe be the mortar that combines it, and the problem stands solved." ${ }^{101}$ These strictures are apparently supposed to be a real criticism of Hegel, but the absurdity against which they are directed first saw the light when they themselves were penned. It is certain that such an absurd position as the one here criticized cannot justly be attributed to Hegel; it is a caricature of Hegel's real position. The 'glue' that binds the world together is, in Hegel's view of the matter, not the eternal falling apart of objects, but simply their necessary interconnectedness; if you attempt to separate them, they will not stay put. Nor is it that negation which disintegrates the universe that Hegel uses as the "mortar' to combine it; it is that negation which, because it is as much positive as negative, does actually combine it. After all, it would appear that one is forced to admit that Hegel is more than a superficial thinker trying to palm off on a long-suffering public palpable absurdities.

Trendelenburg's criticism of Hegel on this point is more serious and, one is inclined to say, more significant than the preceding criticisms, but it seems no less fallacious. This critic triumphantly forces Hegel into the following dilemma: "Either the negation, through which the dialectic development to the second and third moments is mediated, is logical negation (A, not-A) - in which case nothing determinate is produced in the second moment and no synthesis is given in the third; or 
else the opposition is a real one - in which case it cannot be attained by logical means, and consequently the dialectic is not the dialectic of pure thought." 102 Here it is evident that the critic is at least aware that two kinds of opposition or negation are possible, namely, logical and real; and in this respect his criticism differs from the preceding ones But, like these others, Trendelenburg's criticism rests upon an assumption the validity of which he does not attempt to establish. The assumption in this case is that Hegel has no right to claim that the dialectic of pure thought can involve material opposition. This assumption is based upon a further assumption that pure thought and formal thought (abstract cognition) are one. If we are willing to grant this second assumption, then the above dilemma exhausts the possibilities and so accomplishes its purpose; in the nature of the case formal opposition or negation is not material opposition. But if we maintain with Hegel that form and matter are one and inseparable, and that real thought, so far from being merely formal thought confined to the magic circle of the impotent universal, actually does express the nature of its object, then the critic's dilemma is not exhaustive and so loses its significance; in this event, formal opposition becomes a mere abstraction, and dialectical negation, the negation of what Hegel calls pure thought, becomes ipso facto real opposition. So it would seem that before the critic undertook to annihilate the dialectic with an 'either-or' proposition, he should have come to an understanding with the author concerning the nature of that thought of which the dialectic is the expression. The whole problem is whether pure thought, as Hegel uses the term, does involve real opposition; and this must be argued, not assumed at the beginning.

Mr. McTaggart's contention that negation loses import as the dialectic advances from the more abstract to the more concrete categories implies the same general misconception of the nature of negation. In his opinion negation is very prominent in the earlier categories, while in the later categories it has almost entirely disappeared. And he seeks to establish this interpretation by investigating the movement of the dialectic in the categories of Being, and by contrasting the movement there with the movement in the categories of the Notion. ${ }^{103}$ It is not our present purpose to inquire whether this is or is not a correct account of the dialectic as it is actually worked out in the Logic. The point of interest now is the fact that negation, as Mr. McTaggart implicitly conceives it, is not negation as we have seen Hegel define it above. According to the critic thesis and antithesis, in the earlier categories of the Logic, are 
opposed to each other in a more or less mechanical fashion and are more or less externally joined together by means of the synthesis; but, in the later categories, this abstract opposition is wanting. Now to go from this fact (granting for the sake of the argument that it is a fact) to the conclusion that negation becomes less significant as the dialectic advances is clearly to identify negation with abstract opposition The argument is this: in the categories of Being, antithesis is the logical opposite of thesis, and so here we find negation; in the categories of the Notion, antithesis and thesis are no longer sheer incompatibles, antithesis defines thesis, and therefore the negation formerly existing between them has disappeared. In this argument sheer incompatibility and negation are obviously used synonymously. But, as we have already seen, this sheer incompatibility is not Hegel's conception of negation. From his point of view negation does not simply negate; its nature is not exhausted in bare opposition. On the contrary, it always presupposes a positive ground and so is in a very important sense positive. All genuinely significant negation carries with it a positive import; bare negation is a meaningless tautology. Hence it follows that, if the antithesis is to be a true negative, a dialectical negative, as Hegel says it is, then it must to a degree at least define the thesis; and the more perfectly it does this, the more significant a negative does it become. Thus, even accepting $\mathrm{Mr}$. McTaggart's account of the general nature and procedure of the dialectic as true, still we are forced to reject his conclusion. As Hegel conceives the negative, it progressively becomes, not a less and less, but a more and more important factor in the dialectical process; so far from finally disappearing entirely, it ever grows more explicit and more emphatic. And this, one is inclined to think, is the true description of the matter: negation gains in positive import as the universe of discourse becomes more determinate.

Finally, Mr. Bradley's implied criticism of Hegel on this point seems open to the same general criticism as the above. "The law of Contradiction," he says, "has had the misfortune to be flatly denied from a certain theory of the nature of things. So far is that law (it has been contended) from being the truth, that in the nature of things contradiction exists." 104 Now I submit that this statement, as a criticism of the Hegelian theory, is beside the mark. Hegel does not deny the validity of the law of contradiction taken in its abstract and formal sense, that is, as the statement of the relation which exists between logical contradictories. A unitary whole whose elements are sheer logical disparates is, I think we may safely 
say, as genuine a non-entity for Hegel as it is for anyone else. What Hegel does deny, however, is that such abstract contradiction finds a place in reality; and he is prepared to argue that when we attribute it to reality we are guilty of attempting the impossible task of making reality square with the principles of our abstract and formal logic. What he insists upon is that we must define contradiction more concretely, if we would apply the category to the real; and this more concrete definition he gives us in his doctrine of negation. But this position does not necessarily touch the validity (formal validity) of the law of contradiction at all as Mr. Bradley himself is willing to admit. "In the object and within the whole," he tells us, "the truth may be that we never really do have these disparates. We only have moments which would be incompatible if they really were separate, but, conjoined together, have been subdued into something within the character of the whole If we so can understand the identity of opposites - and I am not sure that we may not do so - then the law of Contradiction flourishes untouched. If, in coming into one, the contraries as such no longer exist, then where is the contradiction?" 105 Although it is questionable whether Mr. Bradley stands consistently by this position in his theory of knowledge, we certainly are justified in attributing it to Hegel. So, granting this, it would seem that, on the critic's own showing, Hegel is free from the charge of having 'flatly denied' the significance of the law of contradiction. He had no quarrel with this principle, as a principle of formal logic; I am persuaded that he, as well as his critic, was fully conscious of the fact that "it has not a tooth with which to bite any one." He respected its toothless estate and had no reason, and, so far as I have been able to see, no inclination, to rob it of its legitimate claims, 'absurdly feeble' though they surely are. What he was anxious to do was to make the formal principle conscious of its absurdly feeble condition, and to rejuvenate it by bringing it into vital touch with concrete reality. As the statement of the blank opposition of disparates the principle is indeed abstract and impotent; as the negative of the Notion it is the very pulse of the life of reality itself. This, as I comprehend it, is the position of Hegel with reference to the law of contradiction; and, if I read Mr. Bradley aright, it differs only in terminology from his own view of the matter.

The main points which this chapter has attempted to establish are the following. Hegel insists that immediacy and mediation are inseparable, that all immediacy implies mediation, and that the immediacy of reality involves complete mediation. But this is not to identify the imme- 
diacy of reality with the abstractions of science. For the process of mediation, as Hegel defines it, is a process of determinate negation which reduces experience to an ordered and systematic whole; it affirms as well as denies, and indeed affirms by denying. In short, it is the principle within experience which makes of experience a cosmos and not a chaos. A completely mediated immediacy, that is, reality, is, therefore, just completely organized experience. This negative within thought is not merely negative; it is a negative which annuls the false immediacy only because it is ever leading us onwards to the true immediacy. The many criticisms which are directed against Hegel on this point overlook this fact, and unwarrantedly assume that he means by negation abstract contradiction.

\section{Chapter III. \\ Ontology and Epistemology.}

The conclusions of the two preceding chapters have led us to a further problem which we shall here be forced to face. If it be true that thought does in point of fact express the nature of things, then it would seem to follow that the science of thought is the science of things, that ontology and epistemology coincide. In this connection two questions arise: Does Hegel identify the two? And if so, what does he mean by the identification and what justification is there for it? It is to the task of answering these questions that we now address ourselves.

To the first of the above questions there can, I think, be only one answer. Hegel does identify logic and metaphysics. In the first place, we have his own explicit statement on the point. Since thoughts are "Objective Thoughts," he says, "Logic therefore coincides with metaphysics, the science of things set and held in thoughts - thoughts accredited able to express the essential reality of things." ${ }^{106}$ Besides such an explicit statement, one might offer as evidence the whole logical bias of the Hegelian philosophy which is unquestionably towards this identification. Since the categories "really are, as forms of the Notion, the vital spirit of the actual world," 107 and since things or objects which do not agree with them are accidental, arbitrary, and untrue phenomena; ${ }^{108}$ since the universal aspect of the object is not something subjective attributed to it only when it is an object of thought, but rather belongs to and expresses its essential nature, it follows that the science which has to do with these universals is ipso facto the science of reality. This sci- 
ence, of course, is logic. Logic, therefore, is metaphysics. ${ }^{109}$

For this identification of logic and metaphysics Hegel has been very severely criticized. And this brings us to our second question: What does Hegel mean by the identification, and can it in any way be defended? Perhaps we can best answer this question by attempting to answer the objections to which the identification in question has given rise. One of the most recent and perhaps the clearest and most convincing of Hegel's critics on this point is Professor Seth Pringle-Pattison; consequently we shall devote ourselves to a consideration of his objections. If we succeed in answering satisfactorily his criticism, we shall have succeeded in answering all.

But before passing to this criticism some preliminary work is necessary. We must first attempt to define the exact position of the Logic with reference to the other parts of Hegel's system. This will clear the way for the following discussion But in order not to anticipate that discussion our attention will here be confined exclusively to the problem of the position of the Logic in the system; the problem of the ontological significance of the Logic will occupy us when we come to take up Professor Pringle-Pattison's criticism. What then, we first ask, is the position of the Logic in the system, and in what relation does it stand to the other parts of the Encyclopedia?

The best point of departure in attempting to answer this question is acquaintance with the specific problem that Hegel has before him in the Logic. In order to determine the nature of this problem, however, a consideration of the question concerning the presupposition of the Logic is necessary. For it would seem that one could hardly appreciate the significance of the dialectical development of the categories by plunging at once into the 'bacchic whirl.' A preliminary discussion of what the Logic presupposes, if, indeed, it is not absolutely necessary to an adequate appreciation of its real problem and aim, is at least desirable.

But this problem of the presupposition of the Logic need not detain us long. There can be no doubt, it would seem that in the author's mind the Logic presupposes the result of the Phenomenology. To justify this contention it is necessary simply to let the author speak for himself. "In the Phenomenology of Spirit," he says in the larger Logic, "I have exhibited consciousness in its progress from its first immediate opposition of itself and its object, on to absolute knowledge. This course traverses all the forms of the relation of consciousness to its object, and has as its result the conception of our science. This conception needs no justifica- 
tion here - apart from the fact that it comes out as the final result in the Logic itself - it needs no justification here, because it got its justification there. And it is capable of no other justification than just this production of it by consciousness, all whose own peculiar forms are resolved into this conception as their truth. . This conception of the pure science and the deduction of it are presupposed in the present treatise, in so far as the Phenomenology of Spirit is nothing else but such a deduction of it "110 Again, later in the same work, we read: "It has been remarked in the introduction that the Phenomenology of Spirit is the science of consciousness, the exhibition of the fact that consciousness has the conception of our science, that is, of pure knowledge as its result. To this extent, then, the Logic has the science of the phenomenal Spirit as its presupposition; for that science contains and displays the necessity, and hence the proof of the truth of the standpoint of pure knowledge, as well as the way in which that standpoint is reached." 111 In addition to these explicit statements of the Logic, I may be permitted to quote one other passage from the preface to the Phenomenology itself. Having traced in a sentence or two the development of the Phenomenology from the standpoint of sensuous consciousness to that of absolute knowledge, where we have completely mediated being, Hegel continues: "Just here the Phenomenology comes to an end. In it the way has been prepared for the element of knowledge wherein the moments of Spirit have unfolded themselves in the form of simplicity which knows its object as itself. These moments no longer stand opposed to each other as being and knowing, but remain in the simplicity of knowledge; they are the true in the form of the true, and their difference is only difference of content. Their development, which in this element is organized into a whole, is Logic or Speculative Philosophy." 112 Comment on such plain passages as these seems superfluous: Hegel's meaning in them is unmistakable. The science of Logic assumes the conclusion of the Phenomenology as its starting point and its procedure and result are to be judged only in the light of this assumption.

Without further discussion of this point, then, we pass to the main problem before us. What is the aim of the Logic in the light of its presupposition? The passage quoted last in the preceding paragraph gives us a basis for an answer to this question. In this passage Hegel tells us what the purpose of the Logic is, viewed from the standpoint of absolute knowledge. The passage, translated into simpler language, amounts to this. At the conclusion of the Phenomenology we reached the true defi- 
nition of knowledge; the categories no longer appear as merely subjective ideas, or concepts, opposed to objects to which they are quasi-mechanically related, but they show themselves to be capable of expressing the essential nature of objects, and so are genuinely universal and objective. To organize these categories into a systematic whole and to set forth in a scientific manner their interconnection is the business of the Logic. In other words, the Phenomenology exhibits the essentially objective and universal nature of that thought which is the subject-matter of the Logic; the problem of the Logic being to work out the connection among the categories in abstraction from their essential relation to sensuous experience. In the Phenomenology thought has been observed and its nature determined in its relation to the objects of time and place, but in the Logic temporal and spatial relations are entirely ignored and we move in the ether of pure thought: the concrete categories of the Phenomenology are, in the Logic, to be considered for their own sake and their inter-relations determined apart from their experientibasis. In a sense it may be said that the Phenomenology assumes that thought is always concrete, its procedure consisting in an exhibition of the necessity of this assumption: the Logic, likewise, takes this for granted but as a fact established by the Phenomenology and then proceeds to investigate specifically thought as it is in and for itself. "To raise to knowledge.... those forms of thought which act instinctively in common consciousness and obtain there only an obscure and incomplete reality, to seize them by thought, and thought alone, in their most simple, abstract, and universal existence, to trace and comprehend them in their relations and in their unity — such is the task of the Hegelian Logic." 113

We must guard the statement above that the purpose of the Logic is to deal with thought in abstraction from its empirical nature. Such a statement might be misconstrued to mean that the Logic deals only with abstract thought. And such an opinion would certainly not be without justification, even on the basis of Hegel's own assertions. When we consider his statements concerning the science of logic, all that we have hitherto said about the concreteness of logical thought seems to have been said falsely. For example, Hegel tells us in one place that the realm of logic is "a kingdom of shadows, the world of simple essences, freed from all sensuous concretion." 114 Elsewhere he says that the content of logic is "the presentation of God as He is in His eternal essence before the creation of Nature or of a finite mind." 115 In yet another passage we are informed that logic "has to do not with perceptions, nor, like geom- 
etry, with abstract representations of the senses, but with pure abstractions." 116 But such deliverances as these are balanced by numerous counter-assertions concerning the concreteness of the science of logic. For example, we meet such a passage as this: "Bare abstractions or formal thoughts are no business of philosophy, which has to deal only with concrete thoughts." 117 Or this: "Logic has nothing to do with an act of thought about something that lies outside of the thought as the ground or basis of it, or with forms that furnish mere signs or marks of the truth. On the contrary, the necessary forms and peculiar determinations of thought are the content and the highest truth itself." 118 Furthermore, we are explicitly informed ${ }^{119}$ that das begreifende Denken rather than simply das Denken is the subject matter of logic; and, as I have tried to show in the preceding chapters, this is to say that the thought of the science of logic is concrete.

The question naturally arises, Do not these two sets of passages contradict each other? Is not a 'pure' abstraction equivalent to a 'bare' abstraction, and when Hegel asserts that the science of logic has to do with pure abstractions does he not virtually deny the validity of his claims for its concreteness? A consideration of this essential point will give us a clearer idea of the Logic, both as to its aim and problem and as to its relation to the Phenomenology of Spirit.

The answer to the puzzle before us will be found in an appreciation of the ambiguity which attaches to the terms 'abstract' and 'concrete.' Abstract may mean not concrete in the sense of not sensuous. For example, it is sometimes said that the phenomena of the mind are abstract, because they cannot be touched seen, heard, etc., but are objects of thought only; objects of the world of sense-perception would, in this meaning of the terms, be concrete. This is the signification of the terms as common sense uses them. In this sense, Hegel's logic is unquestionably abstract, as he himself explicitly states; and when he speaks of the abstractness of the logic he is thinking of this meaning of the terms. The content of the Logic may be called abstract, he says, "if the name concrete is restricted to the concrete facts of sense or of immediate perception." 120 "If content means no more than what is palpable and obvious to the senses, all philosophy and logic in particular must be at once acknowledged to be void of content, that is to say, of content perceptible to the senses." 121 Of course, all sciences which have to do with objects not perceptible to the senses are, from this point of view, abstract But there is another meaning of the terms abstract and concrete. An object 
may be abstract in the sense of being unreal, or taken apart from its relations; while the concrete object is the object seen in its deepest and truest significance. The categories of mathematics, for example, may be said to be more abstract than the categories of ethical science; and the ideals that seriously influence our lives for weal or woe are more concrete than the air-castles which we build in our day-dreams. The abstract in this signification, Hegel strongly insists, is not the realm of philosophy: it is just the aim of philosophy to get rid of all abstraction and to see the world as concrete. ${ }^{122}$

From these considerations Hegel's answer to the charge of inconsistency in his statements concerning the science of logic is plain. 'Pure' abstraction is not equivalent to 'bare' abstraction; the former is characteristic of all thought, the latter only of formal thought. In that its subject matter is thought and not the immediately given of sense-perception, logic may be said to busy itself with abstractions, to move in a realm of shades; but in this way every mental science is abstract, and might be metaphorically described as a 'kingdom of shadows.' In that its subject matter is the Notion, however, that is to say, concrete thought, the Logic is not only not abstract, but is the most concrete of the sciences. ${ }^{123}$ "The Notion is not palpable to the touch, and when we are engaged with it, we must be dead to hearing and seeing. And yet . . the Notion is the only true concrete; for no other reason than because it involves Being and Essence, and the total wealth of these two spheres with them, merged in the unity of thought." ${ }^{124}$ We shall have to return to this point later.

And all this shows us again the essential difference, as well as the fundamental similarity, between the Logic and the Phenomenology. They both deal with consciousness; they are both expositions of the essential nature of thought. But whereas the Phenomenology is interested in consciousness primarily as a subject-object relation and endeavors to work out the significance of this relation, the Logic is interested primarily in disclosing the organic nature of thought and so confines its attention to the thought activity in and for itself. The one is an interpretation of thought in its relation to its object: the other is an interpretation of the categories as they are in themselves, temporarily held in isolation from their empirical setting. Hegel has stated this distinction in the preface to the first edition of the larger Logic: "In this manner" — dialectically "I have tried to present consciousness in the Phenomenology of Spirit. Consciousness is Spirit in the form of concrete knowledge, knowledge 
shut in in the form of externality; but the motion of the form of this object, as the development of all natural and spiritual life, rests only upon the nature of the pure essences that constitute the content of the Logic. As phenomenal Spirit, which in its own manner frees itself from its immediacy and external concretion, consciousness develops into pure knowledge which appropriates as its subject matter those pure essences as they are in and for themselves ... Thus is given the relation of the science that I have called the Phenomenology of Spirit to the Logic." 125

To sum up briefly, our conclusion so far is this. The Logic has as its presupposition the whole development of the Phenomenology of Spirit. The Phenomenology, as we have already seen, asserts the inseparability of thought and reality and attempts to define for us the true nature of thought. The Logic presupposes this conclusion, taking for granted that thought is really as it is here defined; and in the light of this presupposition its aim is to give a more detailed account of the nature of thought, to work out the organic unity which exists among the several categories of thought. ${ }^{126}$

Such, then, being the relation between the Logic and the Phenomenology, we pass on to ask concerning the relation between the Logic and the other parts of the Encyclopaedia. This is a much debated problem in connection with Hegel's philosophy, and upon its solution depends the integrity of the system as a system. In accordance with our determination not to anticipate the following discussion, we shall here confine ourselves to the formal aspect of the problem: as little as possible will be said concerning the real ontological significance of the Logic. The question now before us is: As regards the systematic arrangement of the Encyclopaedia, what is the relation of the Logic to the Philosophy of Nature and the Philosophy of Mind?

If at this juncture we turn to Hegel for light on the problem, we are sadly disappointed; very little light is vouchsafed us. His statements on the point are few, and those few are couched in such metaphorical terms it is almost impossible to attach a definite meaning to them. But one fact seems indisputable, the fact, namely, that Hegel believed necessary and actually tried to make some kind of transition from one part of the Encyclopaedia to another. Let us see what he has to say about this transition.

In the second edition of his Hegelianism and Personality ${ }^{127}$ Professor Pringle-Pattison has summarized Hegel's account of the transition as follows: "The Absolute Idea, Hegel says in the larger 'Logic,,' ${ }^{128}$ is 
'still logical, still confined to the element of pure thoughts.... But inasmuch as the pure idea of knowledge is thus, so far, shut up in a species of subjectivity, it is impelled to remove this limitation; and thus the pure truth, the last result of the Logic, becomes also the beginning of another sphere and science.' The Idea, he recalls to us, has been defined as 'the absolute unity of the pure notion and its reality' — 'the pure notion which is related only to itself'; but if this is so, the two sides of this relation are one, and they collapse, as it were, 'into the immediacy of Being.' 'The Idea as the totality in this form is Nature. This determining of itself, however, is not a process of becoming or a transition' such as we have from stage to stage in the Logic. 'The passing over is rather to be understood thus - that the Idea freely lets itself go, being absolutely sure of itself and at rest in itself. On account of this freedom, the form of its determination is likewise absolutely free - namely, the externality of space and time existing absolutely for itself without subjectivity. A few lines lower he speaks of the 'resolve (Entschluss) of the pure Idea to determine itself as external Idea.' Turning to the Encyclopaedia we find at the end of the smaller Logic, a more concise but substantially similar statement. 'The Idea which exists for itself, looked at from the point of view of this unity with itself, is Perception; and the Idea as it exists for perception is nature ... The absolute freedom of the Idea consists in this, that in the absolute truth of itself (i.e., according to Hegel's usage, when it has attained the full perfection of the form which belongs to it), it resolves to let the element of its particularity — the immediate idea, as its own reflection - go forth freely from itself as Nature. ${ }^{129}$ And in the lecture-note which follows we read, as in the larger Logic — 'We have now returned to the notion of the Idea with which we began. This return to the beginning is also an advance. That with which we began was Being, abstract Being, and now we have the Idea as Being; but this existent Idea is Nature."”

Such is Hegel's account of the transition from the Logic to the Philosophy of Nature. Confining our attention for the present to the aspect of the problem before us, let us ask concerning the significance and justification of this attempted transition. There seems to be no doubt that Hegel believed the transition necessary and that he did attempt to make it. The question is, Why, and with what success? One or two preliminary considerations will lead us to an answer.

In the first place, I think we must agree with Haldane that the transition in question is logical only, not temporal. ${ }^{130}$ If what we have been 
arguing is true, namely, that the Notion is genuinely objective and universal, this conclusion is forced upon us: the Absolute Idea would then include in itself the fullness of Nature. And Hegel teaches us that the transition is only logical. For he insists that the Idea cannot be thought of as existing anterior to or independent of Nature; and that, when it passes into Nature, it does not come into possession of a content which before was alien to it. ${ }^{131}$ On the contrary, we are informed that the Idea is nothing but completed Being, the abstract immediacy of Being made concrete. ${ }^{132}$ And so such an account of the relation between the Idea and its manifestations as the following from Falckenberg may be dismissed at once as at best misleading; indeed, if it means what it says, it is ridiculously false: "The absolute or the logical Idea exists first as a system of antemundane concepts, then it descends into the unconscious sphere of nature, awakens to self-consciousness in man, realizes its content in social institutions, in order, finally, in art, religion, and science to return to itself enriched and completed, i.e., to attain a higher absoluteness than that of the beginning." 133 As Hegel conceives the matter, the Idea does indeed enrich itself by passing through these various stages of its existence, or, rather, by exhibiting these differentiations of itself, but it does so only by showing that these differentiations are essential aspects of itself and by disclosing itself as inherent in them from the first. The Idea is prior, not in point of time, but solely in the logical sense.

In the second place, as Vera suggests, ${ }^{134}$ the true significance of the problem involved in this transition, as well as the correct solution of the problem, can be had only in the light of Hegel's philosophy as a whole. In a very important sense the Phenomenology of Spirit is the presupposition of the entire Encyclopedia. As has already been pointed out, the aim of the Phenomenology is simply to show what are the implications of knowledge, and to prove, against Kant, that in knowledge as thus developed we have the expression of ultimate reality. Now, as I think we must conceive the matter, the Encyclopedia simply attempts a more detailed investigation and a more elaborate exposition of this position. We might put it thus. In the Phenomenology we begin with all the reality we know anything about, namely, experience, and we proceed to develop its implications as regards its nature as a subject-object relation. The Logic abstracts from this concrete whole and examines one aspect of it, which here we might call the subject-aspect; while the Philosophy of Nature and the Philosophy of Mind deal with other aspects of the same whole, that is, they might be said to define reality in its 
object-significance. For it must not be forgotten that, when we arrive at the category of absolute knowledge in the Phenomenology, we have reached, not a new kind of experience, but only a more concrete point of view in our common everyday experience; and this point of view is taken by the other parts of the Encyclopaedia as well as by the Logic. Though Haym unfortunately failed to appreciate the full significance of his words, still he is essentially right whehe says that the Phenomenology "is really the whole system.... The later expression of the system in its articulated totality is only a more detailed exposition and completion that which is contained in the Phenomenology." 135 And it seems to me that this fact about the Encyclopaedia is not to be forgotten or overlooked, if we are truly to appreciate the relation of its several parts to each other.

If the preceding considerations are substantially true, then we are forced to conclude (a) that the Logic, Philosophy of Nature and Philosophy of Mind are only three points of view from which one organic whole is observed and interpreted. The first investigates the more strictly cognitive side of experience; the second has to do with its crass objective, its sensuous aspect; while the third undertakes to interpret its spiritual values. As Kuno Fischer points out, each in a sense has the same content: the difference among them lies rather in the form which that content assumes. ${ }^{136}$ Each has a unique sphere and claim of its own, but neither is the whole of reality nor can it be ontologically separated from the others. Thought does indeed, according to Hegel, include its object, whether that object be crass matter or the other so-called functions of the mind; but it includes by subsuming, by taking up and preserving in itself. So other sciences besides that of pure thought have their raison d'etre. ${ }^{137}$ But because thought does thus include its object, we must say (b) that in a sense the Logic comprehends the other two parts of the Encyclopaedia. ${ }^{138}$ And so Haym's criticism loses its force and becomes a simple statement of fact: "So muss die Logik die ganze Philosophie sein, so muss mit ihr das System schliessen." 139 This last point will come up for direct discussion later in the present chapter.

But it will be objected that on this score we are forced to deny the necessity of the transition from the Logic as Hegel has attempted it. And I have purposely courted the objection in order to emphasize my agreement with it. If what has been said above is true - and its validity is attested to by our entire discussion of Hegel's doctrine of the nature of thought — then we must give up the idea of a dialectical transition from 
one to another part of the Encyclopaedia. Such a transition is impossible were it necessary, but it is not necessary. Its necessity has been obviated by the result of the Phenomenology; for this work has shown that in the dialectic of the categories the object cannot be entirely absent, even though, for methodological purposes its presence be as far as possible neglected. A dialectical transition here would in fact be inconsistent with the spirit of Hegel's philosophy; it would seem to indicate that the Idea is a mere abstraction which demands a content to make it real, an abstract universal to be particularized. Hegel himself at times seems to feel this difficulty, although, so far as I am aware, he never explicitly expresses himself on the point. For example, his very frank recognition that the transition which he attempts from the Logic to the Philosophy of Nature is different from the transition of the subjective notion into objectivity, or of subjective purpose into life, one would think is not entirely without significance. ${ }^{140}$ Again elsewhere he seems to show that he fears the transition because he takes pains to warn us against misconceiving its real import. ${ }^{141}$ And in the larger Logic, at the beginning of the discussion of the Absolute Idea, there occurs a passage which is suggestive in this connection: "Since it [i.e., the Idea] contains all determination within itself, and its essence is to return to itself through its self-determination or particularity, it possesses different forms; and it is the business of philosophy to trace it in these forms" - such as nature, art, and religion. ${ }^{142}$

But whether Hegel had any such feeling as I have attributed to him or whether he did not, the fact remains that he felt called upon to make the leap from the Logic to the Philosophy of Nature. He explicitly asserts that "the last result of the Logic becomes also the beginning of another sphere and science," which science is, of course, the Philosophy of Nature. If now, as we have argued, this transition is not only not necessary, but, what is more important, is really inconsistent with the logical bias of the system, then the question why the author deemed it necessary becomes a very pressing one. As a matter of fact he does attempt the transition: what is to be said about the fact?

The answer to this question is, in my opinion, not far to seek. Hegel was very much in earnest about this transition, and he was in earnest about it for the reason that with it stands or falls his system as a system. This, it seems to me, is the secret of his anxiety concerning the matter. Like Kant, he was bound down to his system; he could not get beyond the machinery of his dialectic. The Logic, Philosophy of Nature, and 
Philosophy of Mind had to form a triad of thesis, antithesis, and synthesis, else the formal coherence and symmetry of the system would have been lost. The scheme of the system demands a continuous linear development from one phase of it to another - an absolutely necessary development. If the dialectic is the absolute and universal method, why is there not a dialectical passage from the Logic to nature? There simply must be - and there was. Such procedure is due to the fact that Hegel did not always raise the spirit of his system above the letter. The Method, the unerring and absolute method of the dialectic, had to be looked out for and its claims catered to regardless of consequences; and only too frequently was the method seen in a false light and its claims misinterpreted. If at all times Hegel could have identified his method with his doctrine of begreifendes Denken, the relation of the various parts of the Encyclopaedia to each other would have been differently conceived and the position of the Logic in the system would have been more clearly and intelligibly set forth.

Some commentators seem disposed to justify this leap from the Logic. Noel, for example, goes so far as to maintain that there is a connection between the Logic and what follows in the system analogous to the connection among the several sections of the Logic. ${ }^{143}$ "There must be," he says, "a dialectical passage from the Logic to Nature. The logical Idea must negate itself and pass into its contrary." But there seems to be no very good reason why the logical Idea should, just at this point, negate itself and pass into Nature. Indeed, Noel's position seems to overlook Hegel's own explicit statement, quoted above, to the effect that the transition here in question is different from that which obtains among the categories of the Logic. In this respect Mr. McTaggart is, perhaps, truer to Hegel. It is true that he asserts, "Granted pure thought, we are compelled by the necessity of the dialectic to grant the existence of some sensuous intuition also." But he recognizes Hegel's statement that the transition to the Philosophy of Nature has its own peculiar characteristics. ${ }^{144}$ The fundamentals of Mr. McTaggart's position seem to be: that the transition is both analytic and synthetic; that it really represents the phases of thesis, antithesis, and synthesis; and that Spirit, as the truth and goal of the movement, is present even from the beginning. In so far as this position insists that in the Idea both Nature and Spirit are involved, one is not inclined to call it in question. But does this insistence make the transition from the Absolute Idea to Nature dialectically necessary? Merely by observing the Idea as the highest of the logical cat- 
egories, are we forced to posit nature as its counterpart? If so, are we thereby made aware of the implicit appearance of Spirit, even before it looms on the horizon? Even if we grant, with Noel, that logic contains in germ philosophy in its entirety, and with Mr. McTaggart that, if there were a transition at the end of the Logic, it would necessarily be both analytic and synthetic, still the essential point here has not been touched. Is the transition a dialectical necessity? If so, why is it so? I confess myself unable to see any dialectical advance from the end of the Logic to the beginning of the Philosophy of Nature, or even from the Idea to a matter of sensuous intuition. Is it any less reasonable to say that the first category of the Logic should alienate itself in its other than that the last category should do so? Is not the category of Being as likely to go forth into its opposite as is the Absolute Idea? Certainly so, if as Mr. McTaggart seems to suggest, the fact that the Absolute Idea is 'pure thought' is the impetus of the movement; for Being is just as much 'pure thought' as is the Absolute Idea. In fact, it would seem to be more reasonable to return to the beginning of the Logic and take the sensuous 'alienation' of Being as the point of departure for the Naturphilosophie: at any rate, in this event we should have the privilege of proceeding on lines analogous to those followed in the development of the Logic, namely, from the less to the more determinate. But whether we put ourselves at the first category or at the 'last result' of the Logic, hoping thereby to discover a beginning for our new 'sphere and science,' we find ourselves baffled. In no event do we find that mysterious secret power that would drive us on to Nature. And we fail for the somewhat obvious reason that we are already at Nature and do not need to be driven to it. This so-called transition can be defended only on the basis of the Phenomenology: there it has received the only justification which it needs and of which it is capable. But - and this is the important point - the conclusion of the Phenomenology destroys at once the necessity and the possibility of such a transition; and from this point of view the dialectical passage becomes nothing more than a misguided zeal for schematization. One must feel that neither Noel nor Mr. McTaggart has succeeded in making the leap plausible: if they had succeeded, one is inclined to say that the real significance of the Hegelian Logic would have been greatly diminished, if not completely destroyed.

It might be argued in support of this transition from the Logic that Hegel is simply recognizing here, explicitly, the presupposition that has been implicit in the entire development of the categories. For what is a 
dialectical transition? Does it not consist simply in making explicit a presupposition? And do we not at the end of the Logic recognize what has been a presupposition all through, namely, the spiritual union of thought and its object? Thus the circle is completed, the end is one with the beginning. And with this the necessity of a more concrete treatment is apparent - a treatment that shall take into full account the presupposition thus disclosed. And so we are brought at once into the realm of Nature and of Spirit.

This, it must be confessed, is all that Hegel could consistently have meant by the transition in question. It could signify nothing more than a change in point of view, if the lesson of the Phenomenology is to hold here. One is inclined to think that this is really the essence of the transition. But the question inevitably arises why the presupposition is peculiarly forced upon us in the Absolute Idea. Is not the recognition of the presupposition as explicit in the first categories of the Logic as it is in the last? Does not Hegel make constant appeal to it throughout the whole dialectical advance? Why, then, should the presupposition be forced to the fore in the Absolute Idea as it is not in any of the other categories? It might be answered, Because at the Absolute Idea we have a definition of reality itself. Even so, how was this definition arrived at apart from the phenomena of Nature and Spirit? The fact is that it was not; for the result of the Phenomenology is recognized at every stage of the dialectical development of the categories, and this necessitates the inclusion by the Idea of these phenomena of Nature and Spirit. So far as I can see, the objective aspect of existence is no more clearly and necessarily evident in any one of the categories than it is in all; we are not forced to take account of it in the Idea in a manner different from that in which it forces itself upon us in the categories of Being and Essence. If, when Hegel reached the end of the Logic, he had contented himself with asserting what the above argument would have him assert, namely, that the time had come for us to turn to a detailed consideration of those phenomena that had not been explicitly taken into account by the Logic, if he had simply told us that at the Idea the Logic reached its conclusion and that he here proposed to change his point of view, we could have understood him: the necessity of the change and the partially abstract nature of the Logic, had already been sufficiently explained to us in the Phenomenology. But when he goes on to urge that the Absolute Idea must, by a dialectical necessity, alienate itself in its Other, we begin to wonder where the categories of Being came from and how we ever suc- 
ceeded in getting from this abstract view of the world to the standpoint of the Idea. We had thought all along that in the Idea we were at last in touch with reality; but when this mysterious alienation begins to take place, the earth trembles under us and we wonder if we have been deceived. At this juncture the Phenomenology comes to our relief, when we remember that its conclusion has made the transition both unnecessary and impossible. The argument before us does indeed state what Hegel must have meant, if he remained true to the principles of his doctrine; but it hardly explains what he seems actually to have attempted.

It would seem, then, that this would-be transition from the Logic must be given up. And, furthermore, we must agree with Professor Pringle-Pattison that to admit so much involves a surrender of Hegel's system as he left it. He is systematic to a fault. Within the Logic itself the author's mania for system often clouds, if it does not completely hide, the issue; the omnipotent Dialectic Method, rather than the organic development of thought, is only too frequently the object of interest. And, unfortunately, even the data of nature and history are sometimes forced into this formal scheme whether they will or no. What under other circumstances might have been a very simple change in point of view is, as we have just seen, made incomprehensible and misleading by the same absurd reverence for the triadic movement of the 'absolute method.' No doubt one may easily be too severely critical of this aspect of Hegel's philosophy, both because it is so exasperating and because it is calculated to conceal the real import of the system. Our zeal to remove these barriers to a true appreciation of the system, and to gain an unprejudiced hearing for the author, might blind us to the fact that these impedimenta find their partial explanation at least in the circumstances under which Hegel wrote. Historically speaking this transition from the Logic may claim for itself some sort of justification. Perhaps it was important for Hegel's influence that he set forth his system intact; and to do this seemed to necessitate this transition. For if the dialectic had with unerring precision led from the poor and abstract category of Being up to the fullness of the Absolute Idea, and that, too, apart from a direct consideration of Nature and of Spirit, then it was incumbent upon the dialectic to lead in some way to a consideration of these important aspects of experience; and how could this be more happily accomplished than by the assertion of at least a quasi-dialectical connection between the Idea and these its manifestations? This ground of justification for Hegel's procedure here should not be overlooked, 
and, of course, should be given the weight that is due it. But, after all, though we may be inclined to excuse Hegel for his formality, we have no special reason for being grateful to hi him for it; his system will be appreciated fully only when we throw aside this formality and penetrate to the fundamentals of the system. And the fundamentals of the system can best be disclosed when the fruitlessness and inconsistency of this attempted transition from the Logic are revealed.

So with no great degree of reluctance we surrender the formal arrangement of Hegel's system. But we can ill afford to miss its spirit and the results that follow from it. One of the most marked of these results is the position that epistemology is in a sense ontology, that logic and metaphysics cannot be separated from each other. This brings us back to our original question, the intervening discussion having been necessary to clear the way for an answer. So we ask once again concerning the real meaning and justification of this Hegelian position, that a theory of knowledge cannot be separated from a theory of reality. In accordance with our plan of discussion, we shall attempt to answer this question by examining a criticism to which the contention has been subjected.

The criticism which we shall here examine is to be found in the fourth lecture of Professor Pringle-Pattison's Hegelianism and Personality. The criticism, we seem compelled to say, is based upon a misapprehension of Hegel's real meaning and actual procedure. ${ }^{145}$ The remaining part of this chapter will first attempt to justify this assertion, and then conclude with a statement of what Hegel, in consistency with his own principles, must have meant by the identification in question.

The criticism is based upon the attempted transition from the Logic to the Philosophy of Nature, one phase of which we have already considered. Put in a few words, the criticism seems to be that in this transition Hegel deliberately attempted to deduce nature from the logical Idea, and that, by a copious use of metaphors, he deluded himself into thinking that he had successfully bridged the gulf which separates formal thought from actual existence. To quote: "The concrete existence of the categories (in Nature and Spirit) is to be deduced from their essence or thought-nature; it is to be shown that they cannot not be. When we have mounted to the Absolute Idea, it is contended, we cannot help going further. The nisus of thought itself projects thought out of the sphere of thought altogether into that of actual existence. In fact, strive against the idea as we may, it seems indubitable that there is here once more repeated in Hegel the extraordinary but apparently fascinating attempt 
to construct the world out of abstract thought or mere universals. The whole form and structure of the system, and the express declarations of its author at points of critical importance, combine to force this conviction upon us. The language used can only be interpreted to mean that thought out of its own abstract nature gives birth to the reality of things." 146 All of which amounts to saying that Hegel has taken abstract thought, ontologized it, and then has turned about and attempted to deduce concrete reality from this hypostatized abstraction

It must be admitted at once that such an accusation is not prima facie without some justification. If we turn once more to the passages above quoted bearing on the transition from the Logic, our first inclination is to accept Professor Pringle-Pattison's interpretation of them. Other passages, especially those referring to the absoluteness and finality of the system, seem to bear out the same contention. And when in the Encyclopaedia we run across passages which baldly assert that everything is a judgment or a syllogism, we wonder whether Plato's conception of archetypal Ideas is more removed from concrete experience. And yet such an attempt to deduce nature from abstract thought would be a rather remarkable undertaking on Hegel's part: it would be inconsistent with the entire spirit of his philosophy, the fundamental assumption of which is, as Haldane suggests, ${ }^{147}$ that you cannot deduce the 'that.' Is it possible to interpret these passages so as to make Hegel consistent with the fundaments of his system? If so, it would seem that such an interpretation should certainly be adopted.

I think it is possible to make Hegel consistent in this regard, and this I have tried to do in the preceding pages of this chapter. I fully agree with Professor Pringle-Pattison that the attempted transition from one to another part of Encyclopedia must be given up; and I also agree that with this transition we surrender the system as a system. But I cannot agree with the reasons which the critic advances in support of his conclusions. It was just because his system depended upon it that Hegel made the resolute leap, and not for the purpose of getting from abstract thought to concrete existence. The 'ugly broad ditch' between thought and reality seems to me only a shadow; and, unless indeed we are to credit Hegel with momentary forgetfulness of the foundation of his system, I cannot think that it was more to him. Now it would seem that this interpretation, namely, that the transition from the Logic was attempted for purely schematic purposes, has the advantage over such an interpretation as Professor Pringle-Pattison's, which makes of the transition an 
attempt to deduce existential reality from abstract universals; and the advantage of the former interpretation lies in the fact that it does make Hegel consistent with the basic principles of his theory. We may venture to put the matter in the form of a disjunction. Either Hegel tried to deduce nature from the logical categories or he did not. If he did attempt it, then he contradicts himself; for such an attempt would presuppose that the logical categories are merely abstract thoughts existing in the heads of individuals and possessing no vital significance in relation to the essence of concrete objects. But this is the very conception of thought which we have seen Hegel object to in the systems of his predecessors and in contradistinction to which he emphasizes his own doctrine. And that doctrine is that thought has transcended the opposition between itself and its and is really the expression of the essence of the object. "Pure science presupposes liberation from the opposition of consciousness. It contains thought in so far as it is just as much the object in itself, or the object in itself in so far as it is just as much pure thought." 148

But, on the other hand, if Hegel did not attempt to deduce nature from thought, it would seem that his statements about a transition from the Logic must be explained away. Now the latter horn of this dilemma is comparatively easily disposed of, as has already been pointed out in the preceding part of the present chapter; the so-called transition is only a change in point of view, the author's insistence upon the necessity of the transition being made for the sake of his system. But if we follow Professor Pringle-Pattison in accepting the former, the most significant aspect of Hegel's philosophy will, to say the least, become questionable and he himself will stand accused of the most glaring of inconsistencies. There seems to be no doubt, then, of the conclusion to be reached here.

But leaving aside speculation as to what may or may not have been the immediate purpose of Hegel in this transition, let us try to see what is logically involved in it. Whether or not Hegel has here made a deliberate attempt to deduce nature from thought, such an attempt is certainly not logically imposed upon him.

This contention is based upon what has already been said about the presupposition of the Encyclopedia. In the Encyclopedia we are dealing with one whole, namely, reality: the three parts of the Encyclopedia represent different points of view from which this totality is observed. This conclusion follows necessarily, if our view concerning the significance of the Phenomenology in the system be correct. For the very outcome of the Phenomenology, we remember, has been the disclosure 
of the impossibility of dividing reality into water-tight compartments which are so separated from each other that each may be dealt with entirely independently of the others. Reality, this discussion has taught us, is rather one indissoluble whole whose parts can be separated from each other only by abstraction. The Encyclopedia, therefore, presupposing as it unquestionably does the result of the Phenomenology, must have for its object the one reality, and its several parts must be simply different points of view from which this unitary reality is observed and investigated. Now as a corollary of this, it follows that the transition from the Logic is as Kuno Fischer suggests, ${ }^{149}$ logically nothing more than a change in point of view. If the Encyclopedia presents reality to us from three different standpoints each of which involves the others, and let us not forget that this is the lesson of the Phenomenology — then a transition within the Encyclopedia cannot be anything but a change in point of view. So all that Hegel really was called upon to do in order to get from the Logic to the Philosophy of Nature was simply to announce that he intended to investigate his problems from a new viewpoint: the transition, if one will call it so, had already been made in the Phenomenology of Spirit as we have abundantly seen.

Now it would seem that the accusation that Hegel seriously tried to deduce existence from thought when he made the transition from the Logic to the Philosophy of Nature fails to give the above considerations the weight that is due them. Unless one drops them out of mind entirely, it is difficult, not to say impossible, to catch the significance of the following as a criticism of Hegel: "Most assuredly the Notion contains the category of Being; so does the Ego, that is to say, the idea of the ego, and the Idea of God, both of which are simply the Notion under another name....

But when we ask for real bread, why put us off with a logical stone like this? It is not the category 'Being,' of which we are in quest, but that reality of which all categories are only descriptions, and which itself can only be experienced, immediately known or lived. To such reality or factual existence there is no logical bridge; and thoughts or categories have meaning only if we assume, as somehow given, a real world to which they refer." 150 Surely such a criticism could have been written only in forgetfulness of what Hegel has said about the presupposition of the Logic and the mediated aspect of the category of Being. Being is, indeed, a logical category; but it is more than a mere abstract category, a blank universal, that has only a psychological existence in 
the consciousness of the thinker who happens to possess it. It is a concrete thought that expresses one very general, but withal very essential, characteristic of that which really is. In Hegel's usage, Being, or any other category of thought, is not a mere idea or concept; on the contrary, it is a universal which ipso facto includes within its very nature the particularity of existence. ${ }^{151}$

And this brings us face to face with what seems to be the fundamental error in Professor Pringle-Pattison's charge. I refer to his neglect of the meaning which Hegel attaches to the Notion. This is the bed-rock upon which Hegel bases his contention that logic and ontology are essentially one. It is only the Notion that "sinks itself in the facts"; it is only the Notion that is "accredited able to express the essential reality of things"; and only the Notion is the subject-matter of the science of logic. The Notion, thus, is the tie that binds epistemology and metaphysics together. For if thought comprehends reality and is capable of expressing it, if there is no 'residuum' which lies outside of thought and which in its nature is inexpressible in terms of thought, then the science of thought is in a very important sense the science of things. Now just this conclusion the critic objects to; and his objection seems to rest upon a misinterpretation of the premise.

Let us notice some of Professor Pringle-Pattison's statements. After quoting several passages from Hegel to the effect that Nature is the logical Idea in its otherness, is the Spirit in alienation from itself, and so forth, he continues: "Now I maintain that the whole problem of reality as such is wrapped up in these metaphorical phrases - otherness, petrifaction, materiature, concretion - and that by evading the question, Hegel virtually declines to take account of anything but logical abstractions. He offers us, in a word, a logic in place of a metaphysic; and it may be unhesitatingly asserted that such a proposal, if taken literally, is not only untenable, it is absurd." Nothing, we are further informed, is in very truth a logical category. "A living dog is better than a dead lion, and even an atom is more than a category. It at least exists as a reality, whereas a category is an abstract ghost, which may have a meaning for intelligent beings, but which, divorced from such real beings and their experience, is the very type of a non-ens." A little later he says: "Existence is one thing, knowledge is another. But the logical bias of the Hegelian philosophy tends to make this essential di tinction disappear, and to reduce things to mere types or 'concretions' of abstract formulae." "The result of Hegel's procedure would really be to sweep 'exis- 
tential reality' off the board altogether, under the persuasion, apparently, that a full statement of all the thought-relations that constitute our knowledge of the thing is equivalent to the existent thing itself. On the contrary, it may be confidently asserted that there is no more identity of Knowing and Being with an infinity of such relations than there was with one." 152

If I understand the import of these passages - and their meaning seems unmistakable - there is involved in them an assumption which I dare think is unwarranted. The assumption is that Hegel has actually attempted to reduce sensuous experience to the universals of formal thought, and has tried to make such universals really be the existent things. If it be true that Hegel has attempted this, then it should be admitted without argument that he has attempted that which is both impossible and absurd. It may, perhaps, be rather difficult to say just in what respect an atom is more than a category, just what other reality it possesses besides its meaning for intelligent beings; but there can not be any question that a living dog is better than a dead lion — an object is indisputably more than a mere meeting-point of abstract relations. But does Hegel deny this? Is it quite fair to him to assert that the logical bias of his philosophy is "to reduce things to mere types or 'concretions' of abstract formulae"? Does he really try to force the particularity of existence into the abstract universality of bare cognition? I have already maintained that such an assumption is groundless and even contrary to the real spirit of Hegel's system; and the preceding chapters attempt to set forth the reasons upon which such a contention rests. If I have there failed to accomplish this, it would hardly be worth while for me to undertake it here. Suffice it to reiterate that, when Hegel insists that knowledge or thought and reality are conterminous, he is simply upholding the theory that experience and reality are one: he means by thought, the Notion, not abstract and formal cognition, but organized experience. If such a criticism as the one with which we are here dealing is to be established, it must first be shown that Hegel does not hold such a doctrine of the nature of thought as has here been attributed to him; and this must be shown regardless of innumerable utterances to the contrary, and in spite of the pages of the Phenomenology of Spirit.

In the last analysis, one seems safe in saying, the real difference between Hegel and his critic turns upon the question whether thought is an adequate expression of the real. Both have the same conception of reality, namely, that it consists in the individual; and both agree as to the 
true definition of the individual, namely, that it is identity in difference. ${ }^{153}$ But in answer to the question whether thought is capable of expressing the individual, author and critic part company. The former, as we have seen, answers in the affirmative; while the latter, though he shows a puzzling inconsistency, finally gives a negative answer. ${ }^{154}$ So we face the question, Is thought adequate to express the real as thus defined? Or is it the very nature of the individual to transcend thought?

In order to answer this question we must first come to some understanding concerning the real nature of thought. And two conceptions of its essential nature are possible. One doctrine of thought is that which Mr. McTaggart attributes to Hegel and which has been defined by Lotze thus: "Thought is everywhere but a mediating activity moving hither and thither, bringing into connection the original intuitions of external and internal perception, which are predetermined by fundamental ideas and laws the origin of which cannot be shown; it develops special and properly logical forms, peculiar to itself, only in the effort to apply the idea of truth (which it finds in us) to the scattered multiplicity of perceptions, and of the consequences developed from them." 155 According to this conception of thought, thought is a mediating activity among other mental processes which bear to it an external relation. The other possible conception of thought is that which has been attributed to Hegel in the present study, the nature of which Hegel expresses thus: "If we identify the Idea with thought, thought must not be taken in the sense of a method or form, but in the sense of the self-developing totality of its laws and peculiar terms. These laws are the work of thought itself, and not a fact which it finds and must submit to." 156 Or thus: "In all human perception thought is present; so too thought is the universal in all the acts of conception and recollection; in short, in every mental activity, in willing, wishing, and the like. All these faculties are only further specializations of thought. When it is presented in this light, thought has a different part to play from what it has if we speak of a faculty of thought, one among a crowd of other faculties, such as perception, conception, and will, with which it stands on the same level." ${ }^{157}$

Now whichever of these doctrines of thought we accept as true to the facts of experience, our answer to the above question is fixed. If, on the one hand, Lotze's account be the true description of actual concrete thought, then it is certain beyond any dispute that Being can not be "resolved into it without leaving any residuum." Thought which is merely a process of mediation among brute facts of experience cannot possibly 
be more than a formal method of dealing with data given independently of it; and these data would certainly have to be accounted a part of Being. Such thought might prove a valuable instrument for dealing with reality - though I am not sure that I can see why it should, or, indeed, how it could, do so - but it could at most only compare and relate phenomena: reality would be, and would forever remain, beyond it. But, if, on the other hand, Hegel's account of thought is the true one, then it would seem that we might as dogmatically assert that thought does comprehend and exhaust the real. Either this, or we commit ourselves to the doctrine of the thing-in-itself which Kant has taught us, by his failure to make it comprehensible, to fear. For if thought is conterminous only with experience, then it is also conterminous with the real; otherwise, of course, reality would be trans-experiential. Just how, in Hegel's opinion, such thought is capable of expressing the individuality of reality, I have tried to indicate in the preceding chapter on the process of thought: his doctrine is that thought is adequate to express the individual, because its categories are just such self-particularizing universals - universals obtained, not by abstraction from the particulars, but by the interpretation of them.

It seems to me that, in the above criticism of Hegel, Professor PringlePattison confuses these two doctrines of thought, or rather, that he overlooks Hegel's own doctrine and tacitly attributes to him that of Lotze, and so criticizes him for that of which he is not guilty. For if we take Hegel's more concrete doctrine of the nature of thought into account, the criticism misses the mark. Perhaps I have dwelt long enough on this point; but it is a very vital one in connection with Hegel's system. I submit that it is only this confusion which gives Professor PringlePattison's criticism significance, and that the criticism falls of its own accord when the confusion is cleared away.

Just here emerges a consideration which we may pause to emphasize before we pass on to the concluding remarks of this chapter. And that consideration is that the point at which to attack Hegel's identification of logic and metaphysicsis his doctrine concerning the nature of that thought which is the subject-matter of the science of logic. With the validity of this doctrine stands or falls his contention that epistemology and ontology are essentially one. For if the categories express the nature of ultimate reality, then the science of the categories, namely, logic, is the science of the real. And in order to prove that Hegel has no right to claim that thought expresses fully the real, one must show that his doc- 
trine of thought is false. And this, it would seem, would involve a careful investigation of experience, since Hegel claims to have rooted his doctrine in experience through the procedure of the Phenomenology. So far as I am aware, such an enterprise has been undertaken by none of Hegel's critics. ${ }^{158}$

The answer to the question as to what Hegel really did mean by his assertion that logic and metaphysics are fundamentally one is involved in what has already been said. It remains only to set it forth and to emphasize it. In the first place, it seems that we are forced to say that Hegel does not mean to reduce thought and being to an abstract identity. We have already insisted upon this point, but it will be well to emphasize it again since it is so generally taken for granted that the contrary is true. Critics generally seem to think that, when Hegel asserts that thought exhausts reality, he is asserting that thought about an object actually is the object itself and that experience is no richer than the poverty of abstract cognition. Identity of thought and being means for them undifferentiated identity; upon their interpretation the particular loses itself in the universal, becomes vaporized, as it were, into a mere meetingpoint of abstract relations. But such abstract identity between thought and its object Hegel simply could not teach and at the same time remain true to his system: it is in direct contradiction of his fundamental presuppositions, indeed it contradicts the very thesis he was trying to establish. ${ }^{159} \mathrm{He}$ began by assuming a duality within and basic to experience, namely, the subject-object relation; and certainly he did not wish to destroy the very foundation on which he was building. He never denied the existence of the concrete object, nor did he make any attempt to reduce the object to blank universality. He did indeed reduce the object to terms of the subject; he urged that ultimate reality must be construed as Subject and not as Substance. But he did not destroy the duality within experience. The object was never annihilated as an object, only explained; its alienation disappeared, but its self-identity was never lost. This idea that Hegel tried to reduce factual existence to abstract relations should be dismissed from our minds once for all, unless we prefer to believe that he forgot or set about to contradict the very doctrine which he was endeavoring to establish. Whatever one may see in the leap from the Logic to the Philosophy of Nature, one must grant that Hegel could not have seriously entertained the idea that abstract cognition and existential reality are identical; the inconsistency involved is too patent. ${ }^{160}$

In the second place, what Hegel really does mean by his position 
that logic and metaphysic coincide seems to be this, namely, the assertion of the complete intelligibility or mediated character of reality. Instead of being merely subjective ideas, the categories of the Logic are principles of ultimate reality; and ultimate reality is simply what these principles show it to be. It is only by these instruments that experience gets its organization; and organized experience and reality coincide. The science of the categories is, thus, the science of the real; but being is not deduced, it is only thoroughly rationalized and explained. Of course, we must remember that these categories are not merely conceptions of the Understanding, as Hegel calls it, or of what we call cognition: the categories of feeling and will are just as important as the categories of cognition. And we must also remember that the categories of the Reason are not merely universals bearing an external and mechanical relation to the particulars; they are universals which exist only in and through the particulars subsumed under them, and in which the particulars find their only reality. ${ }^{161}$ Such an identification of logic and ontology, Hegel maintains, is logically involved in the system of Kant: the reason why Kant failed to realize the fact was that he gave his categories an 'essentially subjective significance. ${ }^{\text {162 }}$ That is to say, had Kant only realized that the realm of possible experience is the real and only real, then the categories, which he recognized as principles of the deepest import in experience, would have been regarded as principles of reality, would have attained to truly objective significance; and so the science of these principles would have become the science of the real, the Critique of Pure Reason would have been a metaphysic as well as a treatise on epistemology. Now Hegel argues that thought must be genuinely objective, else we have on our hands a dualism which cannot be transcended. And thought being really objective, logic is inevitably metaphysic.

This leads us in conclusion to remark, in anticipation of a discussion that will follow in the next chapter, that doubtless Hegel would hardly find free from difficulties the epistemology of those who are inclined to criticize him for making logic and metaphysics coincident. He might ask concerning the logical consequences of their position; and more than likely he would intimate that the inevitable answer is the Ding-an-sich of the Kantian philosophy. For what reality is it that lies beyond thought, but a reality that is unknowable in terms of thought? And how can that reality which is unknowable in terms of thought be known at all? And what significance can be attached to an unknowable reality? Is it logically possible to separate knowledge and reality? Hegel 
would urge that knowledge, which is incapable of expressing the nature of the ultimately real, is impotent. "Only in so far as reflection has reference to the Absolute is it Reason, and its activity that of real knowledge." 163 He would furthermore insist that what exists apart from knowledge is an abstraction. "The object as it is without thought and the Notion is a mere idea, a name: the forms of thought and the Notion make of it what it is." 164 To such strictures it would seem that the critics could reply only by admitting that the real does somehow fall within the system of knowledge; for, ultimately, there can be no bits or nuclei of reality that remain opaque to thought. As Professor Bosanquet has remarked: "If the object-matter of reality lay genuinely outside the system of thought, not only our analysis, but thought itself, would be unable to lay hold of reality." 165 And such an empty conception of thought and such a hopeless conception of reality would combine to land us in a rather barren and forlorn subjectivism.

The conclusions of our discussion are as follows. Hegel does argue that logic and metaphysic coincide. But the coincidence is not an abstract identity. Against such a conclusion the lesson of the Phenomenology warns us. The coincidence between the two consists in the fact that the thought, which is the subject matter of logic, is the principle of organization of reality itself; logic, thus, is necessarily a science of reality. The attempted transition from the Logic to the other parts of the Encyclopaedia must be explained as the result of Hegel's anxiety to keep his system intact. It cannot be construed as an attempt on Hegel's part to deduce factual existence from one aspect of conscious experience; for such an attempt would have contradicted the doctrine which Hegel most persistently presupposes, the doctrine, namely, that thought is concrete, not abstract. 


\section{Part II. Chapter IV. Reality as Individual.}

In the preceding chapters of this study we have been concerned exclusively with Hegel's doctrine of the nature of thought. We have learned that, according to his doctrine, thought is co-extensive with experience and consequently with reality itself: it has no datum opposed to and independent of it. ${ }^{166}$ Thus an investigation of the nature of thought was necessary before we could arrive at a just appreciation of Hegel's teaching concerning the nature of the ultimately real. Having now completed this investigation and having learned what Hegel has to say concerning the thought-process, we turn to the other aspect of our general problem and inquire about the details of Hegel's doctrine of reality.

As we have already seen, Hegel insists that reality is the result of a process of mediation; it is not a first principle, but a last result. This is a contention upon which Hegel is constantly insisting. "If knowledge is to grasp the truth," he tells us, "it must not remain at the standpoint of the immediately given and its determinations. On the contrary, it must penetrate this immediate being, assuming that behind it there is something other than itself, which hidden somewhat constitutes its truth." 167 "Every immediate unity is only abstract potential truth, not real truth." 168 "Concerning the Absolute, it is to be said that it is first as a result what it is in truth." 169 The real is not to be found in sense-perception: it is only the result of the process of thought. ${ }^{170}$ This emphasis of the mediated aspect of reality is one of the fundamental doctrines of the Hegelian philosophy, and the author never tires of reminding us of it. ${ }^{171}$ The ultimately real is not shot out of a pistol at us; truth is not given, as it were, 
a coin from the mint. On the contrary, the real must be defined, and its definition comes only with developing experience and the growth of knowledge. It is only the labors of thought that can lead us to the land of reality.

This being true, it follows at once that the form of universality is, as Hegel views the matter, an essential aspect of the real. For, on this hypothesis, reality lies exclusively within the domain of thought; and thinking ipso facto necessitates the form of universality. ${ }^{172}$ This implication of his system Hegel does not overlook. In the Naturphilosophie, for example, he urges that the universal aspect of objects is not to be considered as something foreign to them, a form which belongs to them only when they happen to be thought about; rather, the universal is absolutely essential to their reality, it is the noumenon, as it were, behind the transitory and fleeting phenomenon. ${ }^{173}$

Reason, he tells us elsewhere, "is the certitude that its determinations are just as much objective, e.g., determinations of the essence of things, as they are subjective thoughts." ${ }^{174}$ Again, in opposition to the atomistic view of Locke and the empiricists to the effect that the universal does not in reality belong to objects, Hegel asserts: "To say ... that the universal is not the essential reality of nature . . is tantamount to saying that we do not know real existence." 175 And an unknowable reality is, for Hegel, a contradiction in terms. Reality, then, does assume the form of universality; this is essential to its very being.

From this we may pass at once to the conclusion that the real, as Hegel conceives of it, cannot be the abstract particular. After what has just been said it is hardly necessary to argue this point further. Hegel would unhesitatingly assert that the particular, qua particular, is never found in experience at all. This is exactly what his doctrines of the inseparability of immediacy and mediation amounts to. The immediacy of reality is a mediated immediacy; and since the mediating process is that of thought which can advance only by means of universals, the immediacy of the real must transcend bare particularity. In a word, we may put the matter so: if knowledge is coextensive with experience, then the possibility that a mere particular may appear within experience is eliminated; whatever appears in knowledge must be more than a mere particular, for the universals of thought can lay hold only of that which somehow itself is universal. The abstract particular plays no part in reality. Against the idea that particularity is a form adequate to the real Hegel has some cogent objections to urge. And perhaps it would not be 
too much to say that those objections are rather obvious. In the first place, the particular seems to be absolutely nothing so far as experience is concerned. In order that it may be a part of experience it must, as Kant has shown us in his famous Transcendental Deduction of the categories, become universalized, must lose its abstract particularity. For the particular which is to be experienced must remain identical with itself through a period of time; and self-identity is universality. So the abstract particular has no part to play in experience, is impossible, indeed, within experience. But, in the second place, if we should grant the possibility of the abstract particular within experience, we should find ourselves in the midst of some puzzling problems. And not the least confusing is the question, What is an unrelated particular? Absolutely nothing can be said about it, because anything can be defined only in terms of its relations and a particular has no relations. Indeed, an abstract particular is simply an indefinable absolute. Hegel puts the difficulty thus: "The form of immediacy invests the particular with the character of independent or self-centered being. But such predicates contradict the very essence of the particular, - which is to be referred to something else outside. They thus invest the finite with the character of an absolute." ${ }^{176}$ And of course it is not easy to see how experience could possibly be composed of a number of unrelated absolutes. But it seems useless to stress this point further. It is plain, as Professor Pringle-Pattison has urged, that the mere particular finds a place to exist nowhere outside a logic which is not wholly clear about its own procedure. ${ }^{177}$

But, granting that Hegel is not guilty of hypostatizing the abstract particular, what are we to say about his assertions concerning the universal? Are we so sure that he does not go to the other extreme and urge that experience consists in blank universality? Have we not seen that he maintains that to think the world is to cast it in the form of the universal, and is it not true that he reduces experience to terms of thought? Is he not always insisting that the universal, the Notion, is the very quintessence of the object?

It is true, as we have all along seen, that Hegel has been generally accused of reducing the real to the form of abstract universality. This is the view of Haym, of Trendelenburg, of Lotze, indeed of all the critics of the Hegelian philosophy in general Even the sympathetic critics of the system are all practically agreed in making the same assumption. It is the very nerve of Professor Pringle-Pattison's criticism, which we reviewed in some detail in the preceding chapter; and it is the nerve also 
of the criticisms of Professor Baillie and Mr. McTaggart, which we shall presently consider. Is Hegel really guilty of this accusation that has been brought against him by so many students of his philosophy, or is he not? If he is, then there can be no question that his system is as far from concrete experience as any system well can be. If he is not, then with the assumption fall the criticisms based upon it.

Our answer to the question is already determined, and our reasons for it already set forth. The answer must be an unequivocal and emphatic negative, its justification being found in the entire first part of this study. There it was the aim to let Hegel speak for himself; and if we are to believe what he has said, then we are forced to admit at least that it was not his intention to champion the position that reality is simply an aggregate of blank universals, a 'ballet of bloodless categories.' He does grant that thought is conterminous with experience, and, consequently, with reality itself; the real for him exists only in the form of the Notion. About this there need be no dispute. Again, he as frankly admits that this position forces him to assume the further position that reality can be found only in universality; for "thinking means the bringing of something into the form of universality." 178 Upon this all may agree. But the all-important point here, the point upon which there is difference of opinion, is the determination of Hegel's doctrine of universality. This is really the bone of contention. What does Hegel mean by the form of universality which reality assumes? Does he mean by the universal of the Notion merely formal universality? If we dare maintain our position against the cloud of witnesses on the other side, we must hold that by his doctrine of the universality of the Notion Hegel means, not abstract generality, but concrete universality. This was the central thesis of our discussion of Hegel's doctrine of the nature of thought, which we saw Hegel define, not as mere cognition, but as the very life of mind itself. In this Hegelian thought are included all the categories of the mind, from the barest, most empty sensation which only points dimly to the factual existence of an objective world, to the fullest, most concrete expression of the essential constitution of the world. As Hegel conceives the matter, experience is not reduced to the bare universals of cognition: cognition is only one aspect of the mental life, which includes within itself the categories of feeling and volition as well. To accuse him of reducing reality to blank universality, therefore, is to misapprehend what he means by the form of the Notion. ${ }^{179}$

Both Professor Baillie and Mr. McTaggart give their opinion against 
the conclusion here advanced. These two professedly close and sympathetic students of Hegel maintain that he conceives reality to be nothing more than a process of discursive knowledge, that he reduces experience to blank universality. An examination in some detail of the grounds upon which these critics base their opinions will perhaps serve to clear up the problem before us.

The Phenomenology of Spirit forms the point of departure for Professor Baillie's criticism. According to the critic, Hegel arrives at his fundamental position in the following manner: "All experience involves the relation of subject to object, and all Experience is fundamentally the life of mind; it finds its meaning and explanation in self-consciousness. Now in the Phenomenology it was further shown that self-consciousness finds its most perfect expression in Absolute Science. In other words, that while all Experience is the realization of self-consciousness, Science is its truest form: it is 'the crown of the life of mind.' Therefore . . . the immediacy of Experience is the immediacy of Science; the mediation constituting and constructing Experience is the mediation of Science. What is immediate to life in indissoluble union with environment (in the widest sense of the term) is the same as what is 'given' or 'immediate' in Knowledge. In other words, Reality in its essence is a process of Knowledge." In the paragraph immediately following this statement of Hegel's supposed procedure, the critic continues: "Now it is safe to say that such an identification is absolutely groundless. To assert that the whole teeming life of the world, with its boundless activity, its inexhaustible wealth of content, is for knowledge literally 'giver' in its entirety, and only exists as so 'given' — this is surely the mere perversion of Experience in the interests of a speculative preconception." ${ }^{180}$ Later he gives the following as the gist of his objection: "The process of science must not for a moment be taken to be equivalent to the fullness of the life of Experience itself." 181

The central part of this accusation, we notice, is that Hegel identifies the immediacy of experience, that immediacy which is the real, with the immediacy of science. He is made to maintain that the richness of reality, "the whole teeming life of the world, with its boundless activity its inexhaustible wealth of content," may legitimately be forced into the abstract framework of scientific formulae. The wealth of the factual world and the glory of it, he is supposed to have transformed into the poverty of general principles and universal laws. Under his hands, it is said, the flesh and blood of living reality become so attenuated that only 
the skeleton is left us; and such a skeleton, we are asked to believe Hegel would have us accept for the pulsing life of concrete experience.

Now I venture to think that Hegel cannot fairly be accused of any such absurd contention. He must have known, as well as everybody else knows, that there is more to reality than mere thoughts about it. And he did. This is quite evident from the emphasis that he places from time to time upon the factual aspect of experience. Over and over again he urges that thought is true only in so far as it sinks itself in the facts, which certainly are more than the thoughts about them. With the reader's permission I shall quote some other passages bearing on this point, in order to show that Hegel not only is not afraid of, but insists upon, the 'logic of the fact.' ${ }^{182}$ In the sixth section of the Introduction to the smaller Logic we read: "The actuality of the rational stands opposed by the popular fancy that Ideas and ideals are nothing but chimeras, and philosophy a mere system of such phantasms. It is also opposed by the very different fancy that Ideas and ideals are something far too excellent to have actuality, or something too impotent to procure it for themselves. This divorce between idea and reality is especially dear to the analytic understanding which looks upon its own abstractions, dreams though they are, as something true and real, and prides itself on the imperative 'ought,' which it takes especial pleasure in prescribing even on the field of politics.... The object of philosophy is the Idea: and the Idea is not so impotent as merely to have a right or obligation to exist without actually existing." In the twenty-fourth section we read: "If thought tries to form a notion of things, this notion (as well as its proximate phases the judgment and syllogism) cannot be composed of articles and relations which are alien and irrelevant to the things." And in the second lecture note: "When we think, we renounce our selfish and particular being, sink ourselves in the thing, allow thought to follow its own course, and, if we add anything of our own, we think ill." If these passages (and others of similar import) do not mean that thought and the science of thought have to do with factual existence, then I fail to see what they do mean. Thought always has an objective reference, they tell us, apart from which thought is nothing more than an abstraction; if the object is neglected, if the thing is left out of account. thought is useless. Indeed, if the object is neglected, thought is nothing; for it is just the expression of the essence of the object. This would seem to be Hegel's meaning in these passages, and it certainly is in harmony with the spirit of his system.

The above accusation of Professor Baillie, one seems forced to say, 
is based upon a complete misinterpretation of Hegel's actual procedure. In the preface to the Phenomenology Hegel does, indeed, identify the 'element of science' with the standpoint of absolute knowledge; and this category, as we saw in the first chapter of this study, is the truth of experience. Thus it is true, in a sense, that the 'element of science' is the truth of experience. But - this is the vital point - Hegel does not mean by science here what Professor Baillie seems to think he means by it, namely, a system of abstract and general laws. On the contrary, he means by it just that concrete point of view of the category of absolute knowledge, whose nature and whose necessity as a presupposition of all experience it was the province of the Phenomenology to work out and elaborate. Therefore, when Hegel maintains that we arrive at the truth of experience only when we enter the realm of science and that in this realm we seize reality in its essence, he certainly does not argue that reality is nothing more than scientific laws and universal principles, nor does he assume that the content of abstract science is 'equivalent to the fullness of life itself.' Such abstract principles, he would say, have their part to playin experience; but their part, though unquestionably important and extremely significant for any theory of ultimate reality, is not to assume the role of absolute and exhaustive formulae or principles. That science which is exhaustive of reality is only 'absolute science'; it is on the plane not of the Understanding, but of Reason, where all 'finite' categories are viewed in their true light and where mere generality is seen to be what it really is - a blank abstraction.

Hegel's real position or. this point may perhaps be set forth by the following considerations. The only immediacy which he would think of equating with reality is the immediacy of what he calls 'absolute science.' Now what is this immediacy? The immediacy of 'absolute science' is completely mediated immediacy, or thoroughly rationalized experience. There are various forms of immediacy, such as that of common sense, of science, of religion, of philosophy, each of which, according to Hegel, has a degree of reality attaching to it proportional to the exhaustiveness of the mediation which it involves; the immediacy of 'absolute science' is the highest of these forms of immediacy, and is absolutely concrete because it involves absolutely exhaustive mediation. Furthermore, each more exhaustively mediated form of immediacy does not simply negate the lower; it negates and affirms it, and affirms by negating. This, as we have seen, is the unique aspect of Hegel's doctrine of the negative function of thought. The various stages of im- 
mediacy, therefore, are not opposed to, and more or less independent of each other; on the contrary, each is involved in all and all in each. And from this it follows that the immediacy of 'absolute science,' which is the only completely mediated immediacy, ipso facto includes within itself all the other forms of immediacy; the truth of all finds its expression in this form of immediacy. Thus that immediacy with which Hegel identifies reality is an immediacy which includes within itself the entire realm of experience, in its most trivial as well as in its most momentous and sublime reaches. For such is the immediacy of 'absolute science.' 183

So much for Professor Baillie's misinterpretation of Hegel. I think we have shown that his criticism is beside the mark, and that is all we are concerned to do at present. The criticism itself implies a position the tenability of which we shall have to call in question later on in this chapter. We turn now to a consideration of Mr. McTaggart's objection.

Mr. McTaggart's criticism, though essentially the same as that of Professor Baillie, is presented from a different point of view and so demands separate notice. The conclusion of the Philosophy of Mind is made the basis for this attack. There, it is asserted, Hegel explicitly maintains that philosophy is the highest expression of Spirit, and thus is guilty of equating reality with philosophical knowledge. But, the critic objects, the position that in philosophy one finds the complete exposition of ultimate reality is untenable. "Philosophy itself is knowledge, it is neither action nor feeling. And there seems nothing in Hegel's account of it to induce us to change the meaning of the word in this respect.... We are thus, it would seem, bound down to the view that Hegel considered the supreme nature of Spirit to be expressed as knowledge, and as knowledge only." 184 "But knowledge," we are further informed, "does not exhaust the nature of Spirit. The simplest introspection will show us that, besides knowledge, we have also volition, and the feeling of pleasure and pain. These are prima facie different from knowledge, and it does not seem possible that they should ever be reduced to it." 185 Therefore, the critic concludes, in the final standpoint of the Encyclopaedia Hegel tried "to ignore volition, and to ignore pleasure and pain." And, of course, "a view of Spirit which does this is fatally one-sided." 186

The assumption involved in this criticism is quite evident. It is that Philosophy, as Hegel defines it, has to do with purely discursive knowledge, that is, with cognition as opposed to feeling and volition, and with this alone. As the critic himself puts it:

'Philosophy itself is knowledge, it is neither action nor feeling. And 
there seems nothing in Hegel's account of it to induce us to change the meaning of the word in this respect." Now it is just this assertion that I challenge. In the first place, as I have already argued in the somewhat detailed discussion of Hegel's doctrine of immediacy and mediation, the account which Hegel gives us of philosophical knowledge not only 'induces' us, but forces us, to define philosophy as a science of more than mere cognition. In point of fact, philosophy, as Hegel uses the term, is the science of experience, since it has to do with that life of mind, reason, which is nothing more nor less than experience itself. In the second place, the assumption here is the same as the assumption above, and all we have said in answer to the latter applies equally well to the former. The realm of philosophy Hegel identifies with the realm of 'absolute science'; and it must never be forgotten that the standpoint of 'absolute science' is to be found in the category of absolute knowledge. Philosophical knowledge, therefore, always means more than mere abstract cognition: it is an immediacy which includes within itself the whole life of Spirit.

Mr. McTaggart is willing to admit that the conclusion which he sees in the last division of the Philosophy of Mind is palpably inconsistent with the outcome of the Logic. In the Absolute Idea, he grants, volition as well as cognition is present. Hence the Absolute Idea "must be an idea richer and fuller than that of Cognition — richer and fuller by the content of the idea of volition.... The Absolute Idea then contains within itself the idea of knowledge as a transcended moment." Thus "in giving the abstract framework of absolute reality in the Logic," Hegel has at the same time given "a framework for something which, whatever it is, is more than any form of mere cognition." 187 Now I submit that the actual result of the Philosophy of Mind is not in the least inconsistent with this result of the Logic. Hegel always and everywhere maintains that philosophical knowledge includes within itself feeling, volition, cognition, in short all the action and passion of the human mind; and that, therefore, philosophy is the science of the real, if the realm of experience be the real. This position is the presupposition of the entire Encyclopaedia, and it is just as much involved in the last part as it is in the first. The proof of this contention has already been given in our attempt to state Hegel's doctrine of thought and to determine the position of the Logic in the system.

It is suggestive and instructive to notice that, in criticising Hegel's contention that philosophical knowledge is conterminous with the real, 
Mr. McTaggart attacks the very contention which he himself immediately afterwards champions. To see that this is true, one need only compare with Hegel's thought the critic's ultimate synthesis of the real. In stating the characteristics of the form of unity which he thinks would be an adequate expression of reality, Mr. McTaggart says: "It must be some state of conscious spirit in which the opposition of cognition and volition is overcome - in which we neither judge our ideas by the world, nor the world by our ideas, but are aware that inner and outer are in such close and necessary harmony that even the thought of possible discord has become impossible. In its unity not only cognition and volition, but feeling also, must be blended and united. In some way or other it must have overcome the rift in discursive knowledge, and the immediate must for it be no longer the alien. It must be as direct as art, as certain and universal as philosophy." ${ }^{88}$ It matters not that these lines are supposed by their author to express an idea essentially different from what Hegel means by thought; one could not want a better summary of Hegel's doctrine. Must feeling, volition, and cognition all be blended in the expression of ultimate reality? This, Hegel says, is accomplished in that state of conscious spirit which he calls thought: "It is present in every sensation, in cognition and knowledge, in the instincts, and in volition in so far as these are attributes of the human mind."189 For "in the human being there is only one reason in feeling, volition, and thought or cognition. ${ }^{190}$ Must the rift in discursive knowledge have been removed in this unity? This, Hegel tells us, is the characteristic peculiar to philosophical knowledge: the sciences "are finite because their mode of thought, as a merely formal act, derives its content from without. Their content therefore is not known as moulded from within through the thoughts which lie at the ground of it, and form and content do not thoroughly interpenetrate each other. This partition disappears in philosophy, and thus justifies its title of infinite knowledge." ${ }^{191}$ Must the immediate be no longer alien for the expression of the ultimately real? Our demand, Hegel assures us, is satisfied in Spirit: "As Adam said to Eve, 'Thou art flesh of my flesh and bone of my bone,'so says the Spirit, 'This object is spirit of my spirit, and all alienation has disappeared."' 192 Should that form of expression which exhausts the real be as direct as art and as universal as philosophy? Such a combination Hegel thinks he has found in philosophy itself: "The multifarious whole is reflected in it as in a single focus, in the Notion which knows itself." ${ }^{193}$ In short, philosophical knowledge, as Hegel has defined it for us, meets all the require- 
ments which Mr. McTaggart sees fit to make of the medium through which reality may receive adequate expression. And it does seem rather hard that an author should be criticized for upholding exactly the same position (barring terminology) as his critic champions.

Further detailed discussion of this point seems superfluous. Enough has already been said to show us not only that we are justified in concluding, but that we are forced to conclude, that Hegel does not equate reality with any process of formal knowledge. Such a position would be contrary to his own frequent explicit assertions, as well as to the presuppositions and actual procedure of his system. For his fundamental contention, both by word and deed, is that thought is the unifying principle of experience which includes within its diamond net the entire sphere of the activities and interests of the human soul. It subsumes within itself sensuous experience, moral and religious experience, scientific experience, all experience of which man is capable; it is the all-pervading harmonizer that illumines every phase of experience and makes it what it is. Only such thought as this, that is to say, experience, is what Hegel claims to be an adequate expression of the ultimately real. And with this we leave these misunderstandings and pass on to ask what form reality does actually assume in Hegel's system.

There occurs a passage in Professor Bosanquet's Logic which runs as follows: "It is important that we should dismiss the notion that the higher degrees of knowledge are necessarily and in the nature of intelligence framed out of abstractions that omit whatever has interest and peculiarity in the real world. Nothing has been more fatal to the truth and vitality of ideas than this prejudice." ${ }^{194}$ It is certain that no prejudice has been more fatal to an appreciation of Hegel's philosophy, and that, too, notwithstanding the fact that the author has constantly warned against the danger. And it would seem that the time has come when such a prejudice should be laid aside and an unbiased effort made to see exactly what Hegel has taught concerning the universal aspect which he thinks every unitary experience must have. Is there any other conception of universality possible than that which sets it down to mere abstraction? If there is, may it not be such a universality as will offer us a consistent explanation of experience and a satisfactory account of the ultimately real? May it not also be just the conception of universality that Hegel has in mind when he speaks of the 'Notion,' with which he equates reality and which he ever and anon assures us "is not a mere sum of features common to several things"? 195 
An honest look at experience forces us, it would seem, to assert that the real universal of actual thought is not that of formal logic. It is a notorious fact that we contradict the rules of the time-honored syllogism in our every-day thinking. Every developing science is an enigma to the formal principles of distributed middle and negative premises; and many of the simplest arguments of common sense cannot be forced into the syllogistic form. We are not surprised, therefore, that man, qua man, exists nowhere outside the texts on formal logic: not man has being in the real world, but only men. Professors Bradley and Bosanquet, following the lead of Hegel, have so clearly and exhaustively exposed these discrepancies in the procedure and presupposition of formal logic that it would be superfluous, if not presumptuous, for me to attempt to enlarge on them here.

It is sufficient for our present purpose simply to point out that the fundamental difficulty with the traditional logic is that it deals with an abstraction. It separates from each other two essentially inseparable aspects of experience, namely, form and content, and then concerns itself with one, namely, form, in isolation. There should be no wonder that its results are not applicable to concrete experience; the wonder perhaps is that, when so applied, they do not land us in more numerous antinomies. Of course, there is no such thing as thinking in the abstract, as if thought were indifferent to its object; and the universals that result from such an imaginary process can be nothing more than mere makebelieves. These universals of formal logic, as such, can have no part in reality. ${ }^{196}$

What, then, we ask, is the nature of the universal of concrete thought? I know of no better or clearer definition than that given by Professor Bosanquet in the introductory chapter to his Logic. ${ }^{197}$ He there warns us to beware of thinking of the universals as the result of the process of selective omission of differences among phenomena; this is the error which proves so fatal to the significance of formal logic. The true universal, the universal that actually has a place in concrete experience, is rather the result of a synthesis of differences, the constructive analysis of phenomena. That is to say, progression towards true universality is simply the continuous organization and systematization of the data of experience. So far from it being true that thought takes place in vacuity apart from any content, thinking is nothing but the progressive organization of its content; apart from its content thought is absolutely nothing. Since form and content are thus inseparable, the true form can be 
realized only when it is viewed in its essential relation to its correlative; and when it is so viewed it is seen to include the content within itself. The true universal, therefore, is thought-content. It does not have to wait for its filling from without, for it has within it its own filling, and lives only by virtue of the vital significance that it possesses in reference to its content. In a word, the universal of thought is concrete, a synthesis of particulars. It has no meaning whatever, not even the semblance of one, in isolation from the material aspect of experience of which it is the form. ${ }^{198}$

This change of attitude towards the syllogistic logic of the Scholastics and this doctrine of the concrete universal are really the fundaments of Hegel's system. After the first Part of the present study this statement hardly needs further proof. It is true that the change in view-point was more or less unconsciously present in the epistemology of Kant and Jacobi, as Hegel himself points out. ${ }^{199}$ But the change comes to full consciousness of itself only in Hegel's own work. He openly revolts against the traditional tendency to regard the concept, judgment, and syllogism, as if they were sharply differentiated forms of abstract thought and not living manifestations of truth. ${ }^{200}$ Naturally this change of view concerning the nature of thought brought with it a change of view concerning the result of thought. Since thought is no longer regarded as a process in abstraction, the universal of thought can no longer be thought of as the result of abstraction. If thought is the vital unity of the mind, the true universal of thought is simply the content of mind thoroughly rationalized and exhaustively explained. If thought is the Notion, the universal of thought is the universal of the Notion. And "the universal of the Notion is not a mere sum of features common to several things, confronted by a particular which enjoys an existence of its own. It is, on the contrary, self-particularizing or self-specifying, and with undimmed clearness finds itself at home in its antithesis." ${ }^{201}$ That this doctrine of thought and universality is peculiarly Hegel's own, there seems to be no doubt: the doctrine is the burden of his philosophy.

From these considerations we may pass at once to the conclusion that for Hegel the ultimately real must assume the form of concrete individuality. Neither the mere particular nor the blank universal will suffice; the real must be the particularized universal, the universalized particular. "Actuality is always the unity of universality and particularity," as Hegel himself puts it. ${ }^{202}$ "Everything is a Notion, the existence of which is the differentiation of its members or functions, so that the 
universal nature of the Notion gives itself external reality by means of particularity, and thereby, and as a negative reflection-into-self, makes itself an individual." ${ }^{203}$ The following hypothetical argument seems to sum up the matter: If it be true that thought is conterminous with experience, then certainly experience must somehow assume the form of universality; discrete particulars are excluded from it. If, in the second place, it be true that thought is simply the "indigenous becoming (einheimische Werden) of the concrete content," 204 then its universality must be concrete, that is to say, the particulars must find their place within the sphere of the universal, which, itself, gets its meaning only by virtue of this relation to the particulars. Therefore the form of universality which experience takes (and it must take some form of universality) can be only that of the particularized universal, or, in a word, that of the individual. Now the chief purpose of this study has been to show that Hegel asserts the premises of this argument. It must be shown that this is erroneous before one may legitimately claim that Hegel equates reality either with the bare particular or with the abstract universal, or deny that he gives to the real the form of individuality.

That this is the correct account of Hegel's view of reality may be shown in another way. The argument that is to be found in the Logic, under the head of the Notion, is in direct confirmation of the conclusion we have just reached. So we turn to this argument for further evidence on the point. ${ }^{205}$

For our present purpose it will be sufficient to state the argument merely in its general outline. The triadic movement Hegel expresses under the following heads: (a) The Subjective Notion; (b) The Object; and (c) The Idea. The development here involved may be put in the following general manner. At the standpoint of the Subjective Notion we have presented to us the Notion as indeterminate and formal, the truth is given only implicitly. ${ }^{206}$ In a sense, this may be said to be the point of view of formal logic, from which thought is looked upon as a sort of subjective process whose end is the formation of concepts and the manipulation of those concepts in the higher mental processes of the judgment and the syllogism. But, as Hegel goes on to show, it is impossible to rest at this point of view. It has inherent in it its own deficiency, in that it is an inadequate expression of the real nature of the Notion. Thought cannot be confined to subjectivity; it is objective as well. Thus we are led on to the consideration of the Object — the second stage of the dialectical development. The Object is the 'realization' of the No- 
tion, and the transition is accomplished through the syllogism of necessity, that is, the disjunctive syllogism. ${ }^{207}$ But objectivity, like subjectivity, is not an adequate expression of the Notion; the Notion is neither merely subjective nor merely objective. The content, apart from the form, just as the form apart from the content, is an abstraction; the true view of the matter is reached only when we see that the two are one and inseparable. This unity of the two is the Idea, which is truth complete the ultimately real.

It should be observed that this whole development is nothing more than the progressive definition of the nature of the Notion itself. As we shall see more fully below, the thesis is simply the expression of the form that the Notion, because of its very nature as form, assumes. The antithesis is the 'realization' of the Notion; that is to say, when the Notion has exhaustively differentiated itself in the judgment of necessity, the disjunctive judgment, it is seen to involve the object. The synthesis, finally, as Hegel himself observes, is nothing but the Notion taken in its particularity and universality. "Its 'ideal' content is nothing but the Notion in its detailed terms: its 'real' content is only the exhibition which the real gives itself in the form of external existence." 208 In a word, the Idea for Hegel is simply the Notion taken in its complete nature, as, on the one hand, a substantial somewhat, and, on the other hand, a meaning.

Since, now, the Idea is the form which ultimate reality assumes in Hegel's system, it follows that the real is in the form of the Notion. This conclusion is in exact agreement with what we have been insisting on all along in this study, and it might be supported by numerous passages from various contexts. But this hardly seems necessary: presumably it will not be disputed that the Hegelian philosophy has to do with the unity of the Notion. If, then, we can here establish the claim that the unity of the Notion is that of the individual, our contention above will have been corroborated from another point of departure.

And it would seem that Hegel has left us in no doubt concerning his position on this point. In the first division of his discussion of the Notion, referred to above, he tells us quite plainly that the ultimate form of the Subjective Notion is individuality. The three members of the triad in this division are Universality, Particularity, and Individuality. Individuality is thus made the synthesis of the other two, and consequently must be considered the highest expression of the Subjective Notion. And there seems to be no particular difficulty in understanding what Hegel means by the individual. He means by it "the refiection-into-self of the specific 
characters of universality and particularity," ${ }^{209}$ or determinate universality (bestimmte Allgemeinheit). ${ }^{210}$ In contradistinction to indefinite multiplicity, it is "the particular and the universal in an identity." 211 In a word, individuality means for Hegel what it means for others, namely, unity within difference, harmony within diversity, a systematic whole. The Subjective Notion, therefore, is a whole within which differences are found and through which those differences get their significance and reality. This seems to be a legitimate conclusion from the dialectical movement that takes place within the Notion as Notion.

But just here an objection awaits us. This may all be true of the Subjective Notion, but is it true of the Idea? Can we legitimately argue that, because the ultimate expression of the Subjective Notion is individuality, the ultimate expression of the real must be individuality? Have we not already seen that the Subjective Notion is the thesis of a triad of which the Idea is the synthesis, and is it not therefore false reasoning to say that the form of the Subjective Notion is adequate to the Idea? In a word, does the fact that Hegel maintains that individuality is the consummation of the process of thought justify us in the inference that for him the real is individual?

We have already answered this objection in what we said above concerning the fact that the Idea is simply the Notion exhaustively analyzed. It is true that the Idea is the Notion completely differentiated; but it is the Notion nevertheless. The dialectical development by means of which we are led to the Absolute Idea indicates this; for the Absolute Idea is the synthesis of the triadic development of the doctrine of the Notion. Indeed, the whole dialectical development of the third part of the Logic goes to prove that the Idea is the most perfect expression of the Notion. The Idea and individuality thus coincide. It is true, of course, that by passing in the Idea the Notion is enriched and intensified by all the intervening categories; this enrichment is really the significance of the advance. But this does not at all affect the fact that the form of the Notion does not change in the process, and that the Idea is simply the Notion seen in its truest light.

This is perhaps sufficient answer to the objection. But there is involved in it an assumption the error of which it will be worth while to expose. The assumption is that in the treatment of the Subjective Notion Hegel is dealing with the formal concept of the logic of the schools. One or two passages from the smaller Logic bearing on this point will suffice to show the falsity of the assumption. "It is a mistake to imagine 
that the objects which form the content of our mental ideas come first and that our subjective agency then supervenes, and by the aforesaid operation of abstraction, and by colligating the points possessed in common by the objects, frames notions of them. Rather the Notion is the genuine first; and things are what they are through the action of the Notion, immanent in them, and revealing itself in them." 212 "No complaint is oftener made against the Notion than that it is abstract. Of course it is abstract, if abstract means that the medium in which the Notion exists is thought in general and not the sensible thing in its empirical concreteness. It is abstract also, because the Notion falls short of the Idea. To this extent the Subjective Notion is still formal. This however does not mean that it ought to have or receive another content than its own. It is itself the absolute form, and so is all specific character, but as that character is in its truth. Although it be abstract therefore, it is the concrete, concrete altogether, the subject as such.... What are called notions, and in fact specific notions, such as man, house, animal, etc., are simply denotations and abstract representations. These abstractions retain out of all the functions of the Notion only that of universality; they leave particularity and individuality out of account and have no development in these directions. By so doing they just miss the Notion." 213 These passages are found at the very beginning of the discussion of the Subjective Notion. At the end of this discussion we read: "To say that the Notion is subjective and subjective only, is so far quite correct: for the Notion certainly is subjectivity itself.... But we may go a step further. This subjectivity, with its functions of notion, judgment, and syllogism, is not like a set of empty compartments which has to get filled from without by separately existing objects. It would be truer to say that it is subjectivity itself which, as dialectical, breaks through its own barriers and opens out into objectivity by means of the syllogism." 214 The Subjective Notion, therefore, is not merely subjective; it is not a bare concept of formal logic that has only a psychological existence in some knowing consciousness. On the contrary, it is the life of the objects themselves, and is implicitly that which, when made explicit, becomes the Idea. ${ }^{215}$

If, then, we are right in arguing that the real must conform itself to the Notion, and if the Notion is, when fully expressed, the individual, it seems to follow that the real must assume the form of the individual. And this appears to be Hegel's position as we find it expressed in the third part of the Logic. So our conclusion, which we before reached 
more or less indirectly, is based directly upon the dialectical development of the Logic.

Professor Pringle-Pattison has criticised Hegel for disparaging the individual, and that criticism must be examined here. It is based upon the following passage from the smaller Logic: "Sensible existence has been characterized by the attributes of individuality and mutual exclusion of the members. It is well to remember that these very attributes of sense are thoughts and general terms. . . L Language is the work of thought: and hence all that is expressed in language must be universal.... And what cannot be uttered, feeling or sensation, far from being the highest truth, is the most unimportant or untrue. If I say 'the unit,' 'this unit,' 'here,' 'now,' all these are universal terms. Everything and anything is an individual, a 'this,' or if it be sensible, is here and now. Similarly, when I say 'I,' I mean my single self, to the exclusion of all others; but what I say, viz., 'I,' is just every other 'I,' which in like manner excludes all others from itself. ... All other men have it in common with me to be 'I'" ${ }^{216}$ Commenting on this passage, the critic says: "This demonstration of the universal, or, to put it perhaps more plainly, the abstract nature of thought, even in the case of those terms which seem to lay most immediate hold upon reality, is both true and useful in its own place. But the legitimate conclusion from it in the present connection is not Hegel's insinuated disparagement of the individual, but rather that which Tredelenburg draws from the very same considerations, that the individual, as such, is incommensurable or unapproachable by thought. ${ }^{217}$ Or, as Mr. Bradley puts it still more roundly and trenchantly ${ }^{218}$ 'The real is inaccessible by way of ideas.... We escape from ideas, and from mere universals, by a reference to the real which appears in perception."

Now it seems to me unfair to charge Hegel here with disparagement of the individual. In the passage in question he has in mind discrete parts of experience, unorganized elements of sensuous perception; and it is these abstract sensations and feelings that he calls 'unimportant and untrue.' He does, indeed, in the same section speak of individuality as the essential feature of sense-experience; but that he means by this nothing more than that "sensible existence presents a number of mutually exclusive units," he himself is at pains to tell us. So it would appear that the disparagement is of the isolated particular and not of the individual. According to Hegel, it is not the individual which is the 'unutterable'; for the very form of the judgment is the individual, it is essentially 'a 
universal which is individualized. ${ }^{219}$ The isolated, unrelated elements of abstract sense-perception and conception, these it is to which Hegel refuses to give any ultimate significance; for such discrete particulars are essentially unreal. And in this position Hegel differs little from his critic. 220

The real import of the section from which the above quotation is taken seems to be implied at least in a sentence of the passage which Professor Pringle-Pattison fails to quote. The sentence runs thus: "It will be shown in the Logic that thought (and the universal) is not a mere opposite of sense: it lets nothing escape it, but, outflanking its other, is at once that other and itself." By this I understand Hegel to mean that he is to show in the Logic that thought is involved in sense-perception, that thought is a principle which, as he tells us in the very last sentence of the paragraph from which we have quoted, runs through all "sensations, conceptions, and states of consciousness." And from this it would follow that even sense-experience is universalized, and to regard this experience as composed of discreet units is really to regard it abstractly. That, it would seem, is what Hegel points out in the section under discussion. It is the unrelated which is unutterable, because the universals of thought cannot get hold of it to express it. But the unrelated is not the individual, and one does not see how it could be the real. At all events, Hegel seems free from the charge of disparaging the individual here, meaning by the individual the universalized particular. It is just upon the individual that he is laying the emphasis, as against the doctrine of discrete particularity.

The doctrine of Hegel's critics that the individual is unapproachable by way of ideas is a position which itself demands examination. In the first place, it seems to rest upon the doctrine that ideas, or categories, can be nothing but principles of cognition, that the assertion of the intelligibility of reality in terms of thought limits us to the mechanical categories (the categories of the sciences which have to do with factual existence) in our efforts to interpret reality. Now this doctrine is not selfevidently true, and should be tested as to its validity. Of course if it be true, we must admit at once that thought is not an adequate expression of reality; for we must all agree with Professor Royce that "individuality . . . is a category indefinable in purely theoretical terms." 221 But is it true? According to Hegel's doctrine of thought it is not true; Hegel's thought includes categories of value as well as those of factual existence, and so he insists that the individual is expressible in terms of 
categories, though not necessarily the categories of pure cognition. Whether or not Hegel's doctrine of thought is true to the facts of experience we have tried to determine in the first Part of our study.

In the second place, this position involves a mistaken epistemological principle. Baldly stated, it is that the uniqueness of reality consists in its transcending knowledge. Mr. Bradley puts the position thus: "It is not by its quality, as a temporal event or phenomenon of space, that the given is unique. It is unique, not because it has a certain character, but because it is given." 222 The question naturally arises whether this statement actually agrees with the facts. One is inclined to dispute that it does. At any rate, the unique in this sense is certainly not synonymous with the term as it is commonly used. Let us take one or two examples. What is a unique invention? Popularly, it is an invention that has properties and characteristics different from others of its class. But certainly its uniqueness is not thought of as consisting in the fact that the invention is inexplicable; if it were inexplicable, it would be simply a mystery and not anything unique at all. Suppose it were an intricate machine, which none but the man trained in mechanics could understand. Would it then be truly unique for anyone save the mechanician? It would seem that an invention is unique in terms of its peculiar properties and attributes, which must be known and appreciated as such; it is of such a known nature that it differs from all other creations of mechanical genius. And the more intelligibly one succeeds in differentiating it from other such creations, the more clearly defined does its uniqueness become. This same fact may be illustrated by the example of a unique personality. A person is unique only in so far as he differs from others, and he differs from others only because of certain positive characteristics that make him different. The assertion, "Ben is a unique character," is, I dare say, a rather meaningless jumble of words; naturally, we must know more about Ben before we can appreciate his uniqueness. But " $\mathrm{O}$ rare Ben Jonson!" is an exclamation of genuine significance. What is the difference in the two cases? Is it not simply that in the latter our knowledge has something to attach to itself to, while in the former knowledge can get no foothold? And is it not permissible to argue that the more one knows of the characteristics of Ben Jonson, the more determinate and impressive grows the uniqueness of his individuality? Doubtless, in the minds of his associates and companions in the Mermaid the eccentricities of his genius were much more marked than they can be to us, assuming, of course, that the man was more fully known by personal 
contact with him. So it seems that the person, like the invention, is unique only because he possesses positive characteristics that make him unique; and apart from such positive characteristics uniqueness is lacking.

Now from the epistemological point of view, what does this amount to? Simply, I think, to the conclusion that uniqueness, individuality, is to be measured in terms of knowledge, not of ignorance. Before an object can be unique, it certainly must be self-identical; and the more completely self-identical it becomes, the more emphasized does its individuality appear. Now the vaguest self-identity implies reference beyond self; and apart from this reference to others self-identity is impossible. But reference beyond self is relation, and relations are categories. Thus it would seem that the unique not only does not exclude categories, but, on the contrary, depends upon them for its very existence. It is only when an object is fully known to be itself, that is, when it is seen to differ determinately from others of its class, that it may legitimately be termed unique. Apart from universality individuality is a fiction. Thus the individual gets its uniqueness by being defined. That is unique which is seen to be itself, and only that which possesses attributes and qualities peculiar to itself can be differentiated from others. Of course an object may be negatively defined, that is, as not something else; but in order that such a definition have significance, it must give us positive knowledge of what we are negatively defining. For if the object of interest is not some other object, then the judgment of difference is based upon positive attributes which make its being the other object impossible; otherwise, there would be no sense in asserting the difference. In opposition to Mr. Bradley, therefore, we must argue that the 'given' is unique, not because it is given, but just because it possesses a certain character. No brute fact is, as such, unique; it is a meaning for us, or it is nothing. The uniqueness of reality is to be found only in its determinate character, not in its indeterminate factual existence. ${ }^{223}$

A final objection to the position that reality is unapproachable by thought emerges from the preceding discussion. Is it not logically impossible for those who maintain that the real is inaccessible by way of ideas to assume the position that the real is individual? Are not these two contentions contradictory? The difficulty will be apparent from the following considerations. If the real is given us independently of thought and apart from its activity, then one would think that it must be represented only in the form of particularity. For, as Professor Bosanquet has reminded us, that which is supposed to come to us through abstract 
sense perception could come only as the unrelated particular; for the essence of sense is isolation. Feeling, uncontaminated by thought, stands on the same level with the senses in this respect. ${ }^{224}$ Hegel himself has pointed out that what I feel is only mine, belongs peculiarly and exclusively to me, and, as mere feeling, must forever remain bound down to subjectivity, to bare particularity. But it must not be forgotten that the individual necessarily implies some form of universality. And the question at once arises, Whence does it get this form? If the assertion that has just been made of the senses and the feelings be true, as experience seems to teach that it is true, then universality cannot be produced by them; untouched by thought, they give and can give only the particular. But if the universal character of the individual is the gift of thought, what justification can there be for the statement that the individual is unapproachable by thought? The contention seems to ignore the very process by which the result has come to be. Thus there seems to be a fundamental difficulty in the position which argues that the real is essentially beyond thought, and yet at the same time insists that the individual, and only the individual, is the real. ${ }^{225}$

This difficulty may be accentuated by a somewhat detailed study of the inconsistencies that appear in Professor Baillie's criticism of Hegel as quoted above. The digression, if it be a digression into which we shall thus be led, will perhaps throw some light on Hegel's position by utilizing his principles in criticism of a position antagonistic to his own.

It is quite easy to see that Professor Baillie's criticism is vitally bound up with the assumption that the real immediacy of experience cannot be mediated, and, consequently, lies beyond thought. ${ }^{226}$ But it is not easy to see just what is meant by such an immediacy. Sometimes it is spoken of as if it were the immediacy of sense-perception: for example, we are told that "wherever we have an object present to the subject, there we have immediacy." At other times, however, one is led to believe that the immediacy of reality is the unattainable goal of thought rather than its given point of departure. "Knowledge is not construction but reconstruction of Experience.... Experience again, on the other hand, is the compact and inexhaustible mine of fact to which knowledge ever recurs, which it seeks to fathom, . . . the reproduction of which in its immediacy may be said to be its aim." But in either case, whether the immediacy of reality be the first given from which thought can be only a process of abstraction, or the ideal towards which thought is an endless and essentially futile process of approximation, the conclusion that 
forces itself upon us is the same. And that conclusion is that the immediacy of experience, that immediacy which is reality, is of such a nature that thought is necessarily excluded from it; it is an immediacy with which the categories of knowledge have absolutely nothing to do. "The immediate in Experience, that immediate which is reality, is absolutely continuous with itself and admits of isolation in no sense whatever; the immediacy is indissoluble, otherwise Experience simply ceases to be. This single immediacy of Experience we simply cannot have in knowledge; if so knowledge would not be knowledge but Experience." "The complete realization of the nature of the Absolute must remain for knowledge even at its best an impossible achievement." 227

Now I venture to submit: (a) that such an immediate experience as Professor Baillie here identifies with reality is not possible; and (b) that, if it were possible, it could at most be but subjective and particular. Let us begin with the first of these contentions.

(a) All that has been said above concerning the impossibility of construing the uniqueness of the 'given' in terms of its merely factual aspect is applicable here. For what is this immediate experience but such an indeterminate 'giver,' whose individuality consists in the fact that it is so given? And what is such a unique given but a contradictio in adjecto? That which is merely given cannot possibly be unique, for it has no relations in terms of which its uniqueness is to be defined. The given is not in experience until it is at least recognized as a permanent somewhat which is itself and not something else; but when it is so recognized, it is no longer a merely indeterminate given. Experience certainly involves more than bare abstract fact.

To this may be added the following considerations. The only experience about which we know anything seems to possess at least a degree of unity. Life is at any rate livable, society does actually exist, and its many chaotic aspects cannot blind us to the orderly character of its being. Not even the simplest act of sense-perception, not to mention the more complex processes of intellectual and social activity, would be possible were there no unity within experience. But unity implies a unifying principle, and the unitary whole gets its significance only as it is construed in the light of this principle. What makes of experience a unity? Can the organic nature of experience be explained in terms of the senses, or the feelings, or the will? If in terms of the first, how refute the Sophists? If in terms of the second, how refute the mystics? If in terms of the third, how refute Schopenhauer? Is it not true that experience is a 
unity only by virtue of its principle of rationality; and that if any part of experience transcends or falls without this principle, it, by that very fact, ceases to be aus einem Stücke? The very conception of a unified experience would seem to necessitate the assumption that in its lowest and vaguest stages, as well as in its highest and sub limest reaches, its universal principle is active; and what this universal principle is seems to be a question that hardly admits of debate when once it is clearly put. Now if such are the implications of experience, it is difficult to see what meaning can be given to Professor Baillie's immediate experience from which every rational category is excluded. In point of fact, it seems to be too immediate to be experienced and so is essentially meaningless. Whatever is in experience unquestionably must be experienced; but how anything can be experienced without somehow being known, that is, without at least being recognized as itself and so being subjected to a category, it is not easy to understand. That which by its very nature is incapable of being represented in consciousness cannot enter into the realm of possible experience; and to speak of an immediate experience that cannot be experienced seems to amount to an absurdity. Therefore it would seem that Professor Baillie's conception of an immediate experience, beyond the categories of knowledge, must be given up; it is Nothing more than a mere phantom, a contradiction in terms. ${ }^{228}$

(b) But, for the sake of the argument, let us grant the possibility of this experience in which thought can play no part. What is the predicament in which we find ourselves7 Simply, I think, confined within the realm of abstract particularity. For in what does that experience which lies beyond thought consist, if not in an unrelated series of meaningless sense-perceptions, or of incoherent feelings, or of blind volitions? And what can such a series be but a disconnected array of discrete particulars? It is, of course, difficult to speculate concerning the nature of that which does not and cannot exist. But concerning this experience with which we are here attempting to deal, we may be sure of this, that, whatever else may or may not be true of it, it certainly cannot be objective and universal in any intelligible sense of those words. The essence of abstract sense is isolation and particularity, and feeling and volition, qua abstract feeling and volition, are entirely subjective and can be experienced by no one under the sun save the subject who psychologically possesses them. How, then, can these abstractions be called universal, and how could an experience made up exclusively of them be, in any sense whatever, objective? To put the question is to answer it. And the 
question, candidly faced, would seem to drive us to the conclusion that an experience that lies beyond the categories of rationality must assume the form of unrelated particularity. The prejudice, however, will not easily down. There must be a datum of experience which is just eternally there, and about which nothing more can be said. It forever eludes our grasp when we attempt to seize it by thinking it; but no sane person can deny its existence. Is not this datum given entirely independently of thought's activity? And yet can it be denied that it comes to us, no matter how, as a part of our experience? Have we not here, then, an immediate experience which is more than an unrelated particular, and which, nevertheless, is entirely beyond the categories of thought? Everybody experiences the given, and yet its immediacy cannot appear in knowledge. How does this very obvious fact square with the above assertions concerning the inherent absurdity of an immediate experience beyond thought?

In the first place, attention should be directed here to a question of fact. One seems forced to point out that, as a matter of fact, there is no fixed 'datum' of experience. The so-called 'given' differs for different individuals and for the same individual at different times. In a very important sense that which is given depends upon the purposes and intellectual attainments of the one to whom it is given; and no one can doubt that such a basis is relative and is constantly changing. To the hardpressed Richard on the battlefield the same horse would have been more of a reality by far than to the lazy beggar of Mother Goose renown; and the small boy, bent on mischief, actually sees in the stone at his feet characteristics quite different from what might appear to the eyes of the trained geologist. Other illustrations of this fact will suggest themselves. Of course this contention will not be misconstrued to mean that any phantasm that may chance to run through the mind actually does, for that reason, have a place in existential reality, that the subject creates perceptual experience. I certainly do not wish to minimize the factual aspect of experience. The point upon which emphasis is here intended to be placed is that the 'giver,' apart from an experiencing subject, is a blank abstraction, and that in relation to an experiencing subject it is more than a mere 'given.' The confusion upon which this doctrine of the 'given' rests is this: the object side of experience is taken from its context and then opposed to that experience as something standing over against it and independent of it Berkeley has long since pointed out the fallacy here. In this discussion it is necessary for us to rid our minds of 
this confusion. As Professor Bosanquet sums up the point: "The given and its extension differ not absolutely but relatively; they are continuous with each other, and the metaphor by which we speak of an extension conceals from us that the so-called 'given' is no less artificial than that by which it is extended." 229

In the second place, this insistence upon the 'given' lands us in insurmountable difficulties.. However the position is stated, so long as the immediate experience is too immediate for the categories of thought, it seems open to the above fatal objection that it must forever remain particular and subjective. To say that reality is found in a pure indeterminate datum, an unaccountable residuum of being, is to open the way for an influx of problems similar to those produced by Aristotle's abstract separation of form from matter, or by Kant's differentiation between the experienced phenomenon and its reality. It matters not that the datum is thought of as the material out of which the universals of knowledge are manufactured, or in which thought somehow finds the problems that determine its activity; the difficulties still remain. How the universals of thought are manufactured out of that which is confined to discreet particularity is not easily discovered. Nor can one see at a glance how that which lies beyond thought can really set a problem for thought. If our world were such, one is inclined to think with Professor Royce that it would be "too much of a blind problem for us even to be puzzled by its meaningless presence." ${ }^{230}$ Those who insist upon such an immediate experience should show by what right they appeal to the individual as the real, and by what reasoning they succeed in transcending abstract particularity within this experience. For there is certainly a difficulty here, and one that seems to be sufficiently weighty to cause the position to be, if not entirely abandoned, at least essentially modified.

But Professor Baillie may possibly object that, so far as he is concerned, all this is beside the mark. He may assert that he has no thought of equating reality with an unchangeable datum of experience, or with the abstract particular. His main contention, he may urge, is that reality cannot be exhausted by thought; thought is about reality, but cannot exhaust reality. The notions are not the reality of things, "for these are individual, and a notion, however concrete, is . . always a notion, i.e., a universal." ${ }^{231}$ Reality, then, is not a chaotic state of immediacy, as has been represented in the discussion above; on the contrary, it is a unique whole which, on account of its very uniqueness, lies beyond the possibility of the universals of thought. It is not the starting-point from which 
thought abstracts, but the goal at which it aims - a goal, however, essentially beyond it. In a word, the objector may say, not abstract unrelatedness but an organic unity that is super-rational - such is the immediacy of that which may be called the real.

This objection, however, does not in the least change the situation. It makes no difference whether the 'immediate' is the indeterminate given of sense-perception with which thought works, or the unattainable ideal towards which thought strives; from the logical point of view the two positions are one and the same, and a justifiable criticism of the one holds of the other also. On this point Professor Baillie stands condemned by his own words: "If reality is in any sense beyond knowledge it is of no importance where, in the history of knowledge, the separation is made. To make knowledge bear an essentially asymptotic relation to reality is in principle precisely the same as to separate knowledge and reality absolutely from the start. The only difference is that the former puts the separation far away at infinity - 'reality cannot be exhausted by thought'; the latter plants it down at our feet - 'reality is outside knowledge.' But this is a difference which is unimportant and meaningless: unimportant, since in both cases reality is beyond us, and the question of 'when' it becomes so does not concern knowledge: meaningless, since in both cases we can never say when knowledge actually has failed; the beyond is always a beyond in either case. The position referred to" (that is, the position expressed by Lotze, for example, when he asserts that 'reality is richer than thought') "is therefore rooted in dualism, in spite of the apparent concession of the worth of knowledge up to a certain point. For it must accept the alternative: either knowledge does give the nature of reality, in which case the question of amount and the time it takes to exhaust it is of no significance, since the nature of reality is explicitly known and implicitly cognizable; or there is at the outset a fundamental cleavage between the two, in which case at no point does knowledge give reality." ${ }^{232}$ And if this be true, we are reduced to the necessity of acknowledging that the separation between knowledge and reality, wherever the separation may appear, leads us into the difficulties of an indeterminate immediacy of experience.

As Hegel views the matter, the way out of these difficulties is exactly the reverse of the way in. We must define reality not as Substance but as Subject. That is to say, the real must be conceived of not as an indefinable somewhat about which nothing more can logically be said than that it just eternally is but as a thoroughly comprehensible system whose nature is expressed in its internal rational organization. Even granting that the 
categories which are adequate to its nature may be read in terms of senseperception, or of blind will, or of pure cognition, or of abstract feeling, still we must say, if we are not to talk mere nonsense, that the immediacy of the real is the result of some sort of mediation and is intelligible by means of certain categories which actually do express its essential nature. ${ }^{233}$ But sense-perception, blind will, pure cognition, mere feeling, have no categories to offer us for the unification of experience: the true universal runs through them all, and it is the one reason which is the life of experience. Such is Hegel's doctrine, and he insists that, if we are in earnest about transcending the standpoint of the Critical Philosophy, that is, if we are really in earnest when we deny the existence of a reality beyond the realm of possible experience, we must admit that no part of experience presents the enigmatic aspect of a mere abstract datum. For if that which is real is an indeterminate immediacy, an indefinable somewhat that lies beyond thought, wherein does it differ from the abstract particular or the thing-in-itself, or what earthly connection has it with actual concrete experience? Those who champion the position ought to take it upon themselves to remove the difficulty, and to point out in what respects their solution differs from Hegel's own. ${ }^{234}$

We may conclude this chapter with a brief summary of its main contentions. Hegel equates reality with experience, and not with abstract formal knowledge as Professor Baillie and Mr. McTaggart seem to think. When he asserts that the immediacy of reality is the immediacy of science, or that philosophy exhausts the nature of Spirit, he simply means to say that reality is not an insoluble mystery, but is essentially an ideal construction. an interpretation and organization of the so-called 'given.' The real for him, therefore, is neither the abstract particular nor the blank universal; it is the universal filled, the particular made significant, in a word, the individual. And the position that the real is individual, as he conceives the matter, necessarily involves the admission that concrete thought is no less extensive than the realm of concrete experience. For if any part of experience lies truly beyond thought, it seems to be devoid of universal characteristics and so differs in no intelligible sense from the abstract particular; and it is the validity of this contention that he would ask the upholders of the 'pure experience' theory to challenge. That the essential nature of which cannot be fully expressed in terms of knowledge is an incomprehensible datum which, by virtue of that fact, never appears in concrete experience. And experience, organized and rationalized experience, and reality are one. 


\section{Chapter V. \\ The of the Absolute.}

Hegel's doctrine of the nature of the Absolute is a problem that is not easy of solution. The fact that the Hegelians of the Left and of the Right, while appealing to the authority of the master in justification of their respective positions, reached antithetical conclusions with reference to this problem is an indication of its difficulty. But the result that we have already attained in the preceding chapter offers us a vantage-point in our discussion of the problem. We have shown that the unity of reality, according to Hegel, is a unity that includes differences, and that the differences are essential to the unity. This point will, however, be of more direct interest to us when we come to ask concerning the relation of the Absolute and its differentiations. The problem immediately before us is to determine how this unity must be conceived, what more specifically the nature of the unity is. The thesis which we shall defend is that the Hegelian doctrine concerning this unity is that it is spiritual, and that it exists as a self-conscious Personality. ${ }^{235}$

The point of departure for our discussion we shall find in the Absolute Idea. If we can determine the essential nature of the Idea, then we may claim to have set forth Hegel's doctrine of the nature of the Absolute, since the two terms are practically synonymous in his system. ${ }^{236}$ If Hegel has given any direct proof at all that the Absolute is to be thought of as personal, it must be sought in an investigation of the Idea; and, on the other hand, if it can be shown that the Idea is a self-conscious Individuality, it must be admitted that Hegel teaches the doctrine of a personal Absolute. We ask first, then, Is the category of the Absolute Idea, as defined for us in the Logic, equivalent to a Personality or self-conscious Individuality?

We have already pointed out that Hegel teaches that the Idea is individual for it assumes the form of the Notion, and the form of the Notion is individuality. Even a glance at the Logic will indicate this truth: the Idea is the last category in the dialectical definition of the Notion. But this, in itself, proves nothing more than that the Idea is a unity of differences, and that unity and differences are equally essential. This is a very important result, to be sure; it settles some vexed questions concerning the Absolute and the finite, as we shall see in the discussion of the relation of God to the world. But it still leaves unanswered the problem of the nature of the unity among the differences. Does Hegel think of this unity as personal and self-conscious? 
The answer to this question is to be found in the triadic development which Hegel has given in that part of the Doctrine of the Notion called the Idea. The triad which we find here consists of the categories of Life, Cognition (perhaps Consciousness would more nearly adequately convey Hegel's meaning), and the Absolute Idea. The movement, though considerably hindered by puzzling and bothersome details, is tolerably clear in its main features; and, fortunately, it is only the main features with which we are here concerned. Let us follow this development.

We ask first concerning the standpoint of the thesis. Here, under the category of Life, Hegel tells us that we have the Idea in its immediacy but in an immediacy which is not true. By this is meant, it would seem, that in the category of Life we get the first approximately explicit manifestation of the real nature of the Idea, but in a manner inadequate to that nature. The category is approximately adequate to the Idea, because we have in it the first explicit appearance of a spiritual activity. Its inadequacy consists in the fact that it presupposes an opposition between subjective and objective which it never succeeds in overcoming. It is, indeed, true that the dialectical process within this category consists just in transcending this opposition: in the Kind (Gattung) the particular living thing loses part of its immediacy and becomes, to a degree, objective and universal. Nevertheless, its particularity and universality do not completely coincide. "Implicitly it is the universal or Kind, and yet immediately it exists as only." ${ }^{237}$ And just because of this contradiction, which is essential to it, the category of Life cannot furnish us with the ultimate synthesis of reality. In such a synthesis we could have nothing more than blank identity between the particular and the universal; the particular on this plane is not able to withstand the universal. "The animal never getssofarin its Kind as to have a teeing of itsown; it succumbs to the power of Kind." ${ }^{238}$ Thus we are forced to look for the unity of the Idea in a category other than that of Life. And this brings us to the category which Hegel calls Cognition in general.

Before passing on to the standpoint of this category, it will be well to pause here, and quote Hegel's own words bearing on the defect and the dialectical development of the category of Life as we have just attempted to trace it. "The notion [of Life] and [its] reality do not thoroughly correspond to each other. The notion of Life is the soul, and this notion has the body for its reality. The soul is, as it were, infused into its corporeity; and in that way it is at first sentient only, and not yet freely selfconscious. The process of Life consists in getting the better of the 
immediacy with which it is still beset: and this process, which is itself threefold, results in the idea under the form of judgment, i.e., the idea as Cognition." 239

In his discussion of the category of Cognition Hegel indulges in numerous digressions, which serve only to obscure the outlines of the dialectical advance. But, if we neglect the confusing details, the goal at which the author is aiming seems pretty clearly to be the category of self-consciousness. And he reaches it in some such way as the following. Leaving behind us the category of Life, as confessedly inadequate to the unity of the Idea, we turn first to the level of abstract cognition proper, and examine its claims. ${ }^{240}$ This category is at once seen to be insufficient, and that for two reasons. In the first place, it presupposes a somewhat as given, upon which it impresses itself in a more or less mechanical fashion; this is the standpoint of the sciences, which busy themselves with the discovery of laws without being able to pass judgment upon their ontological significance. ${ }^{241}$ "The assimilation of the matter, therefore, as a datum, presents itself in the light of a reception of it into categories which at the same time remain external to it, and which meet each other in the same style of diversity. Reason is here active, but it is reason in the shape of the understanding. The truth which such Cognition can reach will therefore be only finite." ${ }^{42}$ The second defect of abstract Cognition, which is an inevitable result of its abstractness, is that it fails to do justice to the nature of the knowing mind; mind is regarded from this point of view too much as an empty vessel to be filled from without. "The finitude of Cognition lies in the presupposition of a world already in existence, and in the consequent view of the knowing subject as a tabula rasa." ${ }^{243}$ For these reasons, therefore, we fail to find in Cognition proper release from the dualism in which the category of Life left us bound; we do not get here the unity for which we are seeking. So we turn next to volition. Can Will supply us with a satisfactory synthesis? At first it seems that it might, since from this point of view the objective falls together with the subjective; objectivity is measured in terms of subjective ideals and aims. But this is just the difficulty with the standpoint. Objectivity is too completely reduced to subjective terms, and therefore really opposes itself to subjectivity; the objective never, in point of fact, becomes subjective and the subjective never really loses itself in objectivity. Thus we are reduced to the eternal Sollen of Fichte. "While Intelligence merely proposes to take the world as it is, Will takes steps to make the world what it ought to be. Will 
looks upon the immediate and given present not as solid being, but as mere semblance without reality. It is here that we meet those contradictions which are so bewildering from the standpoint of abstract morality. This position in its 'practical' bearings is the one taken by the philosophy of Kant, and even by that of Fichte. The Good, say these writers, has to be realized: we have to work in order to produce it: and Will is only the Good actualizing itself. If the world then were as it ought to be, the action of Will would be at an end. The Will itself therefore requires that its end should not be realized. In these words, a correct expression is given to the finitude of Will." ${ }^{244}$ So once again, we are disappointed in our search for unity. "This Volition has, on the one hand, the certitude of the nothingness of the presupposed object; but, on the other, as finite, it at the same time presupposes the purposed End of the Good to be a mere subjective idea, and the object to be independent." ${ }^{245}$ Volition presupposes a discrepancy between what is and what ought to be, a discrepancy which, from the point of view of abstract volition, cannot be eliminated; and so our unity is not yet attained.

But a way to that unity has been suggested. If we could secure a conjunction of what is and what ought to be, if, that is to say, we could combine the standpoints of Cognition proper and Volition in a higher synthesis, then it would seem that we should have reached our goal. For in such a synthesis the subjective would be genuinely objective, and the objective would not stand over against the subjective as something foreign to it but would partake of its very nature. "The reconciliation is achieved, when Will in its result returns to the pre-supposition made by Cognition. In other words, it consists in the unity of the theoretical and practical idea. Will knows the end to be its own, and Intelligence apprehends the world as the Notion actual." 246

This synthesis, according to Hegel, is found in the Absolute Idea. It is here that we get our ultimate unity of the real. It will be well to let Hegel speak for himself on this very vital point. "The truth of the Good is laid down as the unity of the theoretical and practical idea in the doctrine that the Good is radically and really achieved, that the objective world is in itself and for itself the Idea, just as it at the same time eternally lays itself down as End, and by action brings about its actuality. This Life which has returned to itself from the bias and finitude of Cognition, and which by the activity of the Notion has become identical with it, is the Speculative or Absolute Idea." ${ }^{247}$ The following passage is perhaps more explicit: "The Absolute Idea is, in the first place, the 
unity of the theoretical and the practical idea, and thus at the same time the unity of the idea of Life with the idea of Cognition. In Cognition we had the Idea in a biased, one-sided shape. The process of Cognition has issued in the overthrow of this bias and the restoration of that unity, which as unity, and in its immediacy, is in the first instance the Idea of Life. The defect of Life lies in its being the Idea only implicit or natural: whereas Cognition is in an equally one-sided way the merely conscious Idea, or the Idea for itself. The unity and truth of these two is the Absolute Idea which is both in itself and for itself. Hitherto we have had the Idea in development through its various grades as our object, but now the Idea comes to be its own object." 248

The development that we have just traced seems pretty clearly outlined and the goal to which it has led us appears to be very well defined. The category of Life fails as a synthesis of reality, because it is not selfconscious; the categories of Cognition proper and Volition fail, because they are only one-sided representations of self-conscious life; the Absolute Idea succeeds, because it transcends the defects of these lower standpoints. And from this it seems only logical to conclude that the Idea succeeds because it is the unity of Self-consciousness in its completion. "This unity is consequently the absolute and all truth, the Idea which thinks itself — and here at least as a thinking or Logical Idea." ${ }^{249}$ One can see no valid reason why we may not believe that Hegel is in earnest when he says, as above, that "the Idea comes to be its own object," and that "its developed and genuine actuality is to be as a subject and in that way as mind." ${ }^{250}$ On the contrary, the dialectical development- here seems to force us to the conclusion that the category of the Absolute Idea is really a Self-consciousness, a knowing and willing Individual, who 'comes home' to Himself from His differentiations in which $\mathrm{He}$ sees Himself mirrored as it were in His eternal essence, a Personality who exists in and for Himself and realizes His ends in the phenomenal world. For within the unity of the Idea, Life, Cognition, and Volition are blended harmoniously together, and the life of knowledge and the life of activity are one. And Consciousness is the only category that gives us such a unity.

Mr. McTaggart objects to the conclusion which we have here reached; he denies that it is the logical outcome of Hegel's system. He readily grants that, according to the system, the unity of the Idea must be construed in terms of spirit; and he is ready not only to admit but to maintain that the author believed it possible for spirit to exist only in the form 
of personality. ${ }^{251}$ But he contends that we have no right to infer from these premises to the conclusion that this unity of the Idea is a personal unity. "It might be said of a College," he urges, "with as much truth as it has been said of the Absolute, that it is a unity, that it is a unity of spirit, and that none of that spirit exists except as personal."252

This objection, however, seems to rest upon a false notion of the nature of the unity that is defined in the Idea. Hegel himself has told us, "The unity of God is always unity, but everything depends upon the particular nature of this unity; this point being disregarded, that upon which everything depends is overlooked." ${ }^{253}$ Now it seems that Mr. McTaggart has misconceived the unity of the Idea; and consequently his criticism of our conclusion which is based upon this misconception is of no significance. Let us see what can be said in justification of this statement.

In the first place, it is important to notice that Mr. McTaggart thinks of the Idea as absolutely identical with its differences: the unity, as he conceives of it, is nothing more than its differentiations, and they are nothing more than it. For instance, he says: "The individual has his entire nature in the manifestation of this whole, as the whole, in turn, is nothing else but its manifestation in individuals." ${ }^{254}$ Again he takes for granted that Hegel "reaches in the category of Life a result from which he never departs in the subsequent categories - that the unity and plurality are in an absolutely reciprocal relation, so that, while the plurality is nothing but the differentiation of the unity, the unity is nothing but the union of the plurality." ${ }^{255}$ And with this supposedly Hegelian position is contrasted at considerable length Lotze's view, that "the Absolute is to be taken as something more and deeper than the unity of its differentiations." ${ }^{256}$ Thus Mr. McTaggart's conception of the unity of the Idea is hardly mistakable; according to him, this unity consists in the relation of abstract identity between the Idea and its differentiations.

A criticism of the tenability of this doctrine of identity will be undertaken later on in this chapter. Our present purpose is to show that it is not, as Mr. McTaggart assumes it is, Hegel's account of the unity of the Idea. But it will not be amiss, perhaps, to pause here for a moment to point out one or two difficulties involved in this interpretation of the critic. In the first place, if the unity and the differences of the Idea are in exact equilibrium, it is not quite evident that any room is left anywhere for that 'simple and indivisible element' which Mr. McTaggart makes the very quintessence of the personality of finite individuals and upon 
which he bases his argument for their immortality. ${ }^{257}$ On this hypothesis it would appear that the finite individual finds himself as sorely pressed as does the Absolute; for the personality of the former is in just as precarious a predicament as is that of the latter. ${ }^{258}$ In the second place, it is difficult to see where such a unity as Mr. McTaggart insists upon becomes actual; there certainly is room to question whether it is ever actualized. If its actualization is possible, it would have to be in a state of society which yet lies in the far distant future; certainly society has not yet attained unto it. So it would appear to be a unity that ought to be but is not - a conception so vigorously criticized by Hegel. In the third place and finally, the problem of the contingent, which on any idealistic theory short of pessimism is a puzzling one, becomes doubly so on $\mathrm{Mr}$. McTaggart's hypothesis. He seems logically bound to assert either that the finite is perfect, or that the imperfections of the finite, qua imperfections, belong to the essential nature of the Absolute; for the Absolute, it is to be remembered, is its differentiations. ${ }^{259}$ To sum up the whole matter, Mr. McTaggart seems to be between the Scylla of a fictitious unity and the Charybdis of differences that defy conjunction. His universal is one which, after it has succeeded in unifying the universe, itself finds nowhere to lay its head; and his particulars tend either to vanish entirely into the universal, or - this is the more imminent danger - to fly asunder and become discrete entities. And one is inclined to think that this is exactly the difficulty into which, as Hegel points out, Leibnitz fell - the difficulty, namely, of resolving the contradiction between an absolutely self-centered individual and a completely unifying universal that swamps its differences. ${ }^{260}$

But to return from this digression, let us ask concerning the justification of Mr. McTaggart's interpretation of Hegel's meaning. The exact balance which the critic supposes between the unity of the Idea and its manifestations is foreign to the author's conception of the matter. In the first place, the dialectical movement, which we have above outlined, bears out this contention. Contrary to Mr. McTaggart's assertion that in the category of Life Hegel reaches a result from which he never departs, namely, an 'absolutely reciprocal relation' between the unity and its plurality, it may be argued that the development from the category of Life to that of the Absolute Idea consists just in transcending this relation of identity, and in asserting a unity which exists for itself within its differences. It would be hard to say in what respect the Idea is an advance beyond the category of Life, if not in the fact that it unites within 
itself the theoretical and practical elements of the spiritual life. And such a synthesis, as we have seen, is that of consciousness. If this is the result to which Hegel leads us, then the unity of the Idea is more than its differences, more than 'the union of the plurality'; for it is inconsistent with the nature of consciousness to be nothing more than its content. The Idea thus seems to be something deeper than the mere conjunction of its differentiations.

Again, Mr. McTaggart's position on this point is contrary to the result of our previous chapter, that the real for Hegel is the individual. If that result be true, then the Absolute Idea must be an actual synthesis of concrete differences, the differences existing for the synthesis and the synthesis existing in its differences and for itself — such a synthesis as cannot be found in any society (however closely unified) of self-conscious finite spirits. It belongs to the very nature of the individual that its differences be more than the union of themselves, and that its unity be more than the conjunction of its differentiations; in other words, abstract identity of the particulars and the universal is foreign to the essence of the concrete individual. If therefore we are right in our position that Hegel's ultimate synthesis, the Absolute Idea, must be individual in its nature, we are also right in insisting that the synthesis is not identical with its differences. And that we are in the right here the whole first Part of our study bears witness.

Mr. McTaggart's difficulty here is traceable to his failure to appreciate the significance of negation in Hegel's doctrine of thought. For the unity of the Idea is a negative unity, and as such is different from the unity that either destroys multiplicity or itself fails to exist. I shall let Hegel state the matter: "As the Idea is (a) a process, it follows that such an expression for the Absolute as unity of thought and being, of finite and infinite, etc., is false; for unity expresses an abstract and merely quiescent identity. As the Idea is (b) subjectivity, it follows that the expression is equally false on another account. That unity of which it speaks expresses a merely virtual or underlying presence of the genuine unity. The infinite would thus seem to be merely neutralized by the finite, the subjective by the objective, thought by being. But in the negative unity of the Idea, the infinite overlaps and includes the finite, thought overlaps being, subjectivity overlaps objectivity. The unity of the Idea is thought, infinity, and subjectivity, and is in consequence to be essentially distinguished from the Idea as substance, just as this overlapping subjectivity, thought, or infinity is to be distinguished from the one- 
sided subjectivity, one-sided thought, one-sided infinity to which it descends in judging and defiling. ${ }^{261}$ A study of this passage discloses the fact that the unity of the Idea, which is a negative unity, is not the unity of exact equilibrium.

Mr. McTaggart has another objection to raise against the thesis we are here maintaining. He not only asserts that the position which we have attributed to Hegel is not logically involved in his system, - he does admit that the dialectic itself furnishes no positive disproof of it but he also contends that the position is one which Hegel himself did not hold. He thinks that Hegel explicitly repudiates the doctrine of a personal Absolute, and he bases his contention on the conclusion of the Philosophy of Religion. 262 "It seems clear from the Philosophy of Religion," he tells us, "that the truth of God's nature, according to Hegel, is to be found in the Kingdom of the Holy Ghost.... And the Kingdom of the Holy Ghost appears to be not a person but a community."263

Before passing on to examine the basis of this argument, I cannot refrain from quoting a few other passages from various contexts, which seem to be in direct refutation of the contention which the critic is trying to establish. I shall cite only those passages which have explicit reference to the point. In the larger Logic at the beginning of the discussion of the Absolute Idea we read: "The Notion is not only soul but free subjective Notion, which is for itself and, therefore, has personality the practical objective Notion which is determined in and for itself, and which, as person, is impenetrable atomic subjectivity." 264 A page or two below, after having spoken of the method as an immanent form of development, the author says: "The Method thus shows itself to be the Notion which knows itself, and which, as the Absolute, both subjective and objective, has itself for its own object." ${ }^{265}$ Again, in the smaller Logic: "It is true that God is necessity, or, as we may also put it, that He is the absolute Thing: He is however no less the absolute Person. That He is the absolute Person, however, is a point which the philosophy of Spinoza never reached; and on that side it falls short of the true notion of God which forms the content of religious consciousness in Christianity." 266 In the Philosophy of Religion we are told that "God is himself consciousness, He distinguishes Himself from Himself within Himself, and as consciousness He gives Himself as object for what we call the side of consciousness." ${ }^{267}$ And later in the same work occurs a passage which seems to have been written designedly to meet a position like that which Mr. McTaggart attributes to Hegel: "The Divine is not to be conceived 
of merely as a universal thought, or as something inward and having potential existence only; the objectifying of the Divine is not to be conceived of simply as the objective form it takes in all men, for in that case it would be conceived of simply as representing the manifold forms of the spiritual in general, and the development which the Absolute Spirit has in itself and which has to advance till it reaches the form of what is the form of immediacy, would not be contained in it." ${ }^{268}$ The fourteenth lecture on the 'Proofs of the Existence of God' has something to say on the point: "That man knows God implies, in accordance with the essential idea of communion or fellowship, that there is a community of knowledge; that is to say, man knows God only in so far as God Himself knows Himself in man. This knowledge is God's self-consciousness, but it is at the same time a knowledge of God on the part of man, and this knowledge of God by man is a knowledge of man by God." 269 Finally, in the Introduction to the Philosophy of History we read: "It is One Individuality which, presented in its essence as God, is honored and enjoyed in Religion; which is exhibited as an object of sensuous contemplation in Art; and is apprehended as an intellectual conception in Philosophy." 270 To these seemingly quite explicit passages others might be added. ${ }^{271}$ But enough have been quoted to establish at least a presumption that, according to Hegel's own statements on the point, God is not a community of finite spirits but a Personality.

We turn now to an examination of the basis upon which Mr. McTaggart rests his contention. Does the dialectical movement in the Philosophy of Religion, from the Kingdom of the Father, through the Kingdom of the Son, to the Kingdom of the Holy Ghost, justify the conclusion that Hegel conceives of God as nothing more than a community of finite individuals? To this question I think a negative answer must be given. Let us follow this movement in some detail.

There is no reason why we should not agree with Mr. McTaggart that the three stages of the Kingdoms of the Father, of the Son, and of the Spirit form a dialectical triad. And from this, we also agree, it necessarily follows that, "if God is really personal, He must be personal in the Kingdom of Spirit." 272 But one fails to see how these premises lead to the conclusion that the Spirit which manifests itself in the synthesis here cannot be a Personality, an Individual. To be sure we must admit that God, on this showing, is adequately represented only in a community of spirits, since the Kingdom of the Spirit is conceived of as such a community. And, of course, it w ould be absurd to contend that a com- 
munity is, or can possibly be, a person. But it is difficult to see, so much being granted, how we are necessarily committed to the conclusion that in the Kingdom of the Spirit God must be impersonal, or that, when adequately represented, He becomes absolutely identical with the spiritual community in which He finds fullest expression. Such a conclusion is forced upon us only when we assume, with the critic, that God is just His manifestations and nothing more. And on this assumption we could not logically confine the Absolute to any community of self-conscious spirits, - unless, indeed, we are willing to endow all forms of nature w ith spiritual qualities; for Hegel unquestionably maintains that Nature is God's manifestation of Himself. But the assumption is arbitrary and groundless, if our position concerning the unity and individuality of the Idea is true.

Furthermore, this triad, as interpreted by Mr. McTaggart, differs essentially from other triads in the Logic and elsewhere. For his argument necessitates the assumption that the movement here consists in an attempt to get away from an entirely erroneous view of God's nature to a true and fundamentally different view. For example, after insisting that the triad is a genuine dialectical process and that, consequently, we must look for an adequate expression of God's nature only in the synthesis, he continues: "If [God] were personal as manifested in the first and second Kingdoms, but not in the third, it would mean that He was personal when viewed inadequately, but not when viewed adequately i.e., that He was not really personal." ${ }^{273}$ This is the critic's interpretation of the actual movement and result of the triad. This interpretation, however, makes of the triad an exception. For usually in the dialectical triad there is a thread of connection running from thesis to synthesis; the two are never separated by a chasm. But on Mr. McTaggart's interpretation of the triad before us, thesis and synthesis would seem to be torn completely asunder; in the thesis, God is viewed as a Personality, while, in the synthesis, He is defined only as the abstract unity of the Church, and is personal in no sense whatsoever. Thus there is no connection between thesis and synthesis: the synthesis is a mere negation of the thesis. If the synthesis is right, therefore, the thesis must be completely wrong, absolutely false - a fact which we have been in the habit of thinking is not characteristic of a dialectical triad. Mr. McTaggart's argument seems thus to make of the present triad an extraordinary exception.

In point of fact, the movement here is not away from personality to 
impersonality. The dialectic does force us to say that the Spiritual Community is necessary to an adequate representation of the nature of God; but this is very far from saying that God is the Community or that the Community is God. The critic does not refer to any passages in which Hegel speaks of this very significant, and withal very peculiar, turn in the dialectic advance; and I have been able to find none. I have, however, found one in which the identification in question seems to be denied, and it runs so: "This third sphere" (that is, the sphere of the Kingdom of the Spirit, the Spiritual Community) "represents the Idea in its specific character as individuality; but, to begin with, it exhibits only the one individuality, the divine universal individuality as it is in-andfor-itself.... Individuality as exclusive is for others immediacy, and is the return from the other into self. The individuality of the Divine Idea, the Divine Idea as a person (ein Mensch), first attains to completeness in actuality (Wirklichkeit), since at first it has the many individuals confronting it, and brings these back into the unity of Spirit, into the Church or Spiritual Community (Gemeinde), and exists here as real universal self-consciousness." 274 If I understand what this means, it indicates that, as Hegel himself views the matter, the third Kingdom, the Kingdom of the Spirit, is the standpoint where God is first viewed in His true Personality; for here it is that $\mathrm{He}$ is seen to be in vital and actual touch with men and things. Thus it appears that the triad is not a movement from the conception of a personal to the conception of an impersonal God; but rather from an inadequate to an adequate representation of God as personal. He is not pure thought, existing behind the world as it were in infinite space; this is the conception of the thesis. On the contrary, He is that spiritual unity, that 'real universal self-consciousness,' realizing His aims and purposes in the lives of finite self-conscious agents whose aspirations are perfected and consummated in Him. In some such way it seems that the movement here must be understood.

Another fact that militates against Mr. McTaggart's position on this point - at any rate from the point of view of the present essay — is that the culmination of Hegel's discussion of the Spiritual Community is the standpoint of the Notion. The three phases within this discussion Hegel designates as follows: (a) The conception of the Spiritual Community; (b) The realization of the Spiritual Community; and (c) The realization of the spiritual in universal reality (Wirklichkeit). So far as our present purpose is concerned, the first two of these divisions may be dismissed without comment. The third, however, is of interest especially when we 
learn that it "directly involves the transformation and remodelling of the Spiritual Community." 275 It is divided into a threefold movement, which consists in three different attitudes taken towards objectivity. Hegel states this movement in outline thus: "Objectivity as an external immediate world, is the heart with its interests; another form of objectivity is that of reflection, of abstract thought, of Understanding; and the third and true form of objectivity is the Notion. We have now to consider how Spirit realizes itself in these three elements." ${ }^{276}$ The development here outlined is not easily followed in detail. But it seems to consist in tracing the essential features of the faith of the Spiritual Community concerning the nature of the objective order, and the attitudes assumed towards such an objective order. In the first stage, the Spiritual Community has opposed to it a worldly element, which seems to exist on its own account; there is here an opposition between the religious and the secular. In the second stage we swing to the other extreme, in which the objective is practically disregarded and the idea of God, being emptied of content, is reduced to an abstraction; this is that "inner self-enclosed life which may indeed co-exist with calm, lofty, and pious aspirations, but may as readily appear as hypocrisy or as vanity in its most extreme form." 277 The first of these two stages Hegel calls the "servitude of Spirit in the absolute region of freedom"; the second is "abstract subjectivity, subjective freedom without content." ${ }^{278}$ The final stage is, as we would expect, the reconciliation of these two extremes. It discovers that freedom, real intelligible freedom, is to be found only in the objective, that objective and subjective, when they are adequately comprehended, fall together. This is the standpoint of philosophy. "What we have finally to consider is that subjectivity develops the content out of itself, but it does this in accordance with necessity - it knows and recognizes that the content is necessary, and that it is objective and exists inandfor-itself. This is the standpoint of philosophy, according to which the content takes refuge in the Notion, and by means of thought gets its restoration and justification." 279 The objective within the Community, therefore, must be known to be in-and-for-itself before the community has attained complete and perfect actualization; and this knowledge is reached only when philosophic comprehension is substituted for intuitive faith. Thus we are once again brought to our former problem concerning the real nature of the Notion and its significance in Hegel's system. If the form of the Notion is individuality, then it would seem that, on the above showing, the Spiritual Community is perfected only 
when its unity is actualized.

It is to be noted, furthermore, that in philosophy and not in the Spiritual Community, as such, is to be found the true realization of the object of Absolute Religion. The Spiritual Community, "in attaining realization in its spiritual reality," falls into "a condition of inner disruption"; and so "its realization appears to be at the same time its disappearance."280 "For us," however, "philosophical knowledge has harmonized this discord," and we have "rediscovered in revealed religion the truth and the Idea." ${ }^{281}$ And from this it seems evident that the nature of ultimate reality is to be sought, not in the Spiritual Community, but in the Idea. We are thus sent back to the study of the dialectic for an answer to our question concerning the Absolute; and we have already seen what answer the dialectic gives.

The foregoing considerations force us to question the validity of Mr. McTaggart's contention that, for Hegel, the Absolute is nothing more than a community of self-conscious spirits. But this interpretation of Hegel may be traversed from another point of departure. I think that it can be shown that a community of self-conscious persons - however close the unity that binds them together - is not, in Hegel's opinion, and cannot be an adequate representation of the unity of the Idea. And it can be shown in some such way as the following.

In one place Hegel tells us that the state is "the divine Idea as it exists on earth." 282 In another passage he speaks of the state as an 'actual God,' and defines it as "the march of God in the world." ${ }^{283}$ In yet another context he says: "It is in the organization of the state that the Divine has passed into the sphere of actuality." ${ }^{284}$ Looked at from the other side, the state is conceived of by Hegel as the highest form of human society. According to the plan which is sketched in the Philosophy of Mind and elaborated at length in the Philosophy of Right, the state is viewed as the choicest product of the moral life, it is "the selfconscious ethical substance." 285 The very highest point that the Objective Mind can attain unto in its strivings towards divinity is the unity of the state; this is the most truly real form of social union. If now it can be shown that Hegel does not admit that Mr. McTaggart's doctrine of a community of self-conscious beings is an adequate expression of the essential nature of the state, then we may safely conclude that he would not admit that the total nature of reality is exhausted in such a community.

Concerning the unity of the state, this highest unity of society, Hegel's 
position is expressed unequivocally in both the Philosophy of Mind and the Philosophy of Right, and in the latter at some length. Put in a word, his position amounts to an insistence that the function of the prince or monarch is absolutely essential to the ideal state, that no state is complete apart from this personal expression of its unity, and that this conclusion is necessitated by a consideration of the idea or notion of the state apart from accidental circumstances of time or place. The unity of the commonwealth, he urges, must be actualized in a personality before it becomes a real unity, or before the state is perfectly organized: the rational articulation of the state demands this incarnation of its unity. "We usually speak of the three functions of the state," says Hegel, "the legislative, executive, and judicial. The legislative corresponds to universality, and the executive to particularity; but the judicial is not the third element of the conception." ${ }^{286}$ This third element, we are immediately told, is to be found in the function of the prince; this is the synthesis of the other two functions of the state, and in this they are brought together in a personal unity. Apart from this expression of the will of the state in the will of the monarch the state is not organized according to the nature of the Notion.

This is not merely an interesting point which Hegel happens to mention incidentally in his theory of the state. It is one upon which he lays special emphasis. I shall quote some of these emphatic passages. "It is easy for one to grasp the notion that the state is the self-determining and completely sovereign will, whose judgment is final. It is more difficult to apprehend this 'I will' as a person.... This 'I will' constitutes the greatest distinction between the ancient and the modern world, and so must have its peculiar niche in the great building of the state. It is to be deplored that this characteristic should be viewed as something merely external, to be set aside or used at pleasure." 287 Again: "The conception of monarch offers great difficulty to abstract reasonings and to the reflective methods of the understanding. The understanding never gets beyond isolated determinations, and ascribes merit to mere reasons, or finite points of view and what can be derived from them. Thus the dignity of the monarch is represented as something derivative not only in its form but also in its essential character. But the conception of the monarch is not derivative, but purely self-originated."288 Once more: "Personality or subjectivity generally, as infinite and self-referring, has truth only as a person or independent subject. This independent existence must be one, and the truth which it has is of the most direct or immediate 
kind. The personality of the state is actualized only as person, the monarch. ... A so-called moral person, a society, community (Gemeinde), or family, be it as concrete as it may, possesses personality only as an element and abstractly. It has not reached the truth of its existence. But the state is this very totality in which the moments of the conception gain reality in accordance with their peculiar truth." ${ }^{289}$ Again: "When a people is not a patriarchal tribe, having passed from the primitive condition which made the forms of aristocracy and democracy possible, and is represented not as in a wilful and unorganized condition, but as a self-developed truly organic totality, in such a people sovereignty is the personality of the whole, and exists, too, in a reality which is proportionate to the conception, the person of the monarch." ${ }^{290}$ Finally: "In the government — regarded as organic totality — the sovereign power (principate) is subjectivity as the infinite self-unity of the Notion in its development; - the all-sustaining, all-decreeing will of the state, its highest peak and all-pervasive unity. In the perfect form of the state, in which each and every element of the Notion has reached free existence, this subjectivity is not a so-called 'moral person,' or a decree issuing from a majority (forms in which the unity of the decreeing will has not an actual existence), but an actual individual - the will of a decreeing individual nonarchy. The monarchical constitution is therefore the constitution of developed reason: all other constitutions belong to lower grades of the development and realization of reason." 291

Now what do all these passages mean?292 At least one strain runs through them all; and that is, that the unity of the state, before it can become real and rational, must be embodied in an actual form, must find expression in an actually existent person. The state which has not the power of uttering this 'I will' - it matters not how intrinsically insignificant the 'I will' may be; it may mean nothing more than the simple signing of the name - is not a completely articulated organization: it lacks an essential function. No merely organic whole is a rational expression of the nature of the state; the unity must be embodied in a personal form which has actual, concrete existence.

This being true, we have good reason to deny that Mr. McTaggart's conception of the unity of the ultimately real - a unity which, as we have pointed out, never really becomes actual - can legitimately be attributed to Hegel. Of course argument from analogy is always dangerous; and no claim is made here that we should be justified in drawing positive conclusions concerning Hegel's doctrine of the unity of the Idea 
solely on the basis of his doctrine of the unity of the state - though it is indubitably true that the analogy is much more significant than one is apt to think, apart from a very careful reading of the author's statements on the point. But it does seem justifiable to conclude that, if an actualized unity is essential to the very idea of the state, the unity of ultimate reality could not be an unrealized, and, one is inclined to say, an unrealizable ideal. If no community of individuals, however organically related they may be, adequately expresses the rational organization of the state - and this thesis Hegel unquestionably maintains - we can be practically certain that the synthesis of ultimate reality cannot be found in any community of self-conscious spirits, however organic or superorganic that community may be and however deep its harmony. The argument is a simple a fortiori one. Hegel emphatically asserts that a group of individuals is not an adequate representation of this 'actual God' on earth: surely, he would be the first to deny that it is a perfect representation of the essential nature of the Absolute Idea. At any rate, the burden of proof seems-to be on those who deny the validity of this conclusion. So we seem to have shown the inadequacy of $\mathrm{Mr}$. McTaggart's interpretation of Hegel from another point of departure. ${ }^{293} \mathrm{I}$ am forced to believe, however. that such an objection would be very much mistaken. A careful reading of the relevant portions of the Philosophy of Right will impress one with the fact that Hegel was really in earnest when he contends, as quoted above, that "the monarchical constitution is the constitution of developed reason," and that "all other constitutions belong to lower grades of the development and realization of reason." He apparently is firmly convinced that in his theory of the state he is presenting the form that Spirit assumes in its most nearly perfect institutional manifestation (see especially Werke, Bd. VIII, §§258, 272, and 279). His own explicit statements bear witness to his sincerity in the matter. To those quoted above we might add such as these: "When thinking of the idea of the state, we must not have in our mind any particular state, or particular institution, but must rather contemplate the idea, this actual God, by itself." (Ibid., §258.) "In the organization of the state, that is to say, in constitutional monarchy, we must have before us nothing except the inner necessity of the idea. Every other point of view must disappear. The state must be regarded as a great architectonic building, or the hieroglyph of reason, presenting itself in actuality. Everything referring merely to utility, externality, etc., must be excluded from a philosophical treatment.” (Ibid., §279.) We thus 
have sufficient evidence, it would seem, to justify us in asserting that Hegel gives us the doctrine of the state which he honestly believes is most nearly the expression of the logical implications of his system. Even if we grant that he was prejudiced in working out this theory, as he undoubtedly was in details, still we must admit that he bases his theory more or less directly on the doctrine of the Idea; and admitting so much, the above argument from analogy holds.

Let us bring together the results of our discussion. Our conclusion is that Hegel's Absolute is an infinite Consciousness, a Personality, who synthesizes in His own experience the experiences of all. "An infinite intelligence, an infinite spiritual principle, which is manifested in finite minds though not identical with them" - such, we agree with Professor Adamson, ${ }^{294}$ is Hegel's doctrine of ultimate reality. And this conclusion we have based upon the dialectic movement in the triad of Life, Cognition, and the Absolute Idea, as well as upon direct statements that Hegel has made regarding the problem. The Hegelian Absolute, we have seen, cannot be identified with a community of self-conscious spirits, as Mr. McTaggart contends. There seems to be no justification for such an interpretation of Hegel either in the final triad of the Logic or in the final triad under Absolute Religion. In the former we pass beyond the exact balance between the unity and its differences to the category of selfconsciousness, where the unity exists for itself in its differentiations; in the latter we are ultimately brought back to the Idea and told to look there for the answer to our question about the nature of God. Furthermore, such a community of spirits as Mr. McTaggart imagines we found would not be adequate to express even the nature of the state as Hegel defines it. Thus from another point of departure we were led to question whether such a community could adequately represent Hegel's synthesis of ultimate reality. For it seemed that, if a personal unity is essential to the nature of the state, we might justly conclude that the synthesis of the real, of which the state is only an imperfect copy, could hardly be less than a personal unity.

This conclusion that the Absolute is a self-conscious Individuality, leads us to a further problem that we must here face. And that problem is concerning the relation between such an Absolute and the world of finite existence. Granting that the Absolute is a self-conscious Personality, in what relation must we say that He stands to our own finite world? The remaining portion of this chapter will be taken up with an attempt to answer this question. 
A first glance at the problem might lead one to conclude that only two solutions of it are possible, and that either solution is fatal to the doctrine of the personality of the Absolute. For it would seem that we must admit either that there is or that there is not an Other to the Absolute. And with this admission we find ourselves in a dilemma. For, on the one hand, if there be in the universe something besides the Absolute, an Other that has the least degree of reality in its own right, then it apparently follows that the Absolute is limited by this Other, is, in other words, not the Absolute. "The slightest suspicion of pluralism, the minusest wiggle of independence of any one of its parts from the control of the totality would ruin it. Absolute unity brooks no degrees, - as well might you claim absolute purity for a glass of water because it contains but a single little cholera-germ. The independence, however infinitesimal, of a part, however small, would be to the Absolute as fatal as a cholera-germ." 295 On the other hand, if there be no Other to the Absolute, if there be nothing in the universe that can claim reality on its own account apart from its relation to the Absolute, then pantheism is our only conclusion. Evidently, if our theory merges everything into the Absolute, it is nothing short of pantheism. So it would seem that the doctrine of a personal Absolute leaves us either in contradiction with ourselves or in a pantheistic metaphysics; and from this dilemma there seems to be no way of escape.

Perhaps it is hardly necessary to say that Hegel wastes no words in arguing for a limited Absolute; he does not fall into self-contradiction on this point. For him the Absolute is the only true reality; all else has its reality, not in itself, but in the Absolute. Concerning Hegel's position here there can, presumably, be no question. On the other hand, there need be no hesitancy whatsoever in asserting that, in Hegel's own mind at any rate, his system is not pantheistic. Pantheism he often denounces as a mistaken theory of reality; he constantly urges that to conceive of the Absolute as the One Reality in which all particularity loses its significance is completely erroneous. Whatever may be the relation that he teaches exists between the Absolute and the finite world, it certainly is not the relation of identity, which, in his opinion, exists between the Spinozistic Substance and its Accidents: indeed, it is just in contradistinction to this doctrine of Spinoza that Hegel is at pains to define his own. As Hegel views the matter, then, neither pantheism nor a finite God is the conclusion to be drawn in answer to our problem.

But how does he find a way of esape from the dilemma? In both the 
Philosophy of Religion and the Philosophy of Mind, Hegel tells us that he is not unaware that his theory may be misconstrued as pantheistic; and he is careful to point out the oversight on which the misconstruction rests. The point he makes is this: the interpretation overlooks the distinction between the Absolute as Substance and the Absolute as Subject. "Those who say that speculative philosophy is pantheism generally know nothing of this distinction; they overlook the main point, as they always do, and they disparage philosophy by representing it as different from what it really is." 296 This distinction being forgotten, unity is construed to mean only abstract identity. "In accordance with that superficiality with which the polemic against philosophy is carried on, it is added, moreover, that philosophy is a system of Identity.... But those who speak of the philosophy of Identity mean abstract unity, unity in general, and pay no attention to that upon which alone all depends; namely, the essential nature of this unity, and whether it is defined as Substance or Spirit.... What is of importance is the difference in the character of the unity. The unity of God is always unity, but everything depends upon the particular nature of the unity; this point being disregarded, that upon which everything depends is overlooked." ${ }^{297}$ It is, then, in the nature of the unity that Hegel expects to find a way out of the difficulty.

Of course the unity which Hegel is here emphasizing is the unity of the Notion. This unity of the Notion it is which he thinks satisfactorily explains the relation of the Absolute to the world of particularity. This is evident from a glance at the Logic. For it is this unity of the Notion that is the culmination of the dialectical development of the categories and receives complete expression in the category of categories, the Absolute Idea. This unity it is, therefore, that is the ultimate expression of reality, the final statement of the relation between God and the world. What, now, is this unity of the Notion? If the interpretation of Hegel given in the present study is not fundamentally false and all of our arguments up to this point totally vicious, it seems that we are forced to say that the unity of the Notion is the category of self-consciousness.

This is the conclusion that is forced upon us by the Phenomenology of Spirit; the Notion is the life of mind. Likewise, the Logic teaches us the same lesson: since the Absolute Idea is the ultimate expression of the unity of the Notion, it follows, if the Absolute Idea is a self-conscious Individual, that the unity of the Notion, that unity which explains the nature of reality, must be self-consciousness. Indeed, this seems to be 
just the point that Hegel has in mind, in numerous passages in the History of Philosophy, the Philosophy of Religion, the Philosophy of Mind, and elsewhere, in which he draws a distinction, as he does in the passages cited above, between the definition of the Absolute as Substance and his own conception of the Absolute as Spirit, or Subject, and urges that the latter definition offers the only way of escape from pantheism in our metaphysics. It is in the category of self-consciousness, therefore, that we are to look for an exemplification of the unity of the Notion.

Let us try to see how this category aids us in our present problem. In attempting to do this, we shall first briefly analyze self-consciousness to discover its fundamental characteristics; and then we shall, on the basis of this analysis, see what must be our conclusions concerning an Absolute Consciousness. For it seems certain that, if we are to argue at all concerning a personal Absolute, we must rest the discussion on an analysis of finite consciousness; there is no other basis of discussion. At any rate, this is what Hegel does, as the Phenomenology shows; and we are interested primarily in setting forth his doctrines and their justification.

Whatever other characteristics finite self-consciousness may have, there are three which can hardly be called in question. The first of these is that consciousness always has a content. By that I mean that there is always something other than the consciousness itself, which exists as the object of it. Apart from this objective reference consciousness is the veriest abstraction. ${ }^{298}$

The second characteristic of consciousness is that it always includes its content as something essentially its own. The content is not received by consciousness as if it were a stranger to be momentarily entertained and then lost forever: on the contrary, the content is the very life of the consciousness that possesses it. As Hegel would say, spirit finds the object to be bone of its bone and flesh of its flesh, and so all alienation between the two has disappeared. This characteristic of the conscious life needs some emphasis; we have so formed the habit of thinking that the content is an element foreign to consciousness, that we are prone to forget the abstraction that is responsible for the habit. It requires only a little reflection, however, to bring to light the vital unity that exists between consciousness and its content - a unity that is absolutely fundamental to the integrity of each. The last characteristic of consciousness that I would call attention to is this: consciousness is never identical with, but is always something more than, its content. Notwithstanding 
the fact that the content is always received by consciousness as its very own, as its other self in fact, still there is a distinction between the two that never disappears; consciousness and its content never fall together in an undifferentiated identity.

The fundamental importance of these three characteristics of consciousness, as well as their vital interconnectedness, may be emphasized by a brief analysis of self-consciousness. It is evident that as a self-conscious being I am of a two-fold nature. In the first place, I am a bundle of sensations, feelings, impulses, desires, volitions, and ideas. This is the object-self. And from this point of view I am eternally changing. At any moment of my existence I am never what I have been, or shall be, at any other moment. At one instant I am a center of impulses and passions; at another, a centre of ideas and ideals. To-day I am a self of pleasures; tomorrow, a self of pains. An everlasting panorama of change, a veritable Heracleitean flux — this is what the objectself really is. But there is another fact about this self-consciousness that must be taken into account; so far we have considered only one side of it. It is true that I am eternally changing, that I am not what I have been heretofore, and that I shall never be again just what I am now. And yet, paradoxical as it may sound, what I have been I am, and what I am I shall be. Underlying the panorama of change, deeper than the self that is in a never-ceasing process of transformation, is another self that gives unity and coherence to the process. This is the subject-self. And this it is that makes education, spiritual development in general, possible; without it our experience would be at best but a chaos of meaningless sensations and incoherent desires. These two aspects or phases seem to be present in all self-consciousness. Take a cross-section of consciousness at any moment, and you will discover that it is of this two-fold nature. Even in our moments of most intense introspection, when we enter as intimately as possible into ourselves, we find that this duality is present; indeed, one is inclined to say, it is then that its presence is most strongly impressed upon us.

It is to be noticed, moreover, that the duality is absolutely essential to self-consciousness. Not only do we find it actually present in selfconsciousness; the implication of experience is that it must exist so long as consciousness itself exists. For selfconsciousness is just this duality: the subject-self and the objectself exist only as they co-exist. This fact may be illustrated by the consciousness that we possess just as we are falling asleep. In proportion as this duality is overcome does the waking 
consciousness sink away; and it rapidly returns when the attention becomes fixed upon some object and the duality, unknown and unexperienced in the land of dreams, is restored. And normal waking consciousness illustrates the same truth. He is most truly self-conscious who sinks himself, as we say, in the object that occupies the focus of consciousness; this is the ethical import of the doctrine of self-abnegation. ${ }^{299}$ But this sinking of the self in the object attended to does not destroy the difference between the self and the object; rather does it intensify the duality. For the object absorbs attention only in proportion as it harmonizes with a set of purposes and interests that are themselves clearly defined. To take a concrete case, let us suppose that I am intensely interested in a botanical specimen. Here there is evidently a unity of subject and object; indeed, it would be difficult to differentiate the two, and the difficulty would increase with the increase of my interest in the specimen. And yet, clearly, there is a difference. The specimen grasps my interest only as it makes its appeal to a self whose centre of being is more or less clearly defined; and the more significant the hold of the specimen on my attention, the deeper and more significant must have been my training in the science of botany. If I am a mere tyro in botanical investigations, the specimen would not make the same appeal as it would were I thoroughly versed in the subject; and the difference is that in the former case the appeal would be made to a less thoroughly developed self. The unity, and consequently the duality, is not as clearly defined in the former case as in the latter. The very unity of consciousness thus seems to be organically bound up with this dual relation of subject and object.

And from this follows immediately a further result. Since this duality is essential to consciousness, these two phases of subject and object cannot fall into identity with each other. Take any case of consciousness that you please, whether it be consciousness of objects in the mental or in the physical world. Do you find there a coincidence between subject and object? Certainly not. The object is never its own consciousness; there is, and can be, no identity between them. It is inconsistent with the very nature of consciousness that these two phases collapse into identity. As Professor Royce says, "When we are aware only of unity, it appears that we then become aware of nothing at all." ${ }^{300}$ The presupposition of consciousness is that there shall be something, an object in the physical world, an object in the mental world, something other than the consciousness itself, of which the consciousness shall be. The two can- 
not be identical with each other.

But this essential duality within consciousness must not be misconstrued as a dualism. In his famous deduction of the categories, Kant unfortunately speaks too much as if the subjectself were superimposed on the object-self as something essentially foreign to it. But the real lesson he has to teach us in that deduction is a deeper one. And that lesson is that the unity and the differences within conscious experience are really one, that there is no chasm between them. It is true that the data which constitute the object-self seem to be facts drawn from a world external to that self, or, at any rate, external to the synthetic unity that binds these data into a unitary and organic whole. But both of these positions fall before criticism, for the data are vitally concerned in their own organization. We must admit that Kant has once for all shown us, at least by implication if not explicitly, that the object-self is not foreign to the subject-self: the data of the Sensibility and the categories of the Understanding are common expressions of one fundamental principle. And this implication of the Kantian philosophy becomes explicit in Hegel. The burden of the Phenomenology, as we saw in our first chapter, is that these two selves are organically bound up with each other, and that, if we are to speak accurately, we must call them, not two selves, but only two points of view from which we look at the one self - subjectobject. And it seems that we are forced to say that this is the verdict of experience. Consequently, to view these two phases of consciousness in isolation is to view them abstractly. Of course, this abstraction is perfectly justifiable, indeed, necessary from the standpoint of the particular sciences; but it is dangerous for metaphysics. Whether the emphasis is placed upon the subject or the object is a matter of indifference so far as the metaphysical difficulty involved in their separation is concerned; metaphysically, they are not separable. The data of the object-self get their reality only when organized by the categories of the subject-self; and, on the other hand, the categories are essentially those data, otherwise it is incomprehensible how the organization could possibly take place. Thus the separation between the two is overreached and the two fall together. They are different, and yet they are one such seems to be the paradoxical relation existing between the two sides of consciousness.

The results of our analysis of finite self-consciousness are these. The characteristics of consciousness are that it has a content, that it differs from this content, and yet at the same time is one with it. More- 
over, each of these is a condition that must be met, if consciousness is to exist at all. If the content is removed, then of course consciousness is destroyed, because there is nothing of which the consciousness could be. Likewise, if consciousness and its content are identified, consciousness ceases, for the identification simply amounts to the removal of the content; and here again the essential duality is done away with. Finally, if a chasm is made between consciousness and its content, consciousness again is made impossible; when an impassable barrier is erected between the two, the duality upon which consciousness depends is once more removed. ${ }^{301}$ This three-fold condition is the presupposition of all finite consciousness.

Now it would seem that, on the basis of this analysis of finite consciousness, we should be justified in making the following assertions concerning an Absolute Consciousness. In the first place, such a Consciousness would necessarily have a content; that is, there would have to be an Other of which the Absolute is conscious. In the second place, this Other would not be regarded by the Absolute as something foreign or external, in the sense that it lay genuinely outside of the Absolute; rather would it be possessed as an essential element within the Absolute. And, lastly, the Absolute would necessarily differentiate this Other from itself in such a way as to preserve the duality that we have found to be essential to the conscious life. And our justification for making these assertions concerning an Absolute Consciousness is simply that these characteristics which we have attributed to the Absolute are those that experience shows us to be fundamental to all consciousness as we know it; and unless we are to reduce our discussions to meaningless logomachy, we must test them by concrete experience. Certainly it seems that we must assume that the conditions prerequisite to finite consciousness must be fulfilled in an Absolute Consciousness.

What now must be our answer to the dilemma with which we began our discussion? In the first place, it would seem that we have found a way of escape from pantheism in our doctrine of the Absolute. For so long as we maintain the self-consciousness of the Absolute, we are forced to maintain also that the Absolute and the world are differentiated from each other. Really, pantheism is logically possible only to the metaphysician who denies the self-consciousness of the Absolute. For pantheism, if it means anything, means identity between the Absolute and the world of finite existence; whatever form the theory may take, it ultimately reduces everything in the universe to an undifferentiated unity 
with the all-inclusive One. But, if the Absolute be regarded as a selfconscious Individual, this abstract identity becomes impossible; because, as our analysis of the category has disclosed, consciousness always demands a content from which it is differentiated. Destruction of this duality is the destruction of the possibility of consciousness. Therefore no theory that maintains that the Absolute is Self-Consciousness can legitimately be accused of pantheism so long as it is consistent. ${ }^{302}$

But have we escaped the other horn of our dilemma? Our own argument has forced us to admit that an Other to the Absolute is essential; indeed, it is this fact that relieves us from any fears concerning pantheism as the outcome of our doctrine. And have we not virtually limited the Absolute by positing this Other, which our analysis of consciousness has compelled us to assume is necessary? The answer to this objection is involved in what we have just been saying about the fact that the two extremes of the equation of consciousness are not foreign to each other; and it might perhaps be sufficient simply to point to this fact in meeting the objection. But, since this criticism against the doctrine of the personality of the Absolute is so general, and that, too, amongst Idealists of a certain type, it seems well in concluding this discussion to devote some attention to it.

I have chosen Mr. McTaggart as the representative of this type of criticism, because his objections are advanced immediately in connection with a study of Hegel's system. ${ }^{303}$ His views can best be expressed in his own words: "The Absolute is a unity of system, and not a unity of centre, and the element of unity in it cannot be a simple and indivisible point, like that of the finite self. For if the unity is of this sort, then, by virtue of its simplicity and indivisibility, it excludes its differentiation from itself in one sense, while including them in another. But the Absolute cannot exclude its differentiations from itself in any sense.... There is nothing outside of the Absolute. And it would therefore be impossible for it to exclude its differentiations from itself in any sense. For in as far as they are not in it, they are absolutely wrong. ${ }^{304}$

In order to evaluate this objection, we must again look at consciousness and ask concerning its real nature. As we have already pointed out, consciousness always demands a content with which it is never identical; without such a content consciousness is nothing but an empty abstraction. Consciousness presupposes differentiations, and in some sense it is true that these differentiations are excluded from it. But this is not the whole story; there is another aspect of the conscious life that we 
cannot afford to overlook. Consciousness not only excludes its differentiations, it also includes them. The exclusion is never absolute; the content is a vital part of the consciousness; in a very important sense it is the consciousness. Consciousness overreaches the distinction between itself and its content and takes the content up into itself, so that the content, though different from, yet is one with the consciousness. As Edward Caird aptly puts it, "The self can be conscious of itself as so distinguished and related, only in so far as it overreaches the distinction between itself and its object." ${ }^{305}$ Thus it is that the self or consciousness may be said both to include and exclude its object; and the fact of inclusion is complementary to the fact of exclusion. Inclusion does not mean the abstract identity of subject-self and object-self; nor, on the other hand, does exclusion mean their abstract opposition. Consciousness includes its various differentiations, because they are its differentiations; it excludes them, because they are its differentiations. Inclusion and exclusion are only different names for the same fact, just as are the concave and convex sides of a curved line.

If, now, we are to argue on the basis of finite consciousness concerning the nature of Absolute Consciousness — and, I repeat, I know of no other basis on which to argue - it would seem that we are forced to conclude that such a Consciousness, granting its existence, would necessarily at once include and exclude its differentiations. Every object in the world would be included in such a Consciousness, because every object in the world would be an object for such a Consciousness. But the inclusion would not, could not, be that of identity. For every object in the world would have to be excluded from such a Consciousness, since no object in the world would actually be that Consciousness. ${ }^{306}$ And the exclusion could not be abstract opposition; the differentiations would still be differentiations of the consciousness for which they exist. The Absolute Consciousness, like all other consciousness, would be confined to the circle of its own differentiations: this we seem forced to admit. But the differentiations of the Absolute, like the differentiations of finite consciousness, would be differentiations still: this also we seemed forced to admit. And with this we have admitted the inclusion and the exclusion of the differentiations of an absolute Consciousness. As Hegel remarks, "God is Himself consciousness, He distinguishes Himself from Himself within Himself, and as consciousness He gives Himself as object for what we call the side of consciousness." ${ }^{307}$ This is exactly what every finite consciousness does in its own limited way: it gives itself as 
object, distinguishes itself from itself within itself, and is at once knower and known, possessor and possessed, subject and object. Such seems to be the paradox of consciousness as such; there is nothing inherently contradictory or absurd about it - unless, indeed, consciousness itself is an absurdity.

Thus we are forced to say that Mr. McTaggart's objection to the doctrine of a personal Absolute rests upon a misconstruction of the true import of the category of self-consciousness. The objection stands or falls with the contention that, if the Absolute were to exclude its differentiations from itself, those differentiations would either cease to be real or stand as a limitation to the Absolute. Now this contention holds only on the condition that the Absolute is forced to oppose to itself its differentiations as something entirely beyond and foreign to it. But it is the very nature of consciousness not to do this, if our analysis has been correct. For as we have repeatedly seen, perhaps to the point of weariness, consciousness is a duality within unity; and if you destroy either the unity or the duality, you utterly annihilate the conscious life. And it seems evident that, if you construct a chasm between consciousness and its differentiations, you do irreparable violence to the unity between the two. At your touch both consciousness and its differentiations vanish into nothingness. There is no meaning in talking about the exclusion of something by consciousness, unless that something is included in consciousness; for consciousness excludes its differentiations just by virtue of the fact that it includes them. To argue, therefore, that an Absolute Consciousness is impossible because it cannot abstractly oppose itself to its differentiations is exactly as convincing as it would be to argue that finite consciousness is impossible because it cannot do the same. You could argue either way indifferently and with equal success in both cases; for your demand sins against the presupposition of all consciousness. Of course an Absolute Consciousness is impossible, provided it is so by definition; but why define it so? It seems to be no more inherently absurd than finite consciousness, and there can be no question that finite consciousness is an actuality.

It is interesting to notice that this objection of Mr. McTaggart is inconsistent with his own analysis of finite consciousness. Speaking in another context of the finite self, which he grants is 'sufficiently paradoxical,' he says: "What does it included Everything of which it is conscious. What does it exclude? Equally - everything of which it is conscious. What can it say is not inside it? Nothing. What can it say is not 
outside it? A single abstraction. And any attempt to remove the paradox destroys the self. For the two sides are inevitably connected. If we try to make it a distinct individual by separating it from all other things, it loses all content of which it can be conscious, and so loses the very individuality which we started by trying to preserve. If, on the other hand, we try to save its content by emphasizing the inclusion at the expense of the exclusion, then the consciousness vanishes, and, since the self has no contents but the objects of which it is conscious, the content vanishes also." 308 Now I submit that, if Mr. McTaggart stands consistently by the position here stated he cannot argue that consciousness, whether finite or absolute, can exclude its differentiations in any sense in which it does not at the same time and ipso facto include them. And this is the ground upon which his objection against the doctrine of a personal Absolute, as I comprehend it, rests. To say that the finite self excludes its differentiations in a manner that would be impossible to the Absolute assumes the very point at issue, and so begs the whole question. Does the finite self exclude its differentiations in a manner impossible for the Absolute? Certainly not, if we are willing to accept Mr. McTaggart's analysis of finite consciousness. The finite self, he tells us, includes everything of which it is conscious, and it excludes everything that it includes. But, be it noted, it does not cease to include because it excludes: inclusion and exclusion, we are told, are 'inevitably connected.' If, now, finite consciousness at once includes and excludes its differentiations, is there anything absurd in the position that Absolute Consciousness may do the same? If the finite consciousness is a differentiation of the Absolute just because of its paradoxical nature - and this, we must remember, is the basis upon which Mr. McTaggart rests his argument for the immortality of the individual - may it not be that the Absolute itself embodies this paradox par excellence? If inclusion and exclusion by consciousness are correlative terms, why is it impossible for a perfect Consciousness to include everything in the universe and yet at the same time and just for that reason exclude it? Why, in short, would it be necessary for the infinite and perfect self to fail just in that respect which constitutes the very essence of the finite and imperfect self? Arguing in this vein appears to be an approach to absurdity; and yet this seems to be the position into which Mr. McTaggart is forced by his own analysis of consciousness. ${ }^{309}$

The whole difficulty with Mr. McTaggart's position may be put in very brief compass. His objection rests upon the disjunction with which 
we began: either pantheism or a finite God, either abstract identity between the absolute and its differentiations or a limited Absolute. But this disjunction depends upon an abstract view of the nature of consciousness. For it implies that consciousness must be either identical with or abstractly opposed to its differentiations, that the Absolute either is the world or must regard the world as something essentially foreign to itself. This disjunction, however, plainly flies in the face of experience. As we have tried to show, and as Mr. McTaggart himself has pointed out, consciousness and its differentiations are neither identical nor yet opposed to each other: they are 'inevitably connected,' and each lives in the life of the other. And when we make a violent separation between them, or assume a position that implies this separation, we should not forget the fact that the possibility of finite consciousness, as well as the possibility of an Absolute Consciousness is thereby denied - simply because we then have done away with the presupposition of all consciousness. And this suggests to us that it would be well to investigate experience further, before we commit ourselves to a position that leads to such singularly disastrous results. This essential unity of the Absolute and its Other Hegel emphasizes in his exposition of the philosophical import of the Christian dogma of the Incarnation. ${ }^{310}$ In this dogma we have expressed in religious terms the philosophical truth that "the divine and human natures are not implicitly different." In Jesus Christ is manifested the Universal, God; the contingent and accidental circumstances of temporal life are disregarded by Him. "Who is my mother and my brother?" "Let the dead bury their dead." But Christ is not only God; he is also the Son of Man, the Man of Sorrows. In his death we have evidence of the fact that He shares the common fate of all human beings; indeed, "in Him humanity was carried to its furthest point," since he died the aggravated death of the evil-doer. This Personality, which reaches to the glories of the Infinite, touches also, by virtue of its divinity, the lowest abyss of the finite. The true lesson of the Incarnation, Hegel would seem to say, is that God is not high and lifted up beyond the world of time and place; but that $\mathrm{He}$ is also here, and that it is only here that $\mathrm{He}$ finds full and complete expression. God's Other is His own very Self, and not an existence beyond Him.

In conclusion, then, we may say that, as Hegel views the matter, the puzzle of God's relation to the world is to a considerable extent one of our own making. By a process of abstraction we separate God from the world, and then proceed to ask how we are ever to get them together 
again; we destroy their essential interconnectedness, and then raise the cry that their relation to each other is to us incomprehensible. Consequently, we must either take refuge in an impotent faith or be content to remain sceptics and agnostics. "The 'reflective' understanding begins by rejecting all systems and modes of conception, which, whether they spring from heart, imagination, or speculation, express the interconnection of God and the world: and in order to have God pure in faith or consciousness, he is as essence parted from appearance, as infinite from the finite. But, after this partition, the conviction arises also that the appearance has a relation to the essence, the finite to the infinite, and so on: and thus arises the question of reflection as to the nature of this relation. It is in the reflective form that the whole difficulty of the affair lies, and that causes this relation to be called incomprehensible by the agnostic." ${ }^{311}$ Hegel's own solution of the problem, which he proceeds to outline for us in the paragraph from which this passage is taken, is to be found on a plane which transcends the point of view of the 'reflective understanding'; and his solution consists really in pointing out that the separation that gives rise to the problem is the result of abstract thinking. This more concrete standpoint he calls the Notion of the speculative Reason, which is, in the last analysis, the category of self-consciousness.

\section{Notes}

1 This statement may be easily misconstrued and should be hedged about with reservations. Since, however, these reservations are to be developed later, I content myself here with merely calling attention to the fact. As we shall see below, the assertion that Hegel deals in the Logic with thought in abstraction is not equivalent to the assertion that he there deals with abstract thought. The reader is asked kindly to regard the above statement as a preliminary one. to be read in the light of what is to follow.

2 Werke, Bd. II, p. 6.

3 Ibid., p. 21.

4 Ibid., p. 64.

5 Ibid., p. 67.

6 Cf. The Origin and Significance of Hegel's Logic, Chapters VI, VII.

7 Phänomenologie des Geistes. p. ciii.

8 Op. cit., pp. 19-20.

9 Werke Bd. III. p. 32. 
10 Enc., §25.

11 Philosophical Review Vol. VI, p. 500.

12 Hegel und seine Zeit, p. 255.

13 Ibid., p. 256.

14 Professor Baillie identifies absolute knowledge with Absolute Mind

(cf. Hegel's Logic, pp. 186 ff.). urging that in the category of absolute knowledge "the standpoint of Absolute Mind has been fully and unequivocally adopted" (ibid., p. 189). This identification seems to me, however, to contribute only to confusion. The point of interest to Hegel in the Phenomenology is the removal of the opposition which at first appears to exist between consciousness and its content. And this he does in the category of absolute knowledge. But when this is accomplished, we have not passed beyond the realm of finite consciousness at all; we have only seen finite consciousness in its true import. The standpoint of absolute knowledge is implicit in all finite consciousness; this fact Professor Baillie insists upon (see ibid., pp. $190 \mathrm{ff}$.). Why, then, baldly identify the category with the standpoint of the Absolute? If we insist on the identification here, we at least shift the emphasis from the point to be emphasized, namely, that this penetration of its object by consciousness is involved in every stage of consciousness from the sensuous up. It may be that absolute knowledge implies the existence of Absolute Mind, but this is another matter; it is simply a confusion of the point at issue here to identify the two.

15 Werke. Bd. V, pp. 324-325.

16 Metaphysics, Bk. I, Chap. vii. §88.

17 See Haym's criticism of Hegel on this point, op. cit., pp. $235 \mathrm{ff}$.

18 Enc., §41. lecture-note (2).

19 Loc. cit.

20 Werke, Bd. IV, p. 127.

21 Enc $\$ 60$, lecture-note (2).

22 Werke, Bd. VIII p. 63 (Philosophy of Right, trans., p. 37).

23 Philosophical Review, Vol. 1, p. 135.

24 See Professor Bosanquet's discussion on this point in Proceedings of the Aristotelian Society, 1905-1906, Vol. VI, pp. $237 \mathrm{ff}$.

25 Werke. Bd. V, p. 237.

26 Werke. Bd. I, p. 178.

27 Bk. III, Chap. i. §309.

28 Werke, Bd. VIII. p. 34 (Philosophy of Right, trans. p. 11). 
29 Philosophical Review, Vol. VI, p. 502.

30 Enc., §19.

31 Werke, Bd. III, p. 26.

32 Ibid. p. 33.

33 Enc., §215.

34 Studies in the Hegelian Dialectic, §14. Compare with this conception of thought Lotze's view of thought's first activity as the process by means of which the immediately given impressions of sense are converted into ideas (Logic, trans., Vol., pp. $13 \mathrm{ff}$ ).

35 Cognition is 'finite' because its content has the appearance of a datum, a 'given,' independent of it and existing in its own right. From the standpoint of the 'Notion,' however, the content is no longer regarded as a foreign element; it is rationalized. (Cf. Werke, Bd. V, pp. 266-268.)

36 Werke Bd. XII, pp. 267-268 (Philosophy of Religion, trans., Vol. III, p. 163).

37 Logic, Bk. III, chap. i, §308.

38 Principles of Logic, p. 533.

39 See Bosanquet's Logic. Vol. I. pp. 63 ff.

40 Enc. $\$ 163$, lecture-note (I).

41 Werke, Bd. XV, p. 516 (trans., Vol. III, p. 441).

42 Enc. $\$ 379$.

43 Enc., $\$ 11$.

44 Ibid., $\$ 24$.

45 Werke, Bd. IX, p. 12.

46 Werke, Bd. VIII, p. 33 (trans., p. II).

47 Enc., $\$ 471$.

48 Studies in the Hegelian Dialectic $\$ 104$.

49 Loc. cit.

50 See, in this connection, an article entitled "Experience and Thought" by Professor Creighton in The Philosophical Review, Vol. XV, pp. $482 \mathrm{ff}$. "Thinking or rationality is not limited to the process of abstract cognition, but it includes feeling and will, and in the course of its development carries these along with it. There is, of course, no such thing as what we have called abstract cognition; but the different moments are all united in the concrete experience which we may name the life of thought" (pp. 487-488).

51 Cf. especially op. cit., $\$ 206$.

52 Cf. Appearance and Reality, Chap. xv. 
53 Microcosmus. Bk. VIII, Chap. i. §8.

$54 \mathrm{Mr}$. Bradley would seem to think that discussion on this point is a matter of terminology. For example, in Appearance and Reality. he says that. if one chooses. One may call that fuller experience, which is an adequate synthesis of the real, thought. "But," he adds. "if anyone else prefers another term, such as feeling or will, he would be equally justified. For the result is a whole state which both includes and goes beyond each element; and to speak of it as simply one of them seems playing with phrases." (p. 171). I am persuaded. however, that the point is more fundamental than such an attitude indicates. And I am also persuaded that he who would escape the conclusion that the abstract particular has a part in ultimate reality must ultimately concede Hegel's contention, - always provided we are in earnest about equating reality with experience. See Hegel, Werke, Bd. XI. pp. 129-130.

55 Hegelianism and Personality, pp. 133-134. I quote from the second edition. Cf. also McTaggart, op. cit., ibid $§ 194$ ff. To mediate the 'this,' he asserts, would be to destroy it. Cf. Lotze, Logic, Book III, Chap. i. $\S 308$.

56 Philosophy of Lotze, p. 273. Cf. Bosanquet. Logic. Vol. II, p. 207 : "In an absolute tautology which excludes or omits difference, identity itself disappears and the judgment vanishes with it."

57 Enc., $\$ 573$.

58 Studies in Hegelian Dialectic. $\$ 181$.

59 Werke, Bd. II, pp. 16-17.

60 Enc., $\$ 78$.

61 Werke, Bd. III, p. 56.

62 Enc., $\$ 65$.

63 Cf. ibid., $\$ 70$.

64 Cf. Werke, Bd. XV, pp. 496 ff. (Hist. of Philos., trans. Vol. III, pp. $420 \mathrm{ff}$.).

65 Werke Bd. XI, p. 158 (Philos. of Relig., trans., Vol. I, p. 162).

66 Werke, Bd. II, p. 16.

67 Ibid., p. 14.

68 Werke, Bd. XV, pp. 597-598 (Hist. of Philos., trans., Vol. III, p. $525)$.

69 Werke, Bd. XIII, p. 55 (Hist. of Philos., trans., Vol. I, p. 41).

70 Werke Bd. II, p. 101. Quoted by A. W. Crawford, Philosophy of P. H. Jacobi, p. 43. 
71 Ibid., p. 59. See N. Wilde, Friedrich Heinrich Jacobi, pp. $63 \mathrm{ff}$. 72 Werke Bd. XV, p. 549 (Hist. of Philos., trans., Vol. III, p. 475).

73 Werke Bd. III, p. 53. See in this connection Wallace, Prolegomena, p. 45; also Levy-Bruhl, La Philosophie de Jacobi, pp. 257-258. 74 Werke Bd. XI, p. 52 (Philos. of Relig., trans., Vol. I, p. 51).

75 Werke, Bd. XV, p. 551 (Hist. of Philos., trans., Vol. III, p. 477). 76 Enc §63. See also Werke, Bd. XV, pp. 489 ff. (Hist. of Philos., trans., Vol. III, pp. 413 ff.).

77 Werke, Bd. XV, pp. 362-363 (Hist. of Philos., trans., Vol. III, pp. 282-283).

78 Ibid., p. 498 (ibid., p. 422).

79 Enc., $\$ 62$.

80 Werke, Bd. XVII, pp. 10 ff.; Enc., $\$ 50$.

81 Werke, Bd. XI, pp. 58-59 (Philos. of Relig., trans., Vol. I, p. 58).

82 Enc., $\$ 74$.

83 Ibid.

84 Cf. Werke, Bd. V, pp. $328 \mathrm{ff}$.

85 Enc., 112.

86 Enc.. $\$ 552$.

87 Werke, Bd. II, p. 44; see also pp. 43, 45.

88 Enc., $\$ 442$.

89 Enc., $\$ 50$.

90 Werke, Bd. V, p. 330.

91 Werke Bd. III, pp. 38-39.

92 Werke Bd. V, p. 331; notice also immediately following pages.

93 Cf. Enc., $\$ 173$.

94 Principles of Logic, p.118.

95 Cf. Bosanquet, Logic Vol. 1, pp. 293 ff.

96 It might be objected here that such a judgment as 'The soul is not an elephant gives us no positive knowledge whatsoever. I grant that the objection is true, but I deny its relevancy, since we are here dealing with significant judgments. This so-called judgment sins against the presupposition of all judgment, and consequently is really no judgment. From the standpoint of epistemology, the infinite judgment does not exist.

97 Werke, Bd. III, p. 7.

98 Ibid.

99 In this connection see Professor G. H. Sabine, "The Concreteness of Thought," The Philosophical Review, Vol. XVI, pp. 154-169. 
100 Cf. Hegel und seine Zeit, p. 331.

101 Will to Believe, p. 273.

102 Logische Undersuchungen, Bd. I, p. 56. I translate from the third edition.

103 Cf. Studies in Hegelian Dialectic, §§8, 9, 109, 117, etc.

104 Principles of Logic, p. 138.

105 Ibid., p. 140.

106 Enc., §24.

107 Ibid., $\$ 162$.

108 Cf. Werke, bd. V, p. 231. Notice also Hegel's frequent statements concerning the contingent.

109 A word should be said here to prevent a possible misconception.

This coincidence of logic and metaphysics must not be construed to mean that the logical categories, as universals, destroy the particularity of being. The identification is not supposed to deny the reality of the factual side of existence; it does not do away with 'existential reality.' That this is Hegel's position will be developed below, when he come to ask concerning the relation that Hegel conceives to exist between these two phases of experience. One should never forget that, in Hegel's view of the matter, the Logic has to be supplemented by the Philosophy of Nature and the Philosophy of Mind.

110 Werke, Bd. III, pp. 31-32.

111 Ibid., p. 57. These two quotations from the Logic are given by Professor McGilvary in his admirable discussion on "The Presupposition Question in Hegel's Logic," The Philosophical Review, Vol. VI, pp. $497 \mathrm{ff}$. This discussion seems to me to put the question beyond dispute. If the reader is interested in this problem and desires an exhaustive discussion of it, he could not do better than to turn up those pages.

112 Werke,. Bd. II. pp. 28-29. In this connection the following passage from the Philosophische Propaedeutik is significant: "Science presupposes that the separation of itself from the realm of truth has been done away with, that Spirit no longer belongs to mere phenomena, as is the case in the doctrine of consciousness ... Science does not seek the truth; it is in the truth, indeed, it is the truth itself" (Werke, Bd. XVIII, p. 94). And this presupposition we have seen to be the actual result of the Phenomenology.

113 Vera, Introduction a la Philosophie de Hegel, pp. 179-180.

114 Werke, Bd. III, p. 44. 
115 Ibid., p. 33.

116 Enc., $\$ 19$.

117 Ibid., §82.

118 Werke, Bd. III, pp. 33-34.

119 Cf. ibid., pp. 24-25; see also Enc., §160.

120 Enc., §160: also §164.

121 Enc., §133, lecture-note.

122 Cf. Werke, Bd. II, p. 35; also Enc., §82.

123 See in this connection Caird, Hegel, p. 157; Wallace, Prolegomena to Hegel's Logic, pp. 302 ff.; and McGilvary, op. cit., pp. 504-507. 124 Enc., $\$ 160$. See also $\$ 43$, lecture-note.

125 Werke, Bd. III, pp. 7-8.

126 There are two further points in connection with the Logic, which, though they are hardly relevant to our present purpose, should not be passed over in silence. I refer to the problems concerning the beginning of the Logic and its empirical basis. One or two general remarks here will have to suffice.

Concerning the beginning of the Logic, it may be said without fear of successful contradiction that the first of the categories is not a lineal descendant from the conclusion of the Phenomenology the Phenomenology is not the presupposition of the Logic in this sense. To be sure, the category of Being must be viewed in the light of the Phenomenology for without the development of the Phenomenology Being would hardly be possible as a concrete category. And in this respect the beginning of the Logic is a mediated immediacy, as Hegel himself suggests. (Cf. Werke, Bd. III, pp. 58, 59) But when we turn from the Phenomenology and look upon the development of the logical categories as such, Being becomes very abstract. Thus viewed, it is not on a level with absolute knowledge, but rather, one is inclined to say. with the beginning of the Phenomenology: in the realm of the Logic, Being is what Sensuous Consciousness is in the Phenomenology — the most abstract and unmediated standpoint. In a word, then, we may say that the beginning of the Logic, viewed as such, is abstract and immediate; but that it must be regarded as in a sense mediated, since it presupposes the entire development of the Phenomenology. (For further discussion of this problem see Professor McGilvary and Mr. McTaggart. Mr. McTaggart's position entirely ignores the Phenomenology, and so does not take account of the mediated aspect of Being. 
It has been objected that Hegel illogically smuggles experience into the Logic as the basis of its development. (Cf. Trendelenburg, op. cit., pp. 36 ff.; and Haym, op. cit., pp. 318 ff.) This objection seems to be groundless. Of course the basis of the Logic is experience, but Hegel is not inconsistent in making it so. As we have pointed out above, the presupposition of the Logic is concrete experience; for it is with concrete experience that the Phenomenology has to do. To assert, therefore, that the Logic deals with blank universals, and that it gets its only plausibility by dragging experience in at the back door after having ostentatiously kicked it out at the front, is to show plainly that the real problem and presupposition of the Logic have been misconceived. The objection is an admirable illustration of the danger involved in an attempt to criticize the Logic taken apart from its context in the system. And so far as one can see, Mr. McTaggart's answer to Trendelenburg's objection illustrates the same danger. (Cf. op. cit., $\S \S 30-43$ ) If one were compelled to confine oneself to the smaller Logic for data on the problem - as Mr. McTaggart does one feels that the verdict would have to be in favor of Trendelenburg's position. It seems more than doubtful whether Mr. McTaggart's argument is adequate to meet the objection against which it is advanced, simply because it fails to take the right point of departure. Personally, I cannot see that the argument has at all succeeded in establishing the point at issue; and, striking in where it does, it seems to me to be hopelessly defective. In point of fact, however, both objector and defender are beating the air. For both the objection and the defense fail to take any account of the author's real position, which can be seen only in the light of the Phenomenology.

127 Pp.111-113.

128 Werke, Bd. V, pp.342-343.

129 Enc., \$244.

130 Cf. The Pathway to Reality, Vol. II, pp. 68-69.

131 Cf. Werke, Bd. VIl, i. pp. 25 ff.' Werke, Bd. V, p. 44; Enc., §43, lecture-note.

132 Cf. Werke, Bd. V, p. 341. See also Enc., §244, lecture-note.

133 History of Modern Philosophy, trans., p. 489.

134 See op. cit., p. 181.

135 Hegel und seine Zeit, p. 255.

136 Cf. Gesch. d. n. Philosophie, Bd. VIII, i, p. 574.

137 This point should never be forgotten in connection with Hegel's 
system. He never denied the necessity of a science of nature and a science of social values.

138 Hegel tells us that "the other philosophical sciences, the Philosophy of Nature and the Philosophy of Mind, take the place, as it were, of an Applied Logic, and that Logic is the soul which animates them both" (Enc. §24. lecture-note (2)).

139 Op. cit., p. 305.

140 Cf. Werke, Bd. V. p. 342.

141 Enc., $\$ 43$.

142 Werke, Bd. V, p. 318.

143 Cf. La Logique de Hegel, pp. 116 ff.

144 Op. cit.. \$27.

145 Doubtless Professor Pringle-Pattison would object here, as he teas objected elsewhere, that it is time to leave off trying to defend Hegel against adverse criticism by complaining that he has been misunderstood. And there is ground for the objection - though one is inclined to doubt whether it has been the misfortune of any other philosopher to be more universally misunderstood. The assertion unsupported by evidence, however, is puerile. My only excuse for reasserting it here is that, if this study has not erred from the beginning, the statement loses its dogmatic character and assumes for itself a basis of justification. For it is my purpose to establish the assertion in the light of the conclusions we have already reached, and to maintain that its justification rests upon the validity of those conclusions.

$146 \mathrm{Pp}, 117-118$. I quote from the second edition.

147 Op. cit., Vol. I, p. 121.

148 Werke, Bd. III, p. 33.

149 Cf. op. cit.. pp. 573-576.

150 Hegelianism and Personality, pp. 126-127.

151 It should be noted that Hegel's frequent 'snort of contempt' is reserved exclusively for the category of Being which presumes to exhaust the nature of ultimate reality.

152 For the quotations here given, see op. cit., pp. 128-134.

153 For justification of this assertion concerning Hegel, I refer the reader to the following chapter of this study. There can be no question concerning Professor Pringle-Pattison's position. In the Scottish Philosophy (p. 170) he very emphatically tells us that "the particular as particular - the mere self-identical unqualified particular - nowhere exists; it is the abstraction of a logic not wholly clear about its 
own procedure. And the thing-in-itself is simply the fallacy of the mere particular in another form. The mere particular and the mere universal are alike abstractions of the mind; what exists is the individual." And when we inquire further as to what we are to understand by the individual, we are informed that it is "a particular that is also universal, or, from the other side, it is a universal - a set of universals - particularized." Or, in other words, it is "identity through difference," "difference subsumed into identity." I shall point out later that this is exactly Hegel's conception of the real, namely, a universal particularized, or, as he himself puts it ('Enc., §167), "a universal which is individualized." As regards the ultimate nature of the system of reality, Hegel and his critic may disagree; but they are in full accord that that which is real can be neither an abstract particularnor a blank universal, but must be a particularized universal.

154 A word concerning Professor Pringle-Pattison's inconsistency on this point may not be amiss. In From Kant to Hegel, by way of criticism of Fichte's implicit assumption that the object is something more than its manifestations, we read: "The noumenon is always a fuller knowledge as yet unreached by us, and so each category has its own validity and function. But it is not an unattainable reality, and to exalt this useful distinction of thought into a barrier which thought is unable to surmount is simply to fall down and worship our own abstractions. A philosophy which remains entangled in this opposition must inevitably end in the paradox that the real is what cannot be known" (pp. 46-47). A passage of similar import occurs in the Scottish Philosophy, pp. 173-174. One is at a loss to know how to reconcile these passages with the one in Hegelianism and Personality (pp. 137-138), in which the opinions of Trendelenburg and Mr. Bradley, to the effect that the real is inaccessible by way of ideas, are quoted with approval. Perhaps the inconsistency here is due to a change of view on the part of the author. I have presumed to call attention to it, because it concerns such a vital epistemological problem.

155 Microcosmos, Book VIII, Chapter $1, \S 8$. The quotation is from the translation of the fourth edition.

156 Enc., $\$ 19$. See the lecture-note also.

157 Enc., §24. lecture-note (1). The doctrine of thought upheld by Hegel is discussed throughout this entire chapter on the 'Preliminary Notion.'

158 The writer has no desire to defend the letter of Hegel's system; the 
preceding discussion simply aims to be faithful to the spirit of his system. It is true that the time has come to leave off trying to defend Hegel by complaining that he has been misunderstood. But it is also true that the time has come when the critics of Hegel's doctrines should penetrate beneath the formality of his philosophy and bring to the surface its basic principles. Were this done. there would be much less useless and valueless criticism than one finds at present. In many instances criticisms stand self-refuted, if only their presuppositions are disclosed.

159 See in this connection Hegel's own words quoted above (Chapter 1) from the Encyclopaedia, section 573. There Hegel states as plainly as possible that there is a marked difference between abstract identity and his doctrine of the unity of the Notion. And upon this difference he rests his case.

160 Abstractness of thought and the attempt to deduce existence from it were early repulsive to Hegel. Cf. 'Werke, Bd. 1. pp. $119 \mathrm{ff}$.; also Kuno Fischer, op. cit., pp. 267-268.

161 Cf. Werke, Bd. VII. i, pp. 16-17.

162 Werke, Bd. III, p. 35.

163 Werke, Bd. 1, p. 178.

164 Werke, Bd. V, p. 329.

165 Logic, Vol. I, pp. 2-3.

166 In the present chapter I use the terms experience and reality interchangeably. This, I think, is true to the spirit of Hegel's system.

167 Werke, Bd. IV, p. 3.

168 Werke, Bd. VII, I, p. 15.

169 Werke, Bd. II, p. 15.

170 Werke, Bd. V, p. 20.

171 Cf. Enc., $\S 22,112$, etc.; also the preface to the Phenomenology. 172 Readers will bear in mind that the term thought is used throughout this discussion in the meaning attached to it by Hegel.

173 Cf. Werke, Bd. VII, I, pp. 16-17.

174 Werke, Bd. XVIII, p. 90.

175 Werke, Bd. xv, p. 389 (History of Philosophy, trans, Vol. III, p. 309).

176 Enc., §74.

177 I may be permitted in this connection to record my feeling that the indeterminate act of will upon which free-willists of a certain type are wont to insist in their arguments for freedom is nothing but such 
an abstract particular. It matters not that they try to make their position plausible by splitting the world into a medley of meaningless possibilities in order to find a haven for the would-be category of 'chance'; the difficulties still remain. For is it possible to attach any meaning to this notion of 'chance'? Is it anything more than an expression of ignorance? Of course, the indeterminist will answer that it means mere negativity. But to the question as to what is here meant by negativity nothing more satisfactory than a tautological answer is given. And even granting that, as Professor James asserts, chance "is a purely negative and relative term, giving us no information about that of which it is predicated, except that it happens to be disconnected with something else" (Will to Believe, pp. 151-154), and granting further that a meaning can be attached to the term as thus defined, what about the event of volition that is supposed to be made possible by it? Can it be anything more than an event which has absolutely no relation to the series in which it occurs, and so an event that is only an abstract unrelated particular? It would seem to be an event in time that, apparently, takes place with other events and yet possesses no real, intelligible relation to them. What such an event could possibly be one is at a loss to conceive. It presents the rather odd appearance of being one among other unrelated absolutes - since every voluntary act is presumably the result of 'chance' - within the limits of a finite experience; and it would be difficult to think of a bigger nest of contradictions than is revealed by such an unsightly state of affairs.

178 Werke, Bd. XIII, p. 112 (History of Philosophy, trans., Vol. I, p. 95).

179 An appreciation of the difference between the universal of cognition, the formal concept. and the Hegelian doctrine of universality, the Notion, is absolutely fundamental to an understanding of the present justification of Hegel. It is unfortunate that we have no terms in English to express, explicitly. this difference.

180 Hegel's Logic, pp. 339 ff.

181 Ibid., p. 373.

182 See in this connection the entire twelfth section of the smaller Logic.

There Hegel points out how thought cannot rest in its 'unrealized universality' apart from the facts.

183 See E. H. Hollands, "The Relation of Science to Concrete Experience." The Philosophical Review, Vol. XV, pp. 614-626.

184 Studies in the Hegelian Dialectic, §181. 
185 Ibid., $\$ 189$.

186 Ibid., $\$ 193$.

187 Ibid., §203.

188 Ibid., §206.

189 Werke, Bd. IX, p. 12.

190 Enc $\$ 471$.

191 Enc., $\$ 133$, lecture note.

192 Werke, Bd. VIII, p. 34 (Philosophy of Right, trans., p. II).

193 Werke, Bd. XIII, p. 68 (History of Philosophy, trans., Vol. I, p. 54).

194 Logic, Vol. I, pp. 62-63.

195 Enc., §163.

196 The above is not intended as a criticism of the disciplinary value of formal logic as a course of study. The criticism is directed at formal logic as a theory of knowledge. Undoubtedly. formal logic has a disciplinary value; but there can be no question about its abstractness. 197 Cf. Vol. I, pp. 63 ff.

198 For an elaboration of this doctrine of the concreteness or thought, see the article by Professor Sabine, already referred to. (The Philosophical Review, Vol. XVI, pp. 154-169.)

199 Cf. Werke, Bd. XVII, p 30.

200 Cf. Werke, Bd. v.; also Enc., I. 150 ff.

201 Enc., §163, lecture-note (I).

202 Werke, Bd. VIII., §270 (Philosophy of Right, trans.. p. 270).

203 Enc., §181.

204 See the preface to the Phenomenology of Spirit.

205 Cf. Enc., $\$ 160$ ff.; also Werke, Bd. V.

206 Cf. Werke, Bd. V, p. 31.

207 Cf. Enc., §193.

208 Ibid., $\$ 213$.

209 Ibid., $\$ 163$.

210 Werke, Bd. V, p. 58.

211 Enc., 171.

212 Ibid., §163, lecture-note (2).

213 Ibid., $\$ 164$.

214 Ibid., §192, lecture-note.

215 "Transition into something else is the dialectical process within the range of Being: reflection (bringing something else into light), in the range of Essence. The movement of the Notion is development: by 
which that only is explicit which is already implicitly present." (Enc., $\S 161$, lecture-note.)

216 Enc., §20. Quoted in Hegelianism and Personality. p. 137.

217 Logische Untersuchungen, Bd. II, p. 230.

218 Principles of Logic, pp. 63, 69.

219 Enc., §167.

220 See Professor Pringle-Pattison's emphatic words on this point in Scottish Philosophy, p. 170.

221 Conception of God, p. 258.

222 Principles of Logic, p. 64.

223 As I understand Hegel, this is just the principle upon which he is insisting when he makes immediacy and mediation conterminous. For him there is no 'given': a bare fact, or datum, is as pure an abstraction as is the unrelated particular with which he would identify it. See here Professor Sabine, "The Concreteness of Thought," The Philosophical Review, Vol. XVI, pp. 155-156.

$224 \mathrm{Mr}$. McTaggart looks for the synthesis in emotion as opposed to feeling (Studies in Hegelian Cosmology, §§282 ff.). But this seems hardly to meet the difficulty - that is, if you abstract emotion from its rational principle of unity; for such abstract emotion could hardly furnish us with the synthesis for which we are seeking.

225 It might be well for those who uphold the doctrine that is here objected to if they would study more carefully the Transcendental Deduction of the Categories in the Critique of Pure Reason Kant's one lesson there is that the categories are essential to immediate experience.

226 Cf. Hegel's Logic, pp. $340 \mathrm{ff}$. for the criticism and the passages here cited.

227 Ibid.. p. 373.

228 Students of Kant will see here simply an attempt to apply the lesson of the Transcendental Deduction.

229 Logic, Vol. I, p. 77.

230 The World and the Individual. first series, pp. 55-56.

231 Hegel's Logic, p. 348.

232 An Idealistic Construction of Exprience, pp. 67-68. It will be noticed that this passage is a very telling criticism of the point of view advocated in the entire last chapter of Hegel's Logic; and, if the one is true, it would seem that the other must be false. So far as I am aware, the author has passed over this contradiction in silence. 
233 Is not the search for an adequate representation of the nature of such a comprehensible whole the task of philosophy? And if such a task is inherently impossible, is, indeed, absurd, then is philosophy worth the pains? Seeking an ideal which is essentially unattainable. but which, were it miraculously attained, would annihilate us, seems on the face of it to be a rather profitless, or it may be dangerous, business; chasing the rainbow for the bag of gold at its end would appeal more strongly to the timorous. Hegel humorously remarks that, on this theory, "thought is capable of comprehending one thing only, its incapacity to grasp the truth and see into it, and of proving to itself its own nothingness, with the result that suicide is its highest vocation." (Philosophy of Religion, trans., Vol. III. p. 161.)

234 See Mr. Bradley's statements on this point in Appearance and Reality, pp. $167 \mathrm{ff}$. Mr. Bradley and Hegel have practically the same ideas on the problem, the difference being that Mr. Bradley insists on narrowing the term thought to what Hegel would call 'finite' thought. Hegel would seem to have the advantage over Mr. Bradley in this respect at least, namely, that he does give us an intelligible unity of reality whereas Mr. Bradley leaves his Absolute in a rather confused and chaotic condition. And one is inclined to suspect that Hegel's advantage emerges from this difference in doctrine concerning the nature of thought.

235 I use the term 'personality' as synonymous with selfhood or selfconsciousness.

236 It may be said that in a sense Hegel makes a distinction between the terms Idea and God, giving to the latter a religious coloring. But he insists over and over again that the object of philosophy and the object of religion do not differ from each other, but are essentially the same. For speculative reason the terms Idea, God. and the Absolute are synonymous. (Cf. Leighton, The Philosophical Review, Vol. V, pp. 609-610. Cf. Hegel Philosophy of Religion, trans., Vol. 1, p. 19; Vol. II, p. 348.)

237 Enc. $\$ 221$, lecture-note.

238 Ibid.

239 Enc. §216, lecture-note.

240 This standpoint will not be confused with the more comprehensive one also called Cognition in the translation - of which it is simply the first stage. Volition being the second.

241 At present the particular sciences make no claim to this ability; 
generally speaking, they see quite clearly that ontological problems do not fall within their sphere. But this has not always been true.

242 Enc., §226.

243 Ibid., lecture-note.

244 Enc., $\$ 234$, lecture-note.

245 Enc., §233.

246 Enc., §234, lecture note.

247 Enc.. $\$ 235$.

248 Enc., §236, lecture note.

249 Ibid.

250 Enc., §213.

251 Cf. Studies in Hegelian Cosmology, Chapter II; also Chapter III, $\S 63$.

252 Ibid., §63.

253 Werke, Bd. XI, p. 97 (Philosophy of Religion, trans., Vol. I, p. 100).

254 Studies in Hegelian Dialectic, $\$ 186$.

255 Studies in Hegelian Cosmology, §35.

256 Ibid. This idea is expressed in $\S \S 51,63$, etc.

257 Cf. ibid., §§85 ff.

$258 \mathrm{Mr}$. McTaggart escapes this difficulty by inconsistently making the finite individual more than a mere manifestation of the whole; there is something unique about the individual, after all, that falls outside the unity that binds him to others.

259 It is only fair to mention that Mr. McTaggart anticipates this charge and denies its justice ( $\S 38-39)$. In spite of this, however, I urge it because it seems to me that it becomes unwarranted only when the conception of an absolutely reciprocal relation between the Absolute and its differentiations is definitely abandoned.

260 Enc., $\$ 194$.

261 Enc., \$215.

262 Cf. Studies in Hegelian Cosmology, §§214-218.

263 Ibid., §63.

264 Werke, Bd. V, pp. 317-318.

265 Ibid., p. 320; see also p. 339.

266 Enc., §151, lecture note.

267 Werke, Bd. XII, p. 192 (trans., Vol. II, p. 329).

268 Ibid., p. 284 (trans., Vol. III, p. 74).

269 Ibid., p. 496 (trans., Vol. III, p. 303). Curiously enough Mr. 
McTaggart cites this passage in support of his interpretation (Cosmology, §224).

270 Werke, Bd. IX, p. 66 (trans., p. 55).

271 See especially the Introduction to the third volume of the larger Logic.

272 Studies in Hegelian Cosmology. §216.

273 Ibid.

274 Werke, Bd. XII, p. 309 (Philosophy of Religion. trans., Vol. III, pp. 100-101).

275 Ibid., p. 340 (trans., ibid., p. 134).

276 Ibid., p. 341 (trans., ibid., p. 135).

277 Ibid., p. 346 (trans., ibid. p., 141).

278 Ibid., p. 350 (trans. Ibid., p. 145).

279 Ibid.

280 Ibid., p. 354 (trans., ibid., p. 149).

281 Ibid., p. 355 (trans., ibid., p. 151).

282 Philosophy of History, trans., p. 41.

283 Werke, Bd. VIII, \$258 (Philosophy of Right, trans., p. 247).

284 Werke Bd. XII, p. 343 (Philosophy of Religion, trans., Vol. III, p. 138).

285 Enc. $\$ 535$.

286 Werke, Bd. VIII, §272 (Philosophy of Right, trans., p. 277).

287 Ibid. \$279 (trans., pp. 290-291).

288 Ibid. (trans., pp. 287-288).

289 Ibid., (trans., p. 287).

290 Ibid., (trans., p. 289).

291 Enc. \$542.

292 Of course, no attempt is made here either to give an exhaustive account of Hegel's conception of the state or to defend his theory. What we are interested in is simply to point out his insistence on the rational necessity of a personal ruler.

293 It may be objected that all this talk about the unity of the state is beside the issue. In developing this doctrine of the state, it may be said, Hegel was only trying to justify the then existing government of his own country; his elaborate arguments were wrought out primarily in the interests of the Prussian monarchy, and not from the objective point of view of the Idea. Therefore, it may be concluded, these arguments have absolutely nothing to do with the logic of Hegel's system, and any interpretation that takes serious account of them is 
useless.

294 Development of Modern Philosophy, Vol. 1, p. 281.

295 James, Pragmatism, p. 160.

296 Werke, Bd. XI, p. 93 (Philosophy of Religion, trans., Vol. I, p. 96). 297 Ibid., p. 97 (trans., ibid., pp. 99-100).

298 I use the terms 'content, and 'objective reference' as synonymous.

An objection might be raised to this use of the terms. But perhaps the objection would rest upon a misconception of my meaning. What I have in mind when I say 'content' of consciousness is simply that object, or group of objects, whatever it may be, to which the consciousness refers. And this I take to be practically what one would mean by the 'objective reference' of consciousness. If my meaning is clear, I do not care to dispute about the use of words.

299 It seems to me false psychology and vicious logic to identity selfconsciousness and the feeling of self as opposed to a not-self as Professor Taylor does in his argument against the selfhood of the Absolute (Elements of Metaphysics, pp. 336. 343-345). Awareness of self as contrasted with a not-self, so far as I can see, is not at all essential to self-consciousness. It is a matter of common speech that a man is most truly his own self when he is least conscious of a more or less disconcerting not-self. The logical problem of selfhood, or self-consciousness, is one thing; the psychological problem of the origin of the sense of self as opposed to an other is another thing. 300 Outlines of Psychology, p. 90.

301 It appears to me that the 'wandering adjective' theory of idealists of Mr. Bradley's type approaches dangerously near this catastrophe. 302 This, I should say. is sufficient answer to all such criticism as that which Professor James is persistently making of what he cells 'absolutism.' Over and over again throughout his works he takes it for granted that the 'absolutist' must reduce the entire world of finite existence into an undifferentiated identity with the Absolute; and his objections to the position all rest on the simple assertion that such a reduction cannot take place, since the perseity of the finite is more than a state of consciousness for the Absolute. But this is not the position of the 'absolutist' who upholds the doctrine of a self-conscious Absolute. Indeed, such a position is impossible for him. For his argument that the Absolute is self-conscious precludes an effort (even if he had any intention of making one) to reduce the finite world to an identity with the Absolute. 
303 Professor Taylor has advanced practically the same objections as those of Mr. McTaggart. See Elements of Metaphysics, pp. $343 \mathrm{ff}$. 304 Studies in Hegelian Cosmology, §86; see also §66. 305 Hegel, p. 182.

306 What would constitute individuality, or thing-ness, from the standpoint of the Absolute is a problem that demands separate discussion. I have no intention of solving it off hand by the use of the term 'object' here.

307 Werke, Bd. XIII. p. 192 (Philosophy of Religion. trans., Vol. II, p. 329).

308 Op. cit., $\$ 27$.

309 One is led to suspect that the inconsistency in Mr. McTaggart's position here is due primarily to a confusion that arises from his terms 'inclusion' and 'exclusion.' Apparently, he does not always succeed in divesting the terms of their spatial reference. When he enlarges on the impossibility of the Absolute's 'excluding' its differentiations from itself, he seems to think of the latter as existentially distinct from the former and as being in contrast with it as a limiting other. This confusion may be due to the fact that Mr. McTaggart hardly gets beyond the category of substance in his theory of the ultimately real: individuality he is inclined to define in terms of a bit of being that is individual solely by virtue of its factual existence.

$310 \mathrm{Cf}$. the third part of the Philosophy of Religion, especially the last of the second general division of the discussion. In these passages Hegel treats of the essential nature of man and shows us that man's essential nature is to be found in his community with God.

311 Enc., $\$ 573$. 